\title{
Finite Element Modelling of Steel/Concrete Bond for Corroded Reinforcement
}

\author{
By \\ Qixin Du
}

\begin{abstract}
A thesis
Presented to the University of Ottawa in fulfillment of the requirements for Master of Applied Science in Civil Engineering
\end{abstract}

December 2015

Department of Civil Engineering

University of Ottawa

Ottawa, Canada

K1N 6N5

(C) Qixin Du, Ottawa, Canada 2016 


\section{Abstract}

Reinforcement corrosion is the most common deterioration problem observed in reinforced concrete (RC) structures located at coastal or cold regions. The corrosion process can impact the performance of these structures by inducing damage on the bonding action between concrete and steel, either by the splitting of the concrete cover due to the volumetric expansion of corrosion products or the lubricant effect at the steel/concrete interface as the corrosion by-products accumulate. The current research aims at investigating corrosion-induced deterioration of bond between steel and concrete through finite element (FE) analysis of the flexural behaviour of corroded RC components. By treating the concrete cover as a thick-wall cylinder subjected to internal pressure, the analytical evaluation of impaired bond capacity is studied first and verified against published bonding tests. Then, the formulation of a numerical model is performed using ABAQUS, wherein a link element to simulate the bond behaviour is formulated and implemented through the ABAQUS user-subroutine (UEL) feature according to the validated analytical model. By introducing corrosion-induced damages, i.e., smaller cross-sectional area of reinforcement, splitting of concrete and bond deterioration, in the FE analyses, the results of the numerical model show good agreement with experimental observations.

Upon validation of the analytical and FE models, a parametric investigation is conducted, wherein the effects of concrete strength, dimension of reinforcing bars, properties of oxide products, different corrosion damage mechanisms and the corrosion location along the longitudinal reinforcement on the flexural behaviour of $\mathrm{RC}$ beams are studied.

The results show that the analytical evaluation for bond degradation is impacted by the selection of the post-cracking material model and the thickness of cover that determine the 'holding capacity' after cracking initiation. Also, the density of rust by-products affects the results of the analytical model at high corrosion levels. From the FE model results, it was observed that each damage 
mechanism due to corrosion contribute to different levels of flexural degradation, although the flexural strength degradation is mainly due to the loss of bonding action. The parametric study also demonstrates that flexural members which have reinforcement corrosion initiated near the supports suffer greater deterioration in flexural capacity than those with damages at mid span. Finally, based on these observations, suggestions for the application of both analytical and numerical models are made. 


\section{Table of contents}

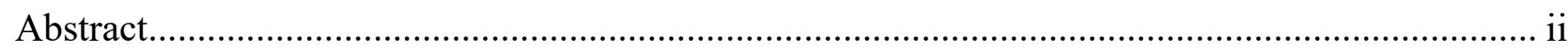

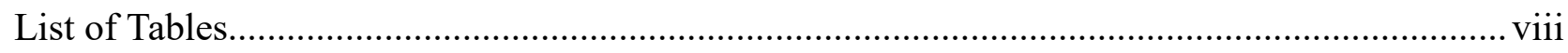

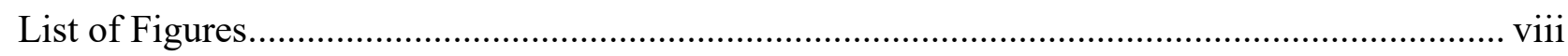

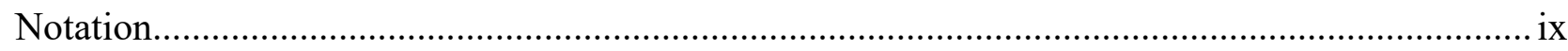

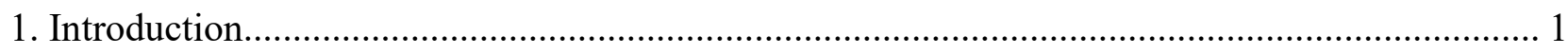

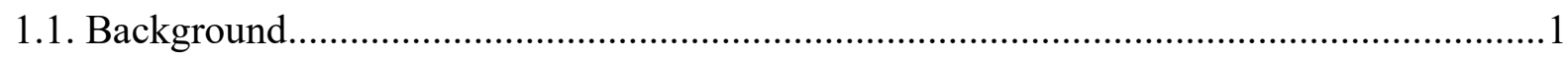

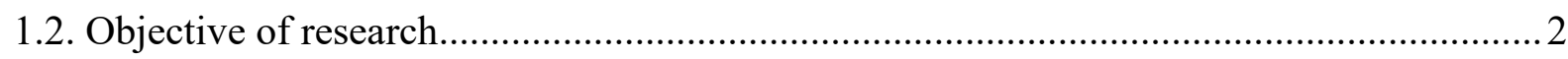

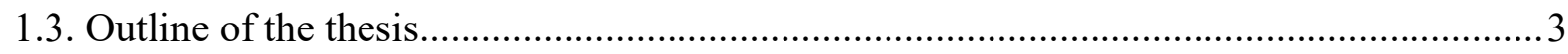

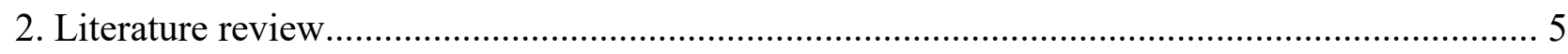

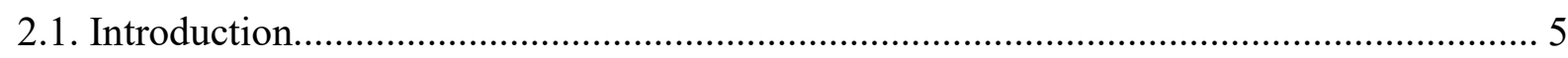

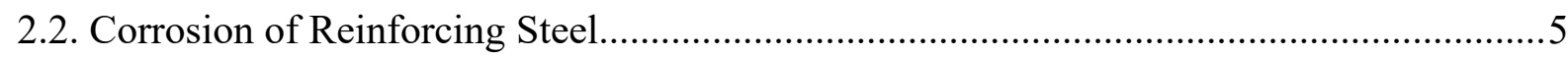

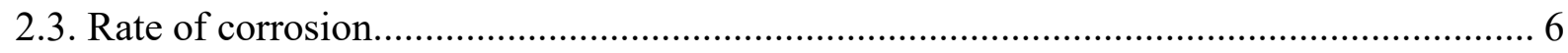

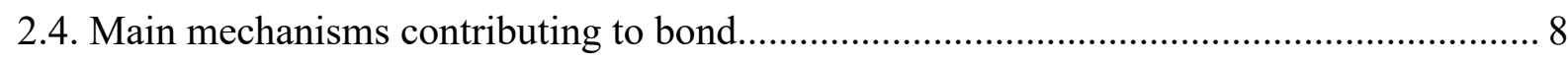

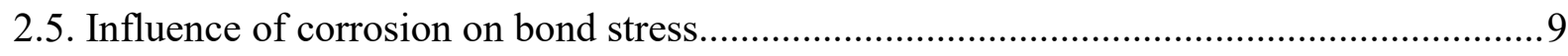

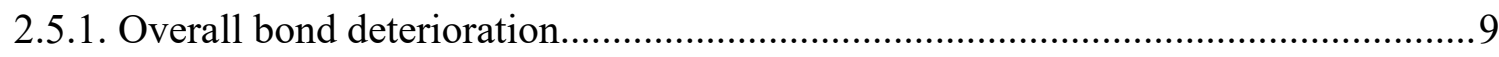

2.5.1.1. Experimental observations................................................................ 10

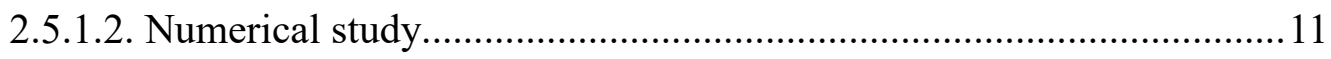

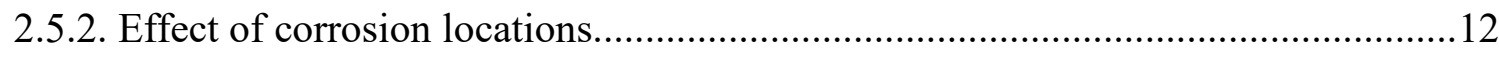

2.5.2.1. Experimental observations................................................................. 12

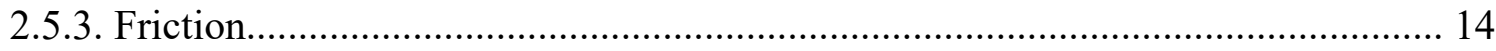

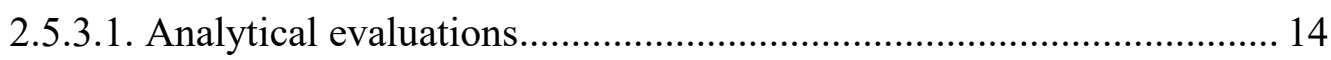

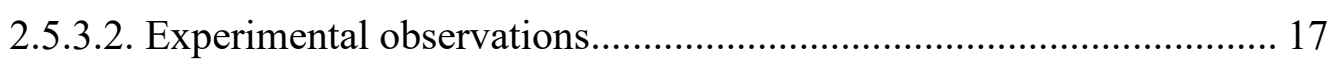

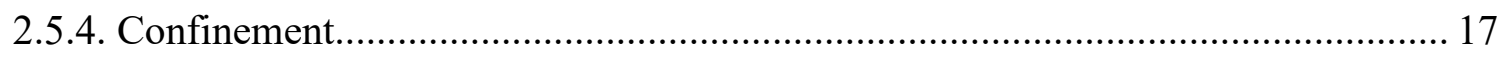

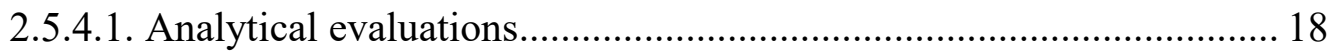

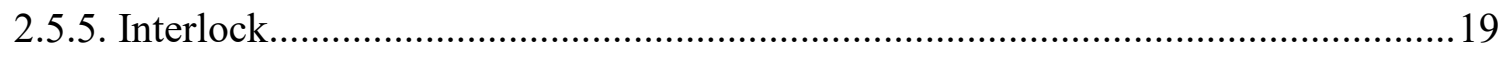


2.5.5.1. Experimental observations............................................................. 20

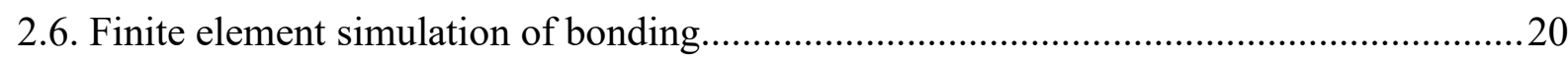

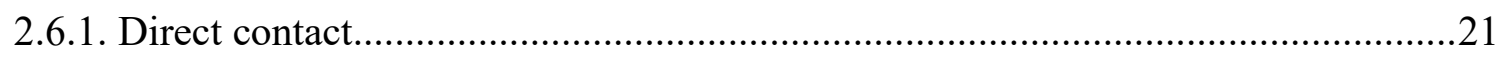

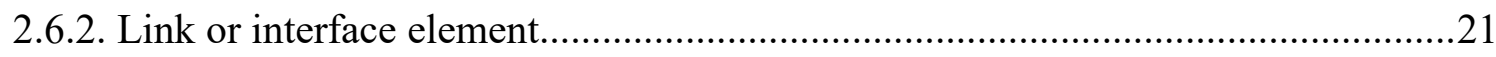

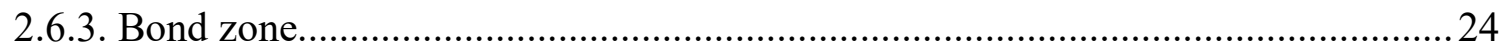

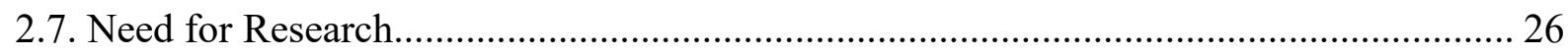

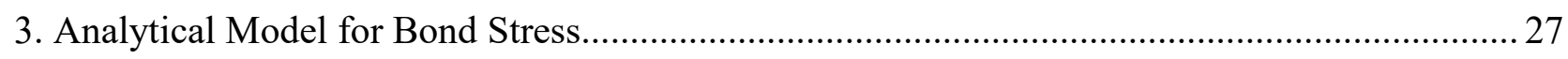

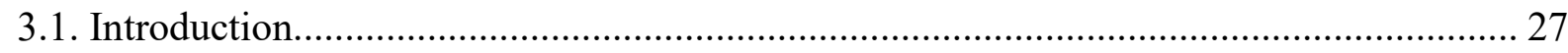

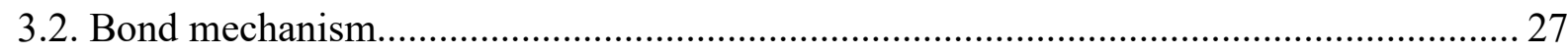

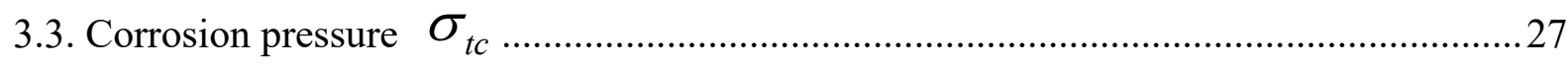

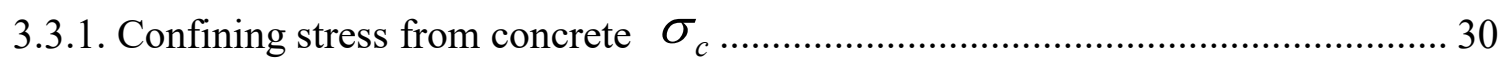

3.3.1.1. Partially-cracked thick wall cylinder..................................................... 30

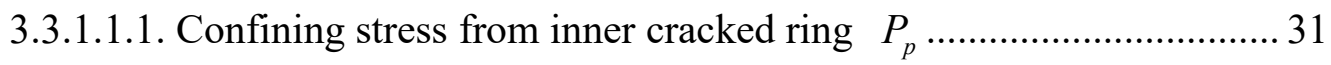

3.3.1.1.2. Confining stress from outer uncracked ring $P_{e} \ldots \ldots \ldots \ldots \ldots \ldots \ldots \ldots \ldots \ldots \ldots . . .41$

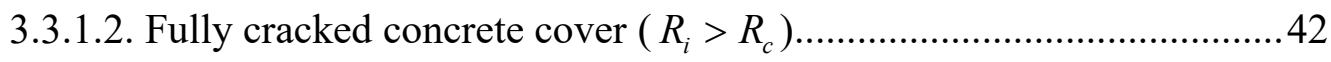

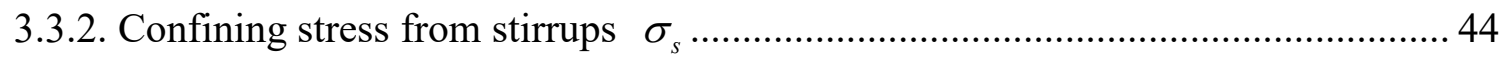

3.3.3. Summary for evaluation of confinement stress................................................. 47

3.3.3.1. Confining stress from concrete.......................................................... 47

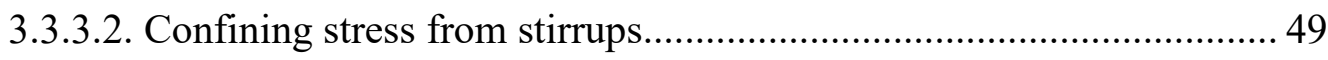

3.3.3.3. Procedure for confinement stress calculation...................................... 50

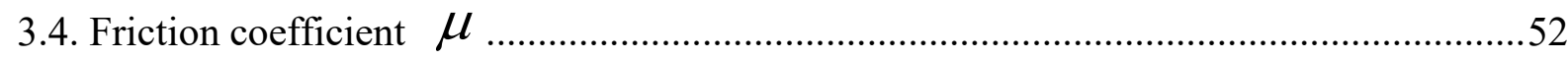

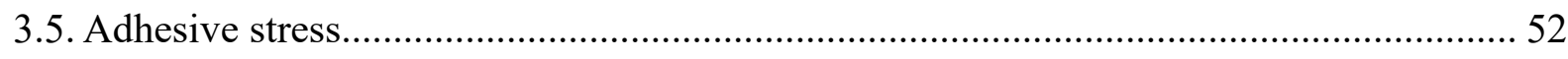

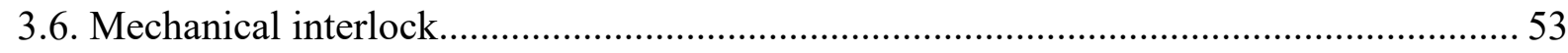

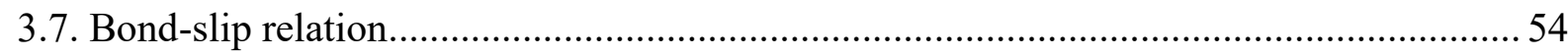

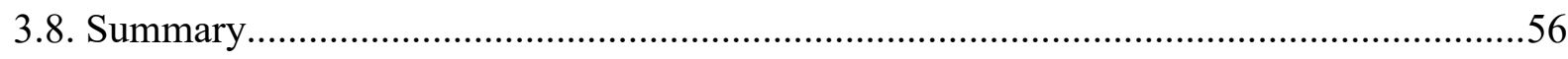




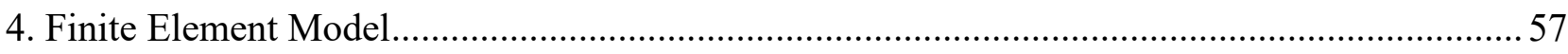

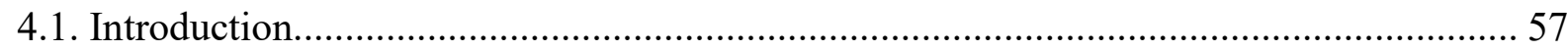

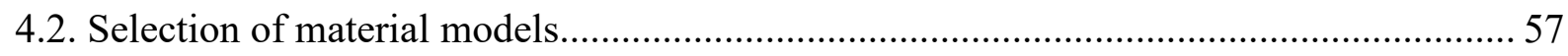

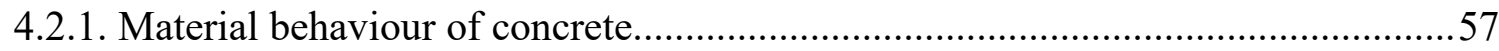

4.2.1.1. Compressive behaviour................................................................... 57

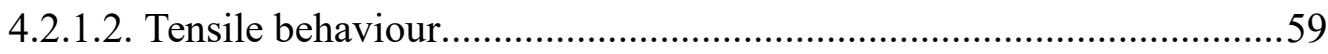

4.2.2. Finite element material model of concrete............................................................ 59

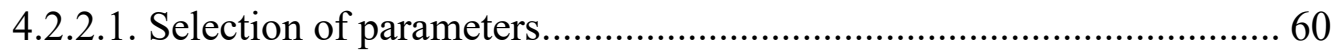

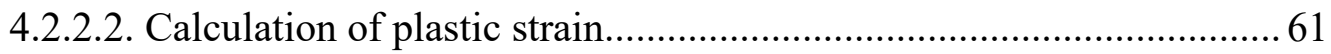

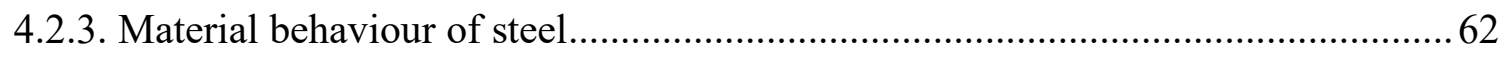

4.2.4. Finite element material model of steel................................................................... 63

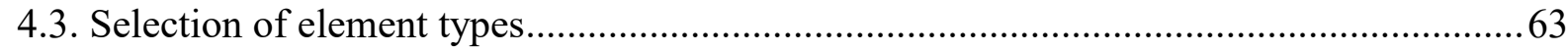

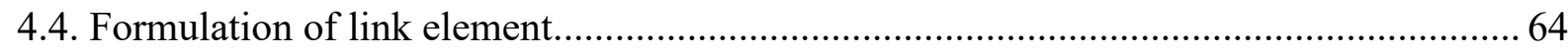

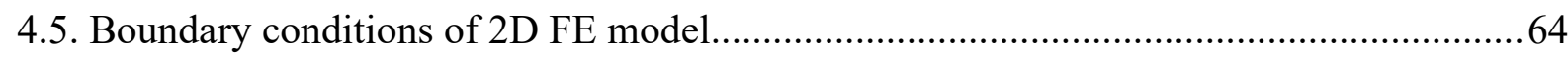

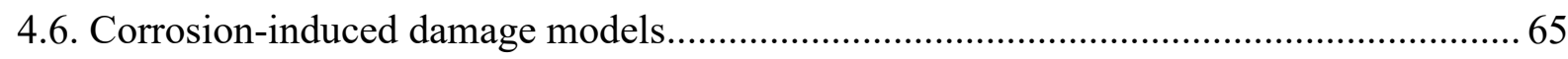

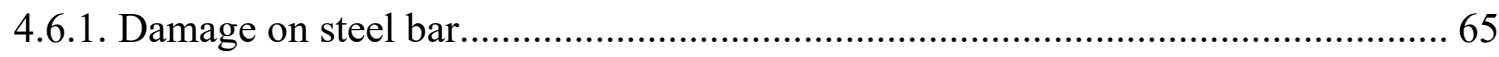

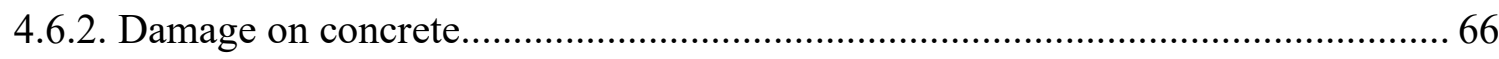

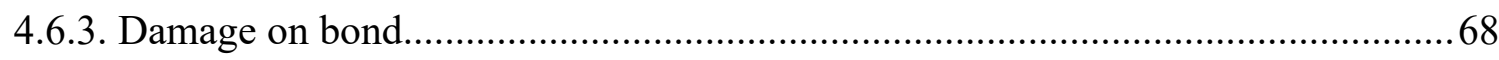

4.6.4. Summary of development of FE model.................................................................68

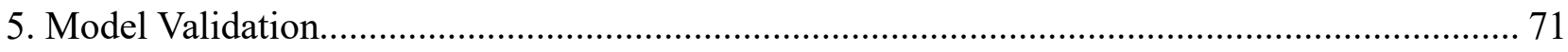

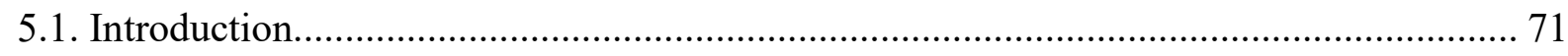

5.2. Validation of analytical evaluation of bond stress......................................................... 71

5.2.1. Comparison with Al-Sulaimani et al. (1990)...................................................... 71

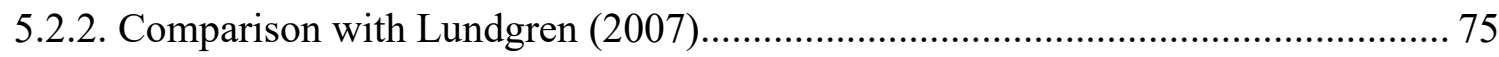

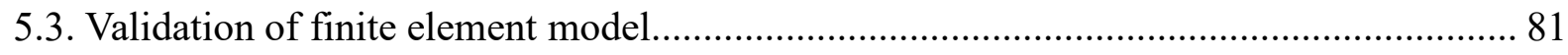

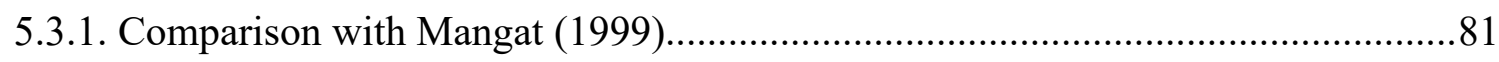

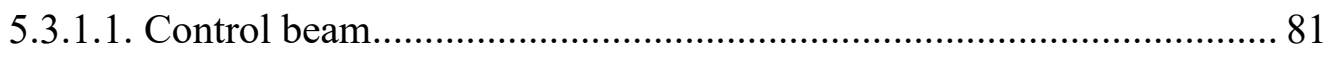

5.3.1.2. Application of link element for uncorroded beam.................................84 
5.3.1.3. Application of link element for corroded beam.....................................86

5.3.2. Comparison with Cairns et al. (2008)................................................................... 90

5.3.2.1. Control specimen...........................................................................93

5.3.2.2. Corroded specimen............................................................................ 94

5.3.3. Comparison with Du et al. (2007)........................................................................ 99

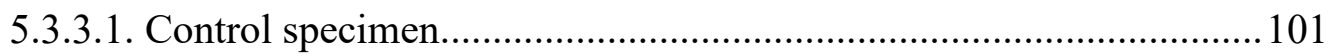

5.3.3.2. Corroded specimen.......................................................................... 102

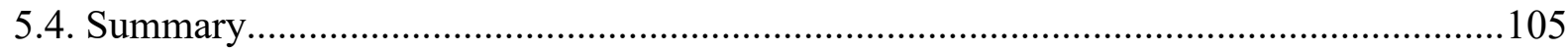

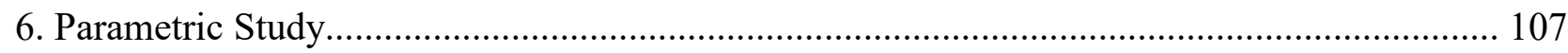

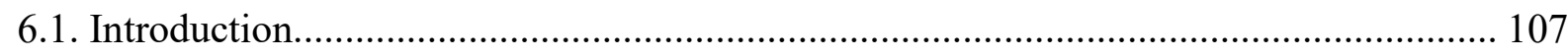

6.2. Parametric study using the analytical model................................................................ 107

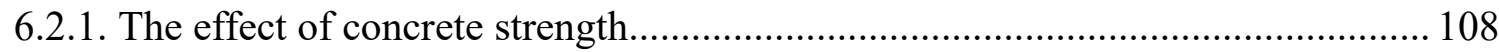

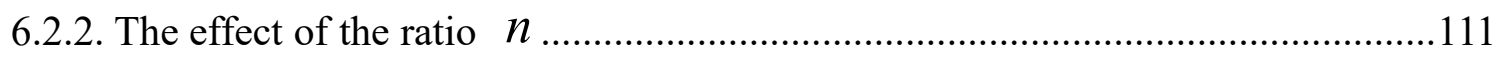

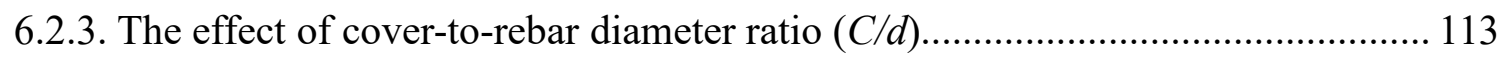

6.3. Parametric study using the finite element model............................................................ 114

6.3.1. The effect of different types of corrosion-induced damage..................................114

6.3.2. The effect of corrosion location along the reinforcement.....................................116

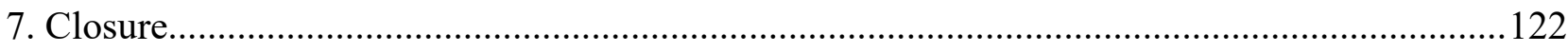

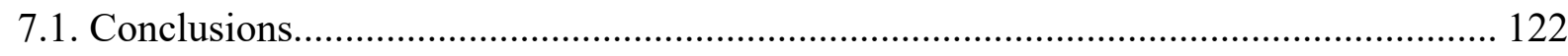

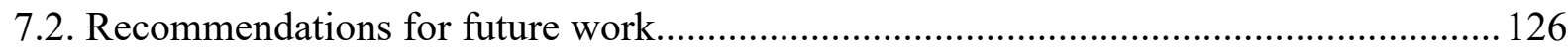

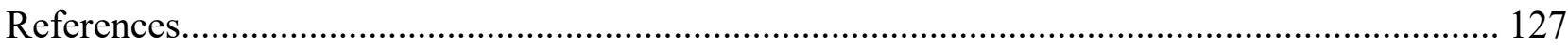




\section{List of Tables}

Table 4-1 Material properties for different grades of concrete according to CEB-FIP (2010).......59

Table 5-1 Material properties used in the analyses.......................................................... 72

Table 5-2 Geometry of FE pullout test specimen............................................................... 76

Table 5-3 Material properties for FE pullout specimen..................................................... 77

Table 5-4 Material properties for beams tested by Mangat (1999) ........................................... 82

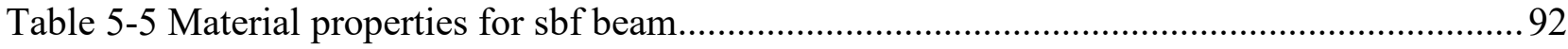

Table 5-6 Experimental results for group sbf............................................................... 95

Table 5-7 Material properties of specimens tested by Du et al. (2007)................................... 100

Table 6-1 Material data used in Lundgren (2007)............................................................... 108

Table 6-2 Material data for concrete as provided by CEB-FIP(2010).................................... 109

Table 6-3 Fracture energy $G_{f}$ and ultimate strain $\varepsilon_{u}$ for different concretes........................ 110

Table 6-4 Finite element specimens with various corroded regions......................................... 118

Table 6-5 Finite element specimens with various exposure regions....................................... 120 


\section{List of Figures}

Figure 2-1 Bond force transfer mechanisms (reproduced from ACI Committee 408 2003)......... 8

Figure 2-2 Evolution of maximum bond strength from different tests (reproduced from Yalciner

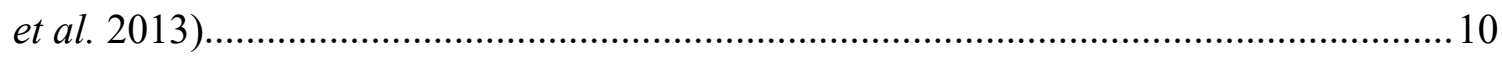

Figure 2-3 Load-deflection curves for beam Samples 1-7 (reproduced from Masnavi 2013)...... 12

Figure 2-4 Effect of exposure length on beam strength (reproduced from Masnavi 2013)......... 13

Figure 2-5 The evaluation of $k(x / r)$ (reproduced from Lundgren 2007).............................. 14

Figure 2-6 Variation of friction coefficient with slip at different mass losses (reproduced from

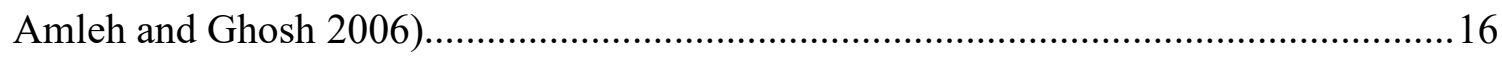

Figure 2-7 Concrete thick wall cylinder model (reproduced from Tepfers 1979).................... 19

Figure 2-8 Configuration of a link element (reproduced from Ngo and Scordelis 1967)...........22

Figure 2-9 Configuration of interface element according to Lundgren and Gylltoft (reproduced

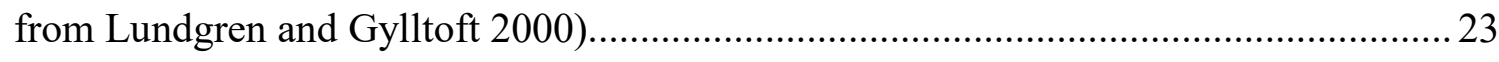

Figure 2-10 Principal stresses in concrete elements located in bond region for perfect bond and bond zone models (not to scale) (reproduced from Ziari and Kianoush 2014).............. 25

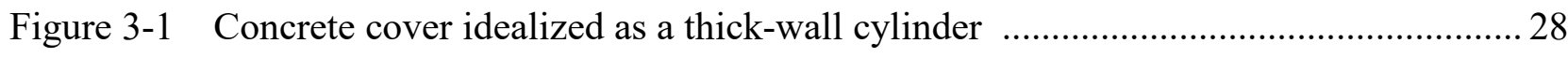

Figure 3-2 Values of $n$ representing different corrosion products...................................... 29

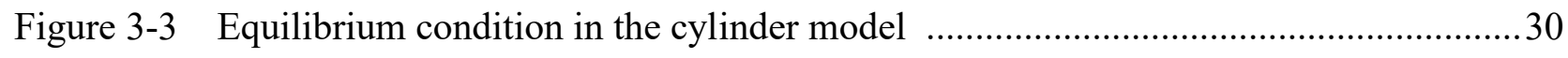

Figure 3-4 Crack shape in concrete cover.................................................................. 31

Figure $3-5 \quad$ Tensile stresses in the thick-wall cylinder..................................................... 32 
Figure 3-6 Comparison of thick wall cylinder with different displacement assumptions..... .34

Figure 3-7 Comparison of radial displacement obtained from Wang's evaluation and modified distribution. 37

Figure 3-8 Tensile stress-strain model for concrete 39

Figure 3-9 Hoop stress and radial displacement distributions in the thick-wall cylinder model.. 40

Figure 3-10 Equilibrium condition in the outer region of the thick-wall cylinder.

Figure $3-11$ Thick-wall cylinder model with stirrup....................................................... 44

Figure 3-12 Equilibrium condition in the cylinder model reinforced by stirrups..................... 45

Figure 3-13 Linear interpolation for the confinement stress $\quad{ }_{c}$ evaluation............................ 48

Figure 3-14 Procedure for confinement stress calculation................................................ 51

Figure 3-15 The bi-linear bond-slip relationship........................................................5

Figure 4-1 Compressive behaviour for concrete (reproduced from CEB-FIP 2010).................58

Figure 4-2 Bi-linear stress-strain relationship for steel f................................................ 62

Figure 4-3 4-node plane-stress element and 2-node truss element (reproduced from ABAQUS

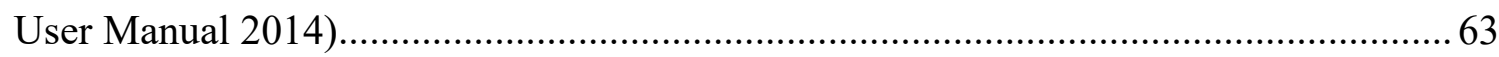

Figure 4-4 Structural member subjected to bending...................................................... 63

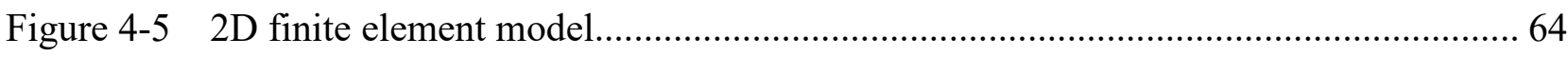

Figure 4-6 Boundary conditions of finite element model...................................................65

Figure 4-7 Corroded reinforcing bars in RC beam cross section....................................... 67

Figure 4-8 Procedure of FE model development..............................................................69

Figure 5-1 Comparison of analytical model to experimental results of specimen with 10-mm 
diameter reinforcement.

Figure 5-2 Comparison of analytical model to experimental results of specimen with 14-mm diameter reinforcement. 74

Figure 5-3 Comparison of analytical model to experimental results of specimen with 20-mm diameter reinforcement. 74

Figure 5-4 Setup of finite element model in Lundgren (2007) (all dimensions are in mm)........ 76

Figure 5-5 Maximum bond stress versus corrosion penetration for specimen \#1......................78

Figure 5-6 Maximum bond stress versus corrosion penetration for specimen \#2......................78

Figure 5-7 Maximum bond stress versus corrosion penetration for specimen \#3......................79

Figure 5-8 Maximum bond stress versus corrosion penetration for specimen \#4......................79

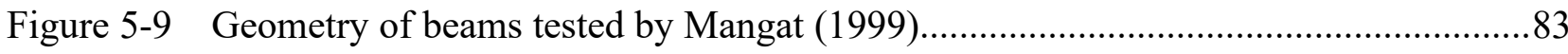

Figure 5-10 FE mesh of control beam as displayed in ABAQUS........................................8

Figure 5-11 Load-displacement response for control beam with perfect bond......................... 84

Figure 5-12 Load-displacement response for control beam with link elements........................85

Figure 5-13 Comparison of load-displacement response for both sets of control beams.............86

Figure 5-14 Load-displacement responses from finite element models..................................8 87

Figure 5-15 Load-displacement responses for tested specimens (reproduced from Mangat (1999))

Figure 5-16 Load-displacement response for beams with $1.25 \%$ corrosion............................ 88

Figure 5-17 Load-displacement response for beams with $2.5 \%$ corrosion.............................. 89

Figure 5-18 Load-displacement response for beams with 5\% corrosion................................ 89 
Figure 5-19 Load-displacement response for beams with $10 \%$ corrosion.

Figure 5-20 Geometry of specimen sbf (in mm) (reproduced from Cairns et al. 2008)............. 93

Figure 5-21 FE mesh of control beam as displayed in ABAQUS ..........................................93

Figure 5-22 Load-displacement response for specimen sbf-00....................................... 94

Figure 5-23 Load-displacement response for specimen sbf-01 ..........................................96

Figure 5-24 Load-displacement response for specimen sbf-05.........................................96

Figure 5-25 Comparison of finite element models.......................................................... 97

Figure 5-26 Analytical evaluation of bond strength for specimens in group sbf...................... 98

Figure 5-27 Bending test setup carried out by Du et al. (2007) ........................................... 101

Figure 5-28 FE mesh of control beam as displayed in ABAQUS....................................... 101

Figure 5-29 Load-defection response for control specimen in Du et al. (2007)...................... 102

Figure 5-30 Corrosion-induced damaged region in FEM................................................ 103

Figure 5-31 Load-defection response for corroded specimen with 8.8\% mass loss along mid-span.. 104

Figure 5-32 Comparison of load-defection responses for FE control and corroded specimens in

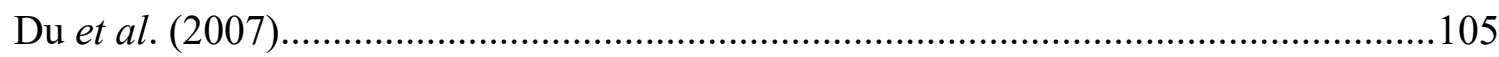

Figure 6-1 Comparison of bond capacity for specimens with different concrete compressive strength 109

Figure 6-2 Tensile stress-strain relation for concretes with different compressive strengths..... 111

Figure 6-3 The comparison of bond capacity of specimens N2, N3.5 and N5

Figure 6-4 Comparison of bond capacity for specimens with $C / d=2(\mathrm{R} 2), C / d=4(\mathrm{R} 4)$ and $C / d$ $=6(\mathrm{R} 6)$. .114 
Figure 6-5 Load-deflection curves for beams with different types of corrosion-induced damage

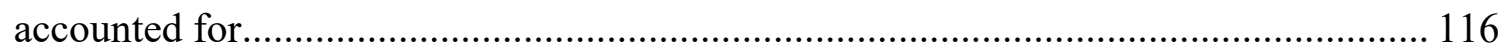

Figure 6-6 Load-deflection curves for beams with different corrosion regions.........................119

Figure 6-7 Load-deflection curves for beams with different exposed regions.........................121 


\section{Notation}

\begin{tabular}{|c|c|c|}
\hline$A_{s}$ & $=$ & cross-sectional area of one stirrup leg \\
\hline$A_{\text {steel }}$ & $=$ & effective area of rebar in FE model \\
\hline$B$ & $=$ & width of the beam \\
\hline$d_{a}$ & $=$ & maximum coarse aggregate size \\
\hline$d_{b}$ & $=$ & original diameter of rebar \\
\hline$d_{s}$ & $=$ & stirrups diameter \\
\hline$E_{c}$ & $=$ & concrete young's modulus \\
\hline$E_{c 1}$ & $=$ & secant modulus from the origin to the peak compressive stress \\
\hline$E_{s}$ & $=$ & steel young's modulus \\
\hline$E_{t}$ & $=$ & concrete modulus after cracks \\
\hline$f_{\text {adh }}$ & $=$ & chemical adhesion \\
\hline$f_{c}$ & $=$ & concrete compressive strength \\
\hline$f_{i}$ & $=$ & mechanical interlock stress due to rebar against the concrete \\
\hline$f_{s}$ & $=$ & corresponding stress in the cylinder at $r_{s}$ \\
\hline$f_{s s}$ & $=$ & tensile stress of stirrups \\
\hline$f_{t}^{\prime}$ & $=$ & concrete tensile strength \\
\hline$f_{u_{-} i}$ & $=$ & maximum interlock stress for uncorroded reinforcement bars \\
\hline$f_{y}$ & $=$ & steel yield strength \\
\hline $\mathrm{Fa}$ & $=$ & chemical adhesion stress \\
\hline
\end{tabular}




\begin{tabular}{|c|c|c|}
\hline$G_{f}$ & $=$ & fracture energy \\
\hline$k$ & $=$ & plasticity number \\
\hline$k\left(x / r_{b}\right)$ & $=$ & deterioration factor for friction coefficient \\
\hline$k_{t}$ & $=$ & bond stiffness \\
\hline$L_{s}$ & $=$ & spacing for adjacent shear bars \\
\hline$M_{\text {loss }}$ & $=$ & percentage of mass loss \\
\hline$n$ & $=$ & ratio between the volume of oxides product and virgin steel \\
\hline$P_{e}$ & $=$ & stress contribution from the uncracked ring \\
\hline$P_{p}$ & $=$ & stress contribution from cracked ring \\
\hline$r$ & $=$ & radial displacement \\
\hline$r_{b}$ & $=$ & original radius of rebar \\
\hline$r_{s}$ & $=$ & radius of the center of the stirrups \\
\hline$r_{s b}$ & $=$ & equivalent steel radius per unit length \\
\hline$R_{c}$ & $=$ & outer radius of concrete cylinder model \\
\hline$R_{i}$ & $=$ & radius of the crack front \\
\hline$R_{s}$ & $=$ & radius of the corroded bar \\
\hline$R_{u 1}$ & $=$ & $\begin{array}{l}\text { radial position in which the hoop strain reaches ultimate strain if the } \\
\text { concrete cylinder is not cracked }\end{array}$ \\
\hline$R_{u 2}$ & $=$ & $\begin{array}{l}\text { radial position in which the hoop strain reaches ultimate strain if the } \\
\text { concrete cylinder is cracked }\end{array}$ \\
\hline$s_{y}$ & $=$ & $\begin{array}{l}\text { relative slip value when the bonding stress reaches the bond } \\
\text { capacity }\end{array}$ \\
\hline
\end{tabular}




\begin{tabular}{|c|c|c|}
\hline$t_{r}$ & $=$ & thickness of rust layer \\
\hline$V_{r}$ & $=$ & volume of oxides product \\
\hline$V_{s}$ & $=$ & volume of virgin steel \\
\hline$\Delta V_{r}$ & $=$ & volume of accumulated corrosion products \\
\hline$x$ & $=$ & attack penetration \\
\hline$x_{c r}$ & $=$ & critical attack penetration depth \\
\hline$\varepsilon_{\theta}(r)$ & $=$ & hoop strain at position $r$ \\
\hline$\varepsilon_{c 1}$ & $=$ & strain at maximum compressive stress \\
\hline$\varepsilon_{c, \lim }$ & $=$ & ultimate strain \\
\hline$\varepsilon_{c r}$ & $=$ & tensile strain at the tensile strength of the concrete \\
\hline$\varepsilon_{e l}$ & $=$ & elastic strain \\
\hline$\varepsilon_{t}$ & $=$ & total tensile strain in the cracked region \\
\hline$\varepsilon_{T}$ & $=$ & thermal strain \\
\hline$\varepsilon_{s}$ & $=$ & strain in the spiral reinforcement \\
\hline$\varepsilon_{e}$ & $=$ & concrete elastic hoop strain \\
\hline$\varepsilon_{p l}$ & $=$ & plastic strain \\
\hline$\varepsilon_{u}$ & $=$ & concrete tensile ultimate strain \\
\hline $\bar{\varepsilon}$ & $=$ & averaged tensile strain \\
\hline $\bar{\varepsilon}$ & $=$ & equivalent expansion strains \\
\hline$\sigma_{s}$ & $=$ & confinement stress due to transverse reinforcement \\
\hline$\sigma_{c}$ & $=$ & confinement stress due to concrete cover \\
\hline
\end{tabular}




\begin{tabular}{|c|c|c|}
\hline$\sigma_{t c}$ & $=$ & $\begin{array}{l}\text { corrosion pressure due to the accumulation of corrosion by-products } \\
\text { around the reinforcing bar }\end{array}$ \\
\hline$\tau_{\max }$ & $=$ & bond capacity \\
\hline$\tau_{u p \_\max }$ & $=$ & maximum bonding stress for the plain bar \\
\hline$\tau_{u r_{-} \max }$ & $=$ & maximum bonding stress for the ribbed bar \\
\hline$\mu_{0}$ & $=$ & initial friction coefficient \\
\hline$\mu$ & $=$ & friction coefficient \\
\hline$w$ & $=$ & $\begin{array}{l}\text { crack width opening around the perimeter of the rust front } R_{r} \text { for } \\
\text { each crack }\end{array}$ \\
\hline$w_{c}$ & $=$ & characteristic width of the advancing micro cracking zone \\
\hline
\end{tabular}




\section{Introduction}

\subsection{Background}

Reinforced concrete (RC) is one of the most widely used construction materials due to its durability, versatility and economical price. However, corrosion of the embedded reinforcement in chloride-laden environments is an extended problem that can affect the structural performance. In general, concrete provides protection against reinforcement corrosion due to the high alkalinity environment it provides (Glass and Buenfeld 2000). However, the passivity afforded by concrete alkalinity is broken down by the either the presence of high amounts of chloride in the concrete pore solution or carbonation of the concrete cover.

From an economic perspective, reinforcement corrosion is a costly problem, where a huge amount of resources need to be employed for maintenance. The total economic impact of corrosion and corrosion control applications was estimated to be $\$ 5.5$ billion (estimated in year 1949) or 2.1\% of the annual GNP in the US (Thompson et al. 2007), whereas in the UK, around 1,365 million pounds per year (estimated in year 1971) was needed to address the problem of reinforcement corrosion, which represented 3.5 per cent of the GNP of 1970 (Bhaskaran et al. 2005). In Canada, deteriorated reinforced concrete infrastructure has cost a total of $\$ 74$ billion to restore it back to its original state (NSERC 2012).

Corrosion-induced degradation of the performance of structures is also a major problem faced by civil engineers. Reinforcement corrosion has been considered as the major cause of deterioration of reinforced concrete structures around the world (Broomfield 2002, Hansson et al. 2007). To counter or minimize this negative impact, a wide range of monitoring and repairing techniques have been developed in practical applications. Also, numerous experimental and analytical studies have been carried out by researchers (e.g., Al-Sulaimani et al. 1990, Li et al. 2014, Lundgren 2007 
and Wang et al. 2004) to evaluate the effect of reinforcement corrosion on structures, which showcase that corrosion attack can lead to reduction of cross-sectional area of reinforcing bars, splitting of the concrete cover and weaker bonding action, causing an overall deterioration of the structural performance, such as a softer residual response and a decreased capacity.

\subsection{Objective of research}

The bonding interaction between reinforcing bars and concrete, which serves as a vital mechanism in RC structures, can be damaged or even eliminated with increasing corrosion levels (Al-Sulaimani et al. 1990). Bending tests conducted on corroded specimens (Mangat 1999) have highlighted that this degraded mechanism severely impacts the residual response of affected members.

In order to evaluate the structural deterioration due to reinforcement corrosion, finite element modelling, whose validity of performing an evaluation for corroded structures has been demonstrated by other researchers, e.g., Val and Chernin (2009) and Li et al. (2014), provides a practical and accurate way for assessment.

Therefore, the aim of this research is to develop a two-dimensional FE model that simulates the bond deterioration in corroded $\mathrm{RC}$ flexural members. For this propose, the following tasks are carried out:

1. Literature review of corrosion mechanisms and their effects on bonding.

2. Development of an analytical evaluation of bond deterioration.

3. Development of a finite element model that incorporates corrosion-induced damages and implements the analytical bond model through the use of link elements.

4. Parametric study to extend the application of the numerical model and to give a prescriptive guide for the residual evaluation of corroded structures. 


\subsection{Outline of the thesis}

Chapter 1 presents background information related to corrosion, the objectives of the research and the layout of this thesis.

Chapter 2 presents a literature review mainly focusing on reinforcement corrosion effects on bond behaviour. Background knowledge on the corrosion mechanism is briefly introduced first. Then an overview of available literature on the effects of corrosion on bond degradation is summarized to identify the general influence of corrosion-induced damages on bonding and factors that impact bond behaviour as corrosion attack propagates. After that, a more detail review is performed to obtain better understanding on how these mechanical properties for bonding can be altered during corrosion. Finally, finite element models proposed by other researchers to mimic the bonding interaction between concrete and steel are also reviewed.

Chapters 3 and 4 present the development of the analytical and numerical models, respectively. In Chapter 3, the analytical evaluation of bond capacity is developed accounting for the affected mechanisms identified in the literature review. For this propose, the approximations and models suggested by other researchers and assumptions based on experimental observations are adopted. For instance, one of the crucial mechanism in bond deterioration, i.e., confinement, is modelled by the thick-wall cylinder model suggested by Wang et al. (2004) with modified hoop strain distribution based on mathematical investigations. Then a closed-form formulation for bond deterioration is obtained by combining those analytical evaluations according to the bonding mechanism.

The development of the finite element model (FEM) is discussed in Chapter 4. Material behaviour for concrete and steel based on the CEB-FIP model code and other studies is given, followed by the selection of material models and element types in ABAQUS, the software used to implement the FEM. A 2D model with corrosion-induced damage is built, where bond behaviour is modelled 
by link elements, which are programmed in ABAQUS through the user subroutine UEL according to the analytical evaluation proposed in Chapter 3, and corrosion-induced cracking of the concrete cover due to volumetric expansion is simulated by applying an equivalent expansion strain in the concrete.

Chapter 5 presents the validation of the analytical and finite element models against published data. The analytical evaluation is verified by comparing experimental and numerical pullout tests, to ensure it can properly simulate the bond deterioration before its application in the FE link elements. After successful verification of the analytical model, the finite element model with link elements and damages due to corrosion is tested against three sets of bending tests: beams reinforced by plain bars, beam reinforced by ribbed bars, and beam with localized corrosion.

In Chapter 6, a parametric investigation using the analytical and numerical models is performed. For this propose, analytical specimens with various concrete strengths, various ratios of the volumes of rust products to sound steel, and different cover thicknesses are tested and compared to obtain a better understanding of the influence of those physical properties on the bond degradation. Also, numerical investigations of RC beams with different corrosion-induced damage mechanisms and corrosion regions are also discussed.

Finally, Chapter 7 closes the thesis with the conclusions of the research observations and the recommendations for future work. 


\section{Literature review}

\subsection{Introduction}

Corrosion of reinforcing steel in concrete is one of the main causes of premature deterioration of reinforced concrete (RC) structures (Chaker 1992). Bond degradation due to corrosion can significantly damage the performance of reinforced concrete elements, since the bond interaction between the steel and the concrete plays a vital role in the mechanical behaviour of RC (Sanchez et al. 2010). This chapter presents a literature review of the effect of reinforcement corrosion on the bond behaviour in RC. First, a background summary of the corrosion process is presented, followed by an overview of experiments and finite element analysis of bond degradation to identify mechanical properties influenced by corrosion. Then according to this observation, a detailed review of impacted factors is given. Also, the development of analytical evaluation of bond degradation and finite element modelling techniques that simulate the bonding interaction at the concrete/steel interface are investigated.

\subsection{Corrosion of Reinforcing Steel}

The process of corrosion is an electrochemical reaction, which is similar to that of a battery. Corrosion is common in steel structures if appropriate protection is absent. However, corrosion in reinforcing steel is rare in freshly cast concrete. This is because a passive oxide film, mainly $\mathrm{Fe}_{3} \mathrm{O}_{4}$, is formed due to the alkaline nature of hydrated cement, which covers the reinforcing steel bar and isolates iron from corrosive factors (Glass and Buenfeld 2000). However, this protection only exists in a high alkalinity environment, i.e., when the $\mathrm{pH}$ is above 12 . There are two situations which will eliminate the passive effect: (i) carbonation and (ii) chloride contamination. 
Carbonation in concrete results from the penetration of carbon dioxide from the atmosphere, neutralizing the $\mathrm{Ca}(\mathrm{OH})_{2}$ that keeps the alkalinity in concrete. This will reduce the $\mathrm{pH}$ to 8 or 9 , in which the passive film vanishes. The rate of carbonation depends on the porosity of the concrete and can be slowed by an appropriate depth of cover and/or a denser concrete.

Corrosion caused by chloride ions is common in coastal regions or in cold regions where de-icing salts are used. It can also result from chloride contamination in mix ingredients such as aggregates and water. This kind of corrosion is usually localized and forms pits on the bar surface. The corrosion cell is formed between exposed iron (anode) and passive steel (cathode), with a path established by the reinforcing steel and the moist concrete cover. Furthermore, a strong energy potential due to the uneven distribution of chloride accumulation along the reinforcing steel bar arises. In order words, the iron considered as anode is consumed rapidly into iron ions, leading to the formation of a pit on the rebar surface. The anodic reaction is given by:

$$
2 \mathrm{Fe}-4 e^{-} \rightarrow 2 \mathrm{Fe}^{2+} \quad \text { Eq } 2-1
$$

At the cathodic site, the oxygen is reduced into hydroxyl ions by reacting with pore water and consuming the electrons released at the anode. The cathodic reaction is given by:

$$
\mathrm{O}_{2}+2 \mathrm{H}_{2} \mathrm{O}+4 e^{-} \rightarrow 4 \mathrm{OH}^{-}
$$

The above two reactions occurring at the anode and cathode, respectively, are essential for the corrosion process.

\subsection{Rate of corrosion}

When a reinforcing bar is subjected to corrosion, the cross sectional area is reduced, which can be 
modelled as a function of time. In order to evaluate the rate of corrosion, Faraday's Law is applied:

$$
\Delta m_{s}=\frac{I_{c o r r} t W}{Z F}
$$

where $\Delta m_{s}$ is the mass loss (g), $I_{\text {corr }}$ is the corrosion current, $t$ is the time (s), W is the atomic weight of steel given by $55.847 \mathrm{~g} / \mathrm{mol}, Z$ is the valence number or ion charge of Fe, which is equal to 2 for $\mathrm{Fe} \rightarrow \mathrm{Fe}^{2+}+2 e^{-}$, and $\mathrm{F}$ is Faraday's constant $(96,485 \mathrm{C} / \mathrm{mol})$.

Assuming uniform distribution of corrosion along the perimeter of the reinforcement cross-sectional area, the mass loss per unit length can be approximated by:

$$
\Delta m_{s}=\pi \cdot d_{b} \cdot x \cdot \rho_{s}
$$

where $d_{b}$ is the diameter of the rebar, $x$ is the attack penetration and $\rho_{s}$ is the density of steel $\left(7.86 \mathrm{~g} / \mathrm{cm}^{3}\right)$.

The corrosion current $I_{c o r r}$ can be rewritten as:

$$
I_{\text {corr }}=i_{\text {corr }} \cdot \pi \cdot d_{b} \cdot L
$$

where $L$ is the length of the reinforcing bar (m) and $i_{c o r r}$ is corrosion current density $\left(A / \mathrm{m}^{2}\right)$.

The value of attack penetration $x$ is obtained by combining Eq 2-3, Eq 2-4 and Eq 2-5:

$$
x=\frac{i_{c o r r} t W}{\rho_{s} Z F}=0.00116 \cdot i_{\text {corr }} \cdot t(\mathrm{~mm})
$$


Thus, the reduced diameter of the reinforcing steel bar at time $t, d_{b c}$, is equal to the original diameter $d_{b}$ minus the attack penetration $(2 x)$ and is written as:

$$
d_{b c}(t)=d_{b}-0.0232 \cdot i_{c o r r} \cdot t
$$

\subsection{Main mechanisms contributing to bond}

Bond can be defined as the interaction and transfer of force between reinforcement and concrete, and the structural performance of reinforced concrete structures is influenced by this bond behaviour, e.g., width and spacing of transverse cracks, strength of end anchorages (CEB-FIP 2010). Bond in RC is achieved through three mechanisms (Lutz and Gergely 1967):

1) chemical adhesion,

2) friction, and

3) mechanical interlocking.

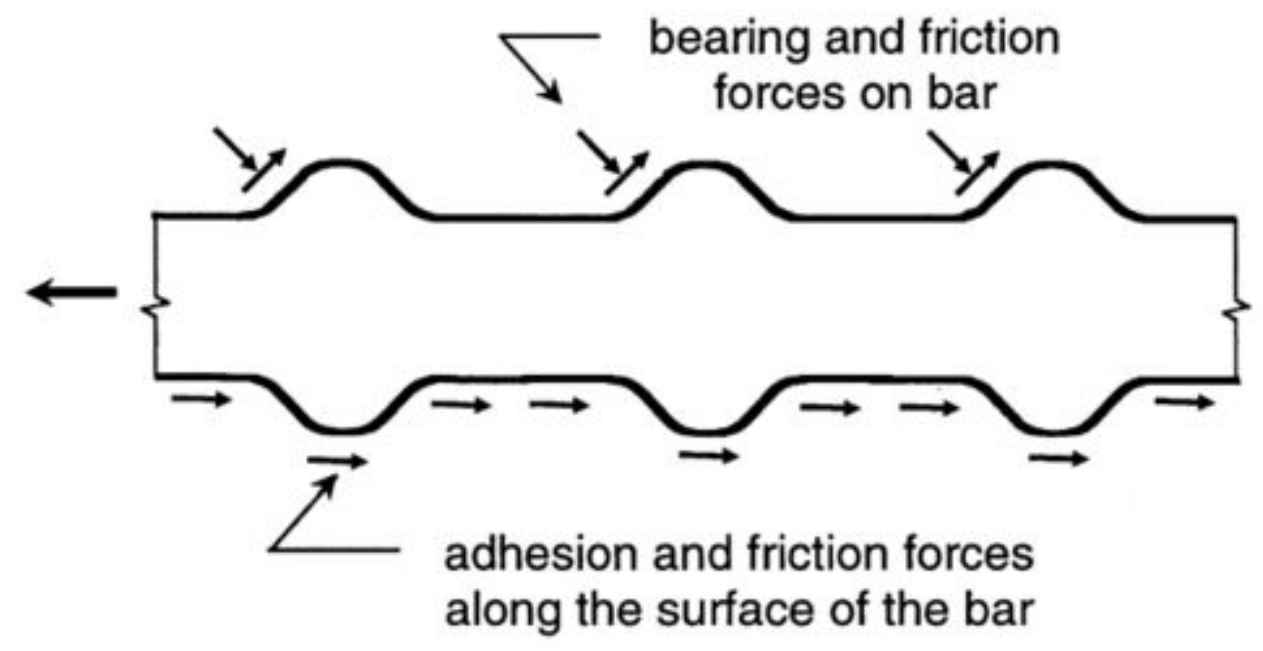

Figure 2-1 Bond force transfer mechanisms (reproduced from ACI Committee 408 2003)

1) The adhesive force results from the deformation of the cementitious layer around the reinforcing bar, which consists of the microscopical interaction between cement stone particles 
(Brameshuber 2006). However, this mechanism is not reliable as an unrecoverable drop occurs once slippage starts and the loss of adhesion can be expected at $0.05 \mathrm{~mm}$ slip (CEB-FIP 2010).

2) Friction is the resistance against a parallel displacement between concrete and reinforcing bar surface, affected by the compressive force perpendicular to the contact surface and the surface roughness of the interface (Brameshuber 2006). The friction in RC structures may result from the confining force at the concrete/steel interlayer, external compression forces perpendicular to the interface, and/or clamping forces due to reinforcement and/or connectors (CEB-FIP 2010).

3) Illustrated by ACI Committee 408 (2003), the interlocking effect is the mechanical anchorage or bearing of the ribs against the concrete surface, which plays the most significant role for ribbed bars at higher load levels. The evaluation of the mechanical interlock should involve the consideration of the surface profile, e.g., the height and spacing of bar lugs of the reinforcing bar.

The above mechanisms both have influences on the bonding behaviour of structures reinforced by ribbed bars, wherein only adhesion and friction force contribute to the main bond resistance of plain bars. The following sections presents a review of the literature on the effect of corrosion on each of these mechanisms.

\subsection{Influence of corrosion on bond stress}

\subsubsection{Overall bond deterioration}

When a RC structure suffers from corrosion, not only the virgin steel is consumed, resulting in reduced cross-sectional area or diminished ultimate strength, but also the physical properties at the interface are impacted, leading to a weaker bond response between the steel and concrete. 


\subsubsection{Experimental observations}

A number of studies using experimental tests and/or finite element analysis have been carried out to investigate the corrosion-induced damage in bond (see Figure 2-2). Most of them found a decreasing trend as the mass loss of reinforcement increased (e.g., A1-Sulaimani et al. 1990 and Chung et al. 2008). This effect can be significant, as some tests reported that $2 \%$ loss in diameter of the steel bar caused $80 \%$ reduction in bond strength (Auyeung et al. 2000). It is also observed that at high levels of corrosion, only a residual value of bond strength remains. However, many researchers have also reported an initial increase in bond strength for low corrosion levels (mass loss). For instance, the increases were noted at up to $2 \%$ corrosion level in $\mathrm{Xu}$ et al. (2010), $0.4 \%$ in Mangat (1999) and 1 3\% in Huang (2014), which result from the enhanced friction around the reinforcing bar due to the increased surface roughness of bars and confining stress. Then the elimination of the bar lugs, the splitting of concrete and the lubricating effect due to the accumulation of rust products lead to continuous degradation of bond strength (A1-Sulaimani et al. 1990, Chung et al. 2004, Fang et al.2004).

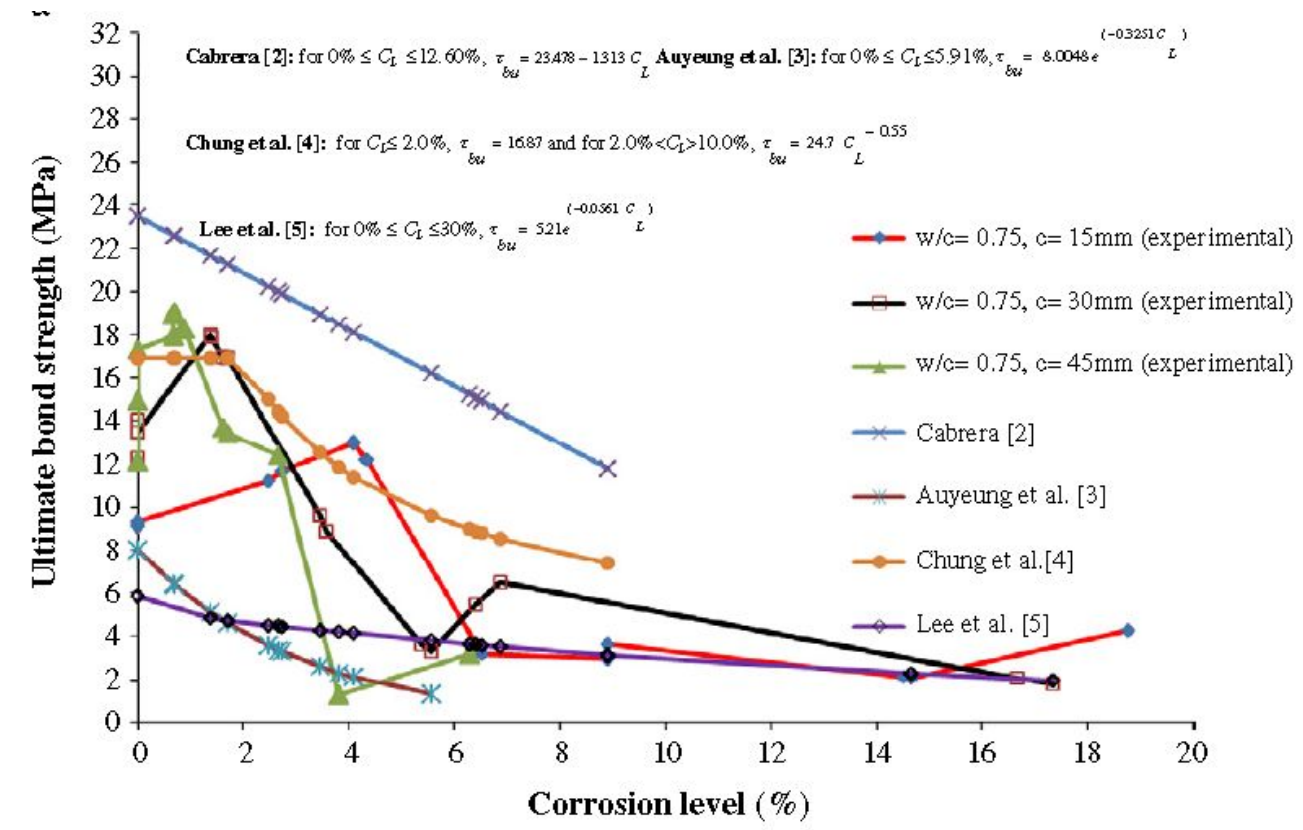

Figure 2-2 Evolution of maximum bond strength from different tests (reproduced from Yalciner et al. 2013) 
Fang et al. (2004) tested a series of corroded specimens with different bar types (deformed and plain) and confinement conditions (with and without transverse reinforcement). The electrolytic corrosion method was used to accelerate the corrosion process, but the transverse reinforcing bar was isolated and not subjected to corrosion. The results from pullout tests show that the bond performance varies. For specimens with ribbed rebars and transverse reinforcement, a small influence in bond was observed, whereas for those with ribbed rebars but without confinement, the corrosion level played an important role in bond degradation, with bond strength at $9 \%$ steel mass loss being only one third of that of a non-corroded specimen. For specimens with smooth rebars, although an initial increase in the bond strength was reported, the specimens with confining reinforcement tended to maintain bond strength at higher levels of corrosion (even at more than $5 \%$ ), whereas for those without transverse confinement, a rapid decrease in the bond strength was reported at lower corrosion levels ( $2 \sim 4 \%$ of steel mass loss).

\subsubsection{Numerical study}

Lundgren (2007) extended the experiment conducted by Fang et al. (2004) in axisymmetric finite element modelling, applying interface elements, developed by Lundgren (2002), at the interface between the steel and the concrete to represent the bond mechanism. Corrosion was taken into consideration by modifying the interface element properties. The influence of types of reinforcing bars (ribbed and plain), and the confinement conditions was also investigated. The author found that the finite element analysis was able to capture the observed behaviour in the experimental tests. The results show that the thickness of concrete cover impacts the bond performance, since the bond capacity kept increasing as long as the cover does not crack. The ribbed bar specimens experienced less initial bond increase than plain bar specimens. 


\subsubsection{Effect of corrosion locations}

As mentioned in the previous section, chloride contamination is the major cause of corrosion for reinforced concrete structures located along the coast or in cold climates. Because corrosion caused by chlorides is affected by the distribution of chloride accumulation, which can be unevenly distributed, localized corrosion and the formation of pits on the steel bar surface are commonly observed, which means some parts of structure can suffer more loss of bonding. Hence, the assumption of uniformly distributed corrosion (usually adopted for corrosion caused by carbonation) may not be applied for all corrosion cases, and the damages on different locations might have a different impact on the residual structural performance.

\subsubsection{Experimental observations}

In the bending experiments carried out by Masnavi (2013) (see Figure 2-3), some of the beam specimens with different combinations of exposure patterns with respect to location and length were tested to simulate the spalling of concrete and the resulting de-bonding. The mid-span of specimens 2 4 had its concrete cover removed with varying lengths, whereas specimens 5 7 had the concrete cover removed in regions near the supports.
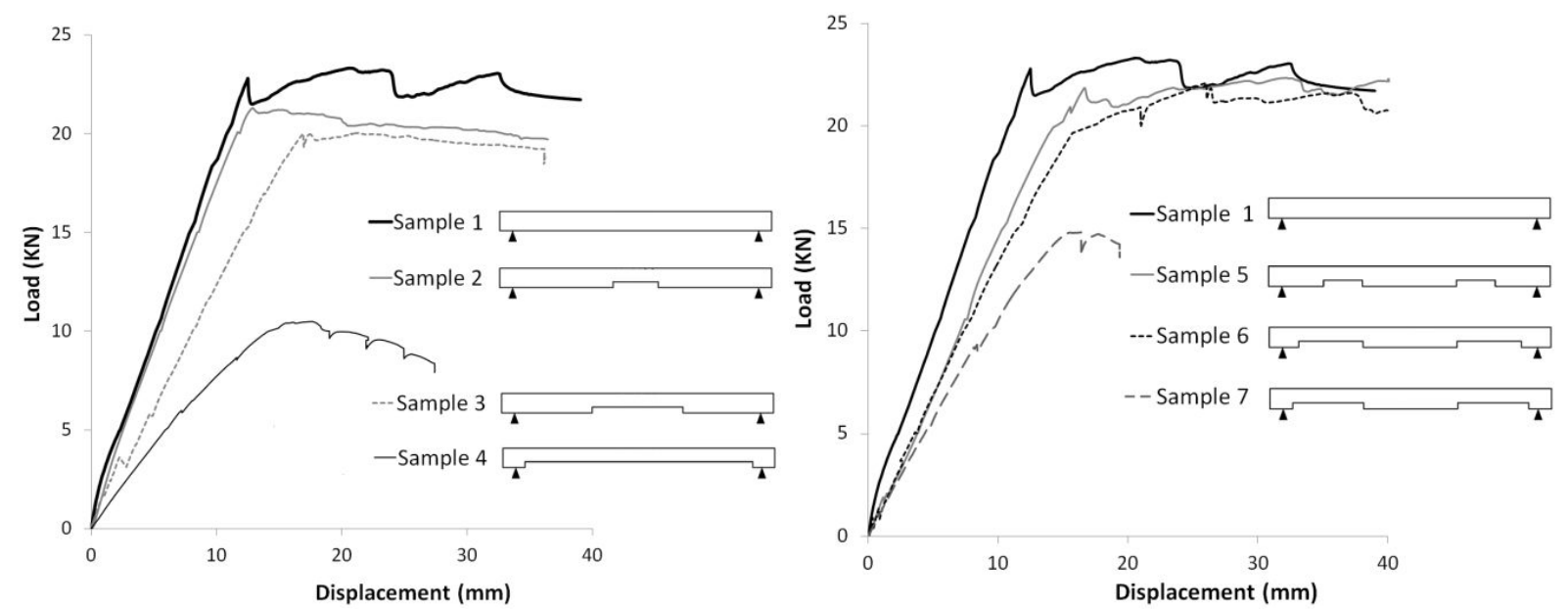

Figure 2-3 Load-deflection curves for beam Samples 1-7 (reproduced from Masnavi 2013) 


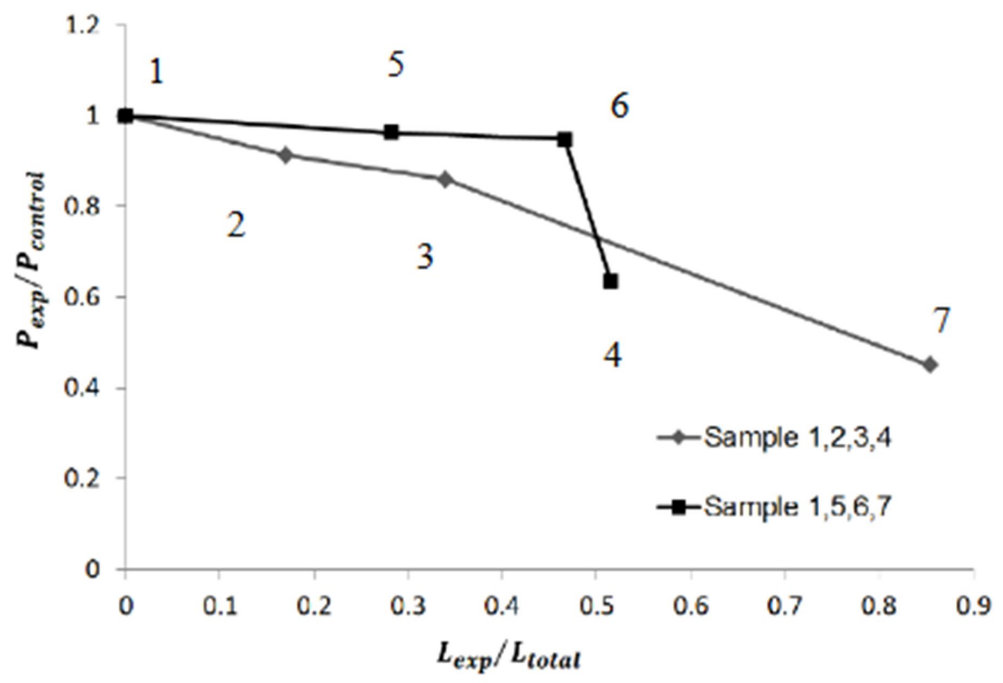

Figure 2-4 Effect of exposure length on beam strength (reproduced from Masnavi 2013)

From the experimental results (Figure 2-3 and Figure 2-4), it is observed that the rate of capacity decrease for specimens with short exposure lengths at midspan is slightly higher than those whose concrete cover is removed near supports. It is also observed from Figure 2-4 that the deterioration effect is more significant if the exposure area is closer to the supports, because the damaged area in Sample 7 was nearer to the supports compared to Sample 5, leading to greater degradation of the arch action and lower flexural capacity.

Similar observations can be found in Cousin and Martin-Perez (2010). The authors tested three sets of pre-tensioned prestressed concrete beams, which were corroded with various regions or length prior to 4-point bending. The second and third sets of specimens both had $200 \mathrm{~mm}$ length of corrosion out of a $250-\mathrm{mm}$ span, but the second set of beams had the corrosion area located at the center of the span, whereas the corroded regions of the latter specimens were near one of the supports. From the experimental results, although sets 2 and 3 had the same percentage of corroded length, the specimens with damages near the ends presented weaker residual responses. 


\subsubsection{Friction}

\subsubsection{Analytical evaluations}

Some authors claim that as iron oxides accumulate at the steel interface, frictional properties can be altered, since rust products form a weaker layer, and a lubricant effect should be anticipated. However, an initial increase in friction at early corrosion stages due to increased surface roughness was also observed in experimental tests (Jin et al. 2001).

Several empirical models for the coefficient of friction as a function of corrosion have been proposed to be used in numerical analysis. Lundgren (2007) assumed a slight increase of friction until $1 \%$ corrosion, which is written as:

$$
\mu(\kappa)=k(x / r) \cdot \mu_{0}(\kappa)
$$

where $\mu_{0}(\kappa)$ is the friction coefficient for the uncorroded bar, which was taken as 0.7 and 1.0 for plain and ribbed bars, respectively, in Lungdren (2007), and $k(x / r)$ is a function of the attack penetration $x$. Values for $k$ as a function of $x / r$, where $r=d_{b} / 2$, are given in Figure 2-5.

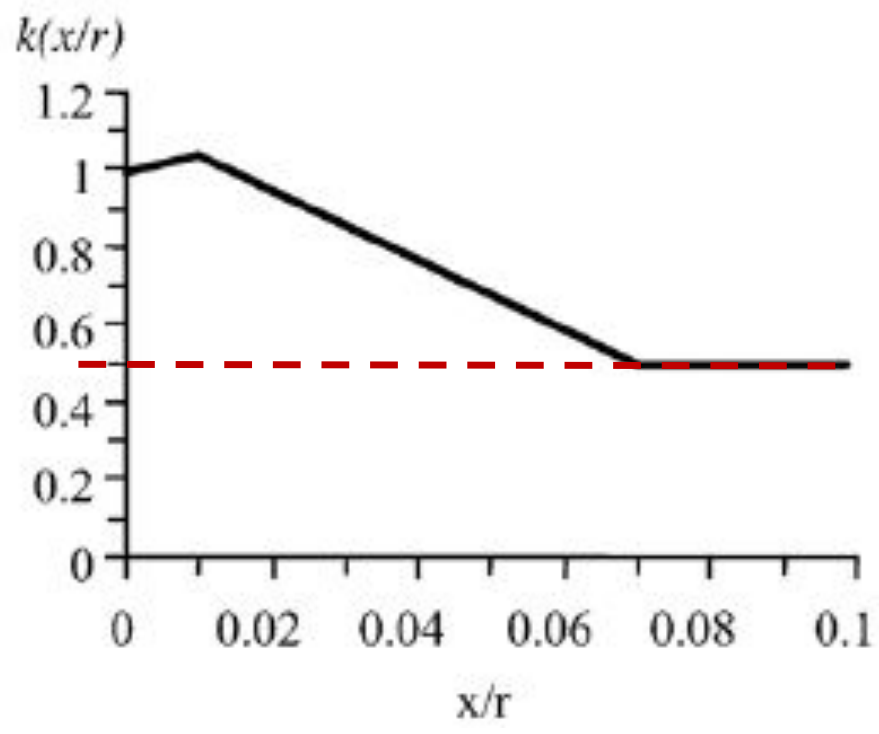

Figure 2-5 The evaluation of $k(x / r)$ (reproduced from Lundgren 2007) 
A lower limit of 0.5 was set to account for the fact that, for pull-out failure, shear cracks form between the ribs of the rebar, and friction is only active between concrete surfaces. Therefore, the influence of corrosion is not significant for friction at large slips.

The friction coefficient suggested by Coronelli (2002) decreases once the corrosion depth $x$ exceeds the attack penetration $x_{c r}$ associated with through concrete cover cracking, and it is written as:

$$
\mu(x)=\tan \phi=0.37-0.26\left(x-x_{c r}\right)
$$

where $\phi$ is the friction angle between concrete and reinforcement. Note that, unlike Lundgren (2007), the initial increase is not included in Eq 2-9, as the increase occurs at low corrosion levels, i.e., at approximate 10 to $15 \mu m$ attack penetration according to Coronelli (2002).

Amleh and Ghosh (2006) modelled the friction coefficient with an exponential expression, wherein the friction coefficient decays from the static value to kinetic one, and it is given as:

$$
\mu=\mu_{k}+\left(\mu_{s}-\mu_{k}\right) e^{-d_{c} \gamma_{e q}}
$$

where $\mu_{k}$ is the coefficient of kinetic friction, $\mu_{s}$ is the coefficient of static friction, $d_{c}$ is an empirical decay coefficient, and $\gamma_{e q}$ is the slip. Therefore, the friction coefficient is affected by the slip and the empirical decay coefficient, which can be evaluated by mass loss due to corrosion.

For a corroded surface, Amleh and Ghosh (2006) suggested that a decay of the static friction coefficient with increasing corrosion levels is expected, whereas the kinetic value of friction coefficient (0.4) remains constant. Parametric studies using Eq 2-10 were performed, and the decay coefficient and static friction coefficient were evaluated as a function of mass loss $m_{s}$ as follows: 


$$
\begin{gathered}
d_{c}=0.0261 m_{s}+0.45 \\
\mu_{s}=\exp \left(-0.035 m_{s}\right)
\end{gathered}
$$

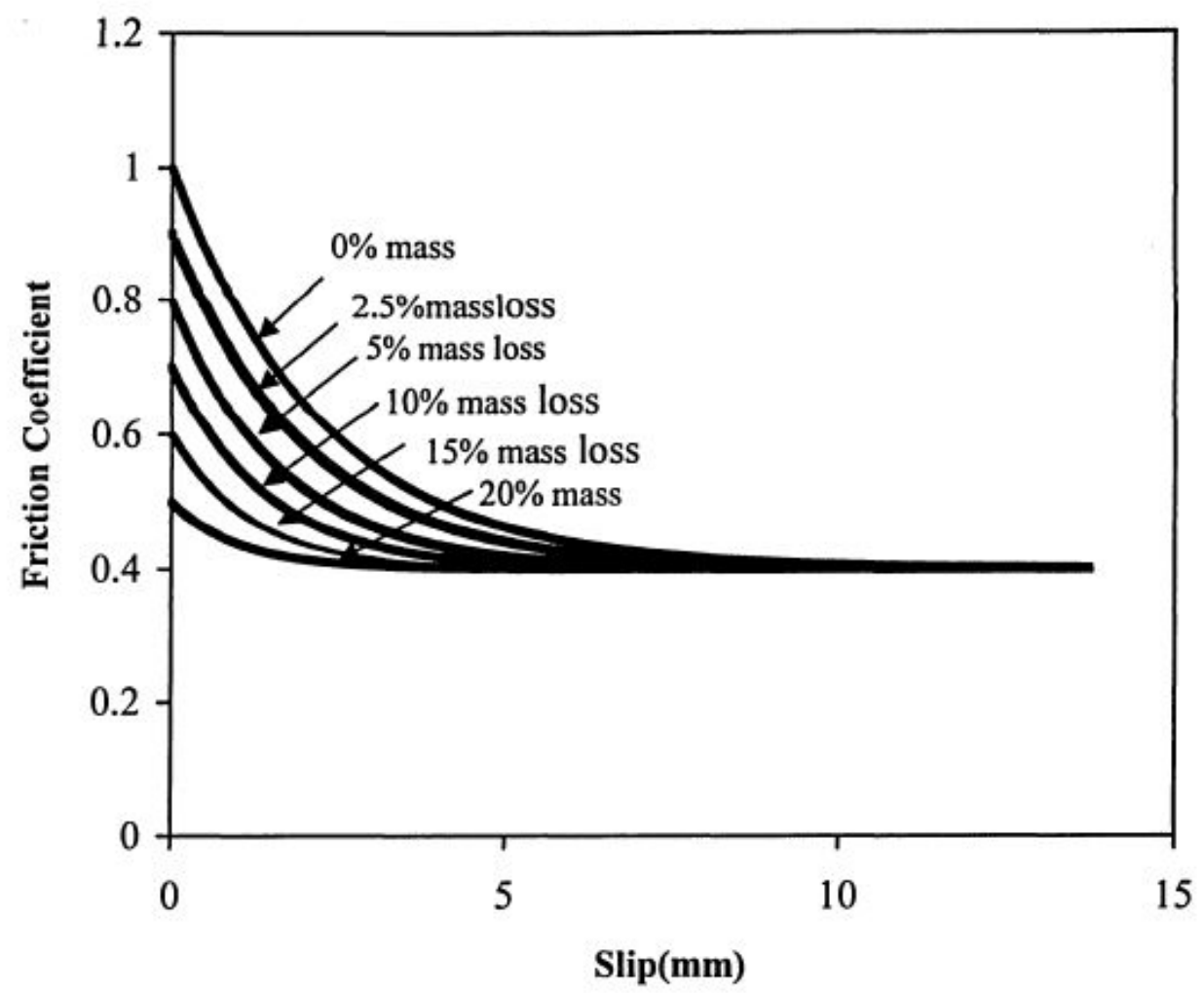

Figure 2-6 Variation of friction coefficient with slip at different mass losses (reproduced from Amleh and Ghosh 2006)

Substituting Eq 2-11 and Eq 2-12 into Eq 2-10, the coefficient of friction $\mu$ is rewritten as:

$$
\mu=\mu_{k}+\left(e^{\left(-0.035 m_{s}\right)}-\mu_{k}\right) e^{-\left(0.0261 m_{s}+0.45\right) \gamma_{e q}}
$$

where $m_{s}$ is the steel mass loss in $\%$.

Figure 2-6 plots the trend of $\mu$ with respect to varying mass loss as the slip increases. 


\subsubsection{Experimental observations}

The value of friction coefficient at the interface between steel and concrete in uncorroded specimens has been investigated by Baltay and Gjelsvik (1990), who tested reinforced concrete specimens made out of Type III Portland cement and 3/4-in maximum size gravel. By applying a normal compression force on the concrete prior to the steel sample being pulled by a hydraulic jack, the normal compression force and the pullout force were measured, which gave the observed value of a friction coefficient between 0.3 and 0.6 .

To investigate the friction characteristics at the corroded steel/concrete interface, an experiment was carried out by Cairns et al. (2007). A total of four test series were conducted, which consisted of a concrete block 50-mm thick by $100 \mathrm{~mm} \times 130 \mathrm{~mm}$, sandwiched between two mild steel plates 50-mm wide and 20-mm thick. Threaded rods were used at the ends of the specimen to clamp the steel/concrete sandwich. After the specimens were corroded, they were subjected to loading, with a vertical load applied to clamp the specimen between the steel plates and a horizontal load applied to displace the concrete in the lateral direction, relative to the steel plates. From the observation of experimental data, Cairns et al. (2007) concluded that when a surface crack width in the cover is less than $1.0 \mathrm{~mm}$, the lubricant effect of rust products may not be significant because an increase of friction due to the accumulation of oxides is noted until $0.2 \mathrm{~mm}$ corrosion expansion.

\subsubsection{Confinement}

The increase of confining stress at the steel/concrete interface, which mainly results from the surrounding concrete cover, the stirrups and a field of compressive stress, contributes to larger friction stress, and the importance of different confinement levels has been illustrated experimentally (Fang et al. 2004) and numerically (Berra et al. 2003, Lundgren 2007). They suggest that $\mathrm{RC}$ with higher amount of confinement tends to have stronger resistance to cracking 
due to corrosion products build-up around the reinforcement, and, hence, it has less bond degradation, as the appearance of corrosion cracks triggers a decreasing trend of bond strength for further corrosion levels.

\subsubsection{Analytical evaluations}

Tepfers (1979) performed an analytical study to investigate the bond behaviour for uncorroded deformed bars. Since the splitting stress in the concrete cover, which equilibrates the induced normal stresses due to confinement, causes cracks when a reinforcing bar is pulled out, the author developed an analytical model to evaluate the confining capacity. The author modelled the concrete as a thick-wall cylinder subjected to internal pressure (shown in Figure 2-7), whose thickness is determined by the cover depth.

When the expansion of the cylinder inner surface in initialed due to splitting, the pressure at the interface starts to build up around the bar. Once the concrete is cracked, as the internal pressure is larger than the tensile capacity of the cover, the thick-wall cylinder can be divided into two parts: (i) an inner plastic ring (from $d_{b} / 2$ to crack front $e$ ) and (ii) outer uncracked ring (from $e$ to the outer edge of the cylinder $\left.c_{y}+d / 2\right)$, where $c_{y}$ is the depth of cover, original diameter $d_{b}$ is the original diameter of reinforcing steel bar, and $e$ is the radius of the crack front. Thus, the outer part is viewed as a linear-elastic material, whereas the inner part is in the tensile concrete softening stage. 


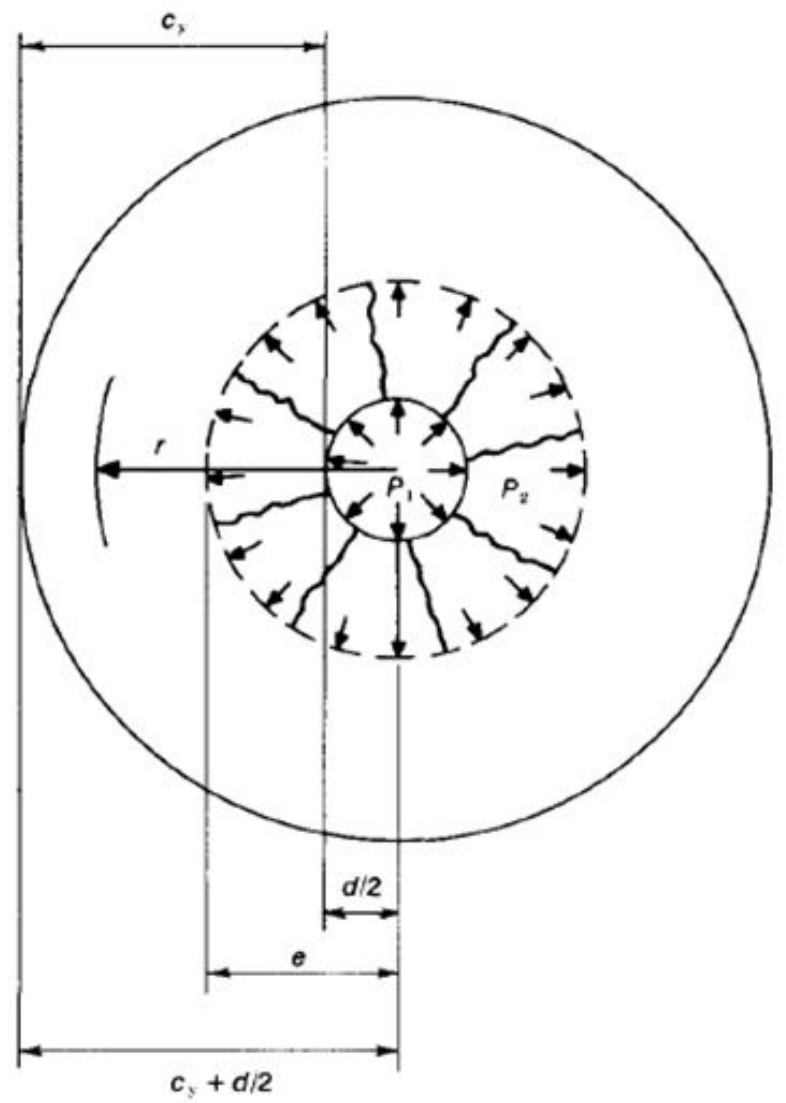

Figure 2-7 Concrete thick wall cylinder model (reproduced from Tepfers 1979)

Since rust has a larger volume than virgin steel, the concrete cover is also subjected to inner expansion due to corrosion products build-up. Wang et al. (2004) adopted the thick-wall cylinder analogy to evaluate the confinement and splitting stresses due to corrosion. The authors solved the expansion displacement by assuming the rust product was free to expand and could diffuse into cracks. By using the tensile softening behaviour suggested by Pantazopoulou and Papoulia (2001), the analytical results showed the confining stress also had a similar trend with bond degradation, which experienced an initial increase and then a decrease as the attack penetration propagated.

\subsubsection{Interlock}

For deformed bars, the interlock effect between ribs and concrete plays a significant role in 
bonding between steel and concrete and makes the assumption of perfect bond feasible. Some analytical and numerical models considering the mechanical interlocking have been proposed by researchers, such as Wang et al. (2004) and Lundgren (1999), to evaluate the bond stress.

\subsubsection{Experimental observations}

At high levels of corrosion, the geometry of the rebar, for instance the height of the rib, is changed, leading to diminished interlock. According to Chung et al. (2004), this phenomenon occurs before the corrosion in the cross section is initialized, and it eliminates most of the interlock stress at $2 \%$ of corrosion, as observed in experiments conducted by the author, in which the rib no longer existed or only a small portion remained.

Similar conclusions can be found in Almusallam et al. (1996), where pullout tests were performed on specimens of $152 \times 254 \times 279 \mathrm{~mm}$ with $12 \mathrm{~mm}$ diameter ribbed bar. They reported about $45 \%$ rib profile loss at about $7 \%$ corrosion and around $70 \%$ profile loss at $12 \%$ rebar corrosion. Also, only a small change in the bond strength due to the reduction in the rib profile was observed in the range of 43 to $100 \%$ corrosion, which indicates that the ribs are degraded to the extent that their interlocking action with the concrete becomes negligible. Therefore, further degradation of the ribs does not affect the bond strength to any noticeable extent.

\subsection{Finite element simulation of bonding}

The constitutive behaviour of bond, i.e., a bond-slip relation, has been investigated by many researchers in finite element (FE) analysis, and different modelling techniques have been proposed and verified against experimental data. In order to model bond behaviour in FE, the methodology to mimic interaction between concrete and steel bar should be investigated. There are several methods summarized below. 


\subsubsection{Direct contact}

In finite element modelling, the bond behaviour between concrete and rebar can be treated as a contact problem if the interaction or contact properties are defined properly.

Berra et al. (2003) used axi-symmetric finite element analysis in ABAQUS to investigate the bond degradation corresponding to varying confinement situations and corrosion expansion levels. The interaction was assumed to be perfectly or partially compatible for nodes at the interface, and the corrosion effect was considered by applying a steel volume expansion, which introduced damage in the concrete cover. Although this approach gave good numerical results in FE pullout tests, the drawback of this interaction assumption is that the friction properties, which should be altered when corrosion is initialized, cannot be taken into account since the nodes at the interface, where the compatibility is applied, are forced to move together.

Amleh and Ghosh (2006) developed a nonlinear 3D model for finite element pullout tests. The author assumed the bond stress was attributed to friction and performed parametric studies to obtain the friction coefficient, which is a function of attack penetration and slip. The contact pressure due to corrosion was defined by the contact pressure-overclosure relationships provided by ABAQUS, which increases exponentially as clearance between the concrete inner surface and reinforcing bar reduces. The numerical solution showed promising results when they were validated against some pullout tests conducted by Cabrera and Ghoddoussis (1992) and Al-Sulaimani et al. (1990).

\subsubsection{Link or interface element}

The link or interface element serves as a mechanical medium that transfers the stress between steel and concrete. Link elements are located at the inter-layer and connect the nodes of different 
elements. As a consequence, the concrete and steel elements can be viewed as two separated layers and cooperate through those connections while undergoing loading rather than their interface be considered as a contact problem.

The first application of a link element in RC to model bond was proposed by Ngo and Scordelis (1967). This link element consists of two springs in orthogonal directions (Figure 2-8), representing the normal stress, like corrosion-induced internal pressure or inclined force from interlocking, and tangential stress, i.e., bond stress. However, the authors did not give expressions for the stiffnesses of these links.

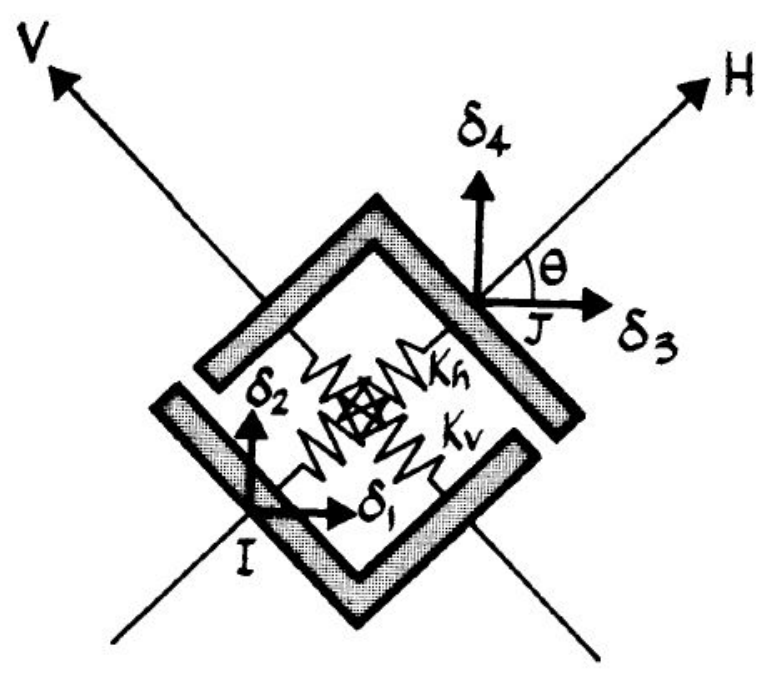

Figure 2-8 Configuration of a link element (reproduced from Ngo and Scordelis 1967)

Lundgren and Gylltoft (2000) developed an interface element (see Figure 2-9) for finite element analysis. This non-dimensional element is also used at the concrete-steel interface, and its stiffness matrix is given by

$$
\left[\begin{array}{l}
t_{n} \\
t_{t}
\end{array}\right]=\left[\begin{array}{cc}
D_{11} & \frac{\left|u_{t}\right|}{u_{t}} D_{12} \\
0 & D_{22}
\end{array}\right]\left[\begin{array}{l}
u_{n} \\
u_{t}
\end{array}\right]
$$


where $t=\left[\begin{array}{c}t_{n} \\ t_{t}\end{array}\right]=\left[\begin{array}{ccc}\text { normal } & \text { splitting } & \text { stress } \\ \text { bond } & \text { stress }\end{array}\right]$

$u=\left[\begin{array}{l}u_{n} \\ u_{t}\end{array}\right]=\left[\begin{array}{cc}\text { relative } & \text { normal } \\ & \text { displacement at the layer } \\ \text { slip } & \end{array}\right]$

$D_{11}, D_{12}$ and $D_{22}$ are the stiffness coefficients for the link element.

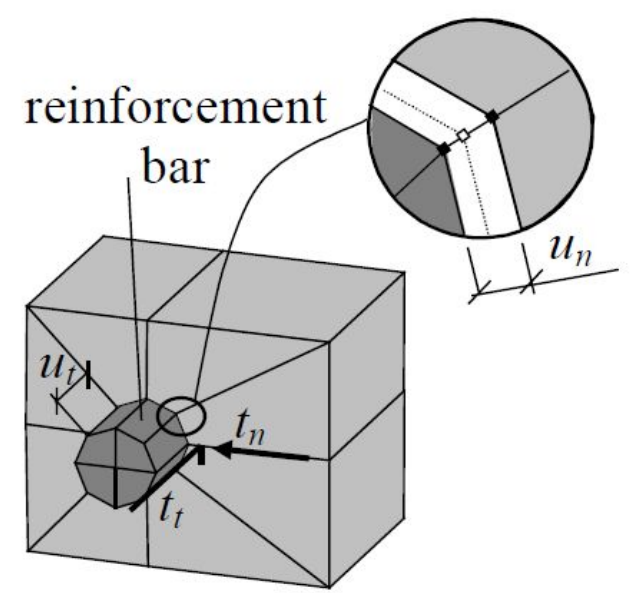

Figure 2-9 Configuration of interface element according to Lundgren and Gylltoft (reproduced from Lundgren and Gylltoft 2000)

For deformed bars, this frictional model is able to describe the radial deformation resulting from splitting stresses by specifying the nonzero stiffness term $\frac{\left|u_{t}\right|}{u_{t}} D_{12}$. To evaluate this stiffness, the theory of elasto-plasticity is applied, which includes the knowledge of yield lines, flow rules, and hardening laws. For plain bars, this term is set to zero.

The application of link and interface elements was demonstrated by some researchers and their validation was shown by comparing numerical results to experimental tests.

Lee et al. (2002) built a FE model with link and interface elements, and conducted pullout tests to 
investigate the degradation of bond capacity and rigidity. They first performed the experiments with a series of specimens, which had different grades of concrete, cover thickness and corrosion levels by using accelerated corrosion. Rather than using an analytical solution for bond behaviour, the bond response, such as capacity and rigidity, was measured from tests and then inputted into the finite element model. The authors reported the validation of the link element was demonstrated by showing a good agreement with their experimental data.

Li et al. (2014) applied similar elements in the nonlinear finite element software ABAQUS to investigate the degradation of bond strength and stiffness due to corrosion. The connecting element, called translator element, that connected concrete and steel at the interface was established. Only the displacement in the slip direction was enabled in the element, mimicking the bond response, while all the other degrees of freedom for the two connecting nodes were relatively restrained to each other. By modifying an explicit bond relation proposed by Almusallam et al. (1996) as necessary input data for the element, they compared their numerical results against bending experiments, where corroded seawalls with dimensions of $1000 \times 2000 \times 150 \mathrm{~mm}$ were subjected to loading. The results demonstrate the promising application of this translator, which is similar to a link element, as the model is able to capture the observed behaviour in their experimental tests.

\subsubsection{Bond zone}

The application of link elements may require significant amount of time if the structure is large. Rather than using a link element, a bond zone is established in Ziari and Kianoush (2014). The bond zone is a small concrete region next to the reinforcing bar, whose material properties are modified to represent better bond interaction.

Based on the observation that the formation of diagonal compression struts caused by the micro 
cracking is noted during the pullout of reinforcement, and due to high concentration of compressive stresses against the bar lugs, the authors adopted a smaller value of tensile strength and fracture energy in the bond zone. The reason is that if the tensile strength and fracture is reduced, the stress from the steel bar can be transferred to the surrounding concrete through diagonal compressive stresses $\left(\sigma_{1}\right)$ in Figure 2-10 (where $\sigma_{1}$ and $\sigma_{2}$ are principal stresses), as the principal tensile stresses $\left(\sigma_{2}\right)$ are virtually zero, while in the perfect bond model without material modifications, the bond force can be transferred through tensile stresses.

The result of this methodology is affected by the depth of the modified region, since the larger the zone leads to larger angle of the bond bearing stress. Therefore, half the bar diameter is suggested for the depth of the bond zone.

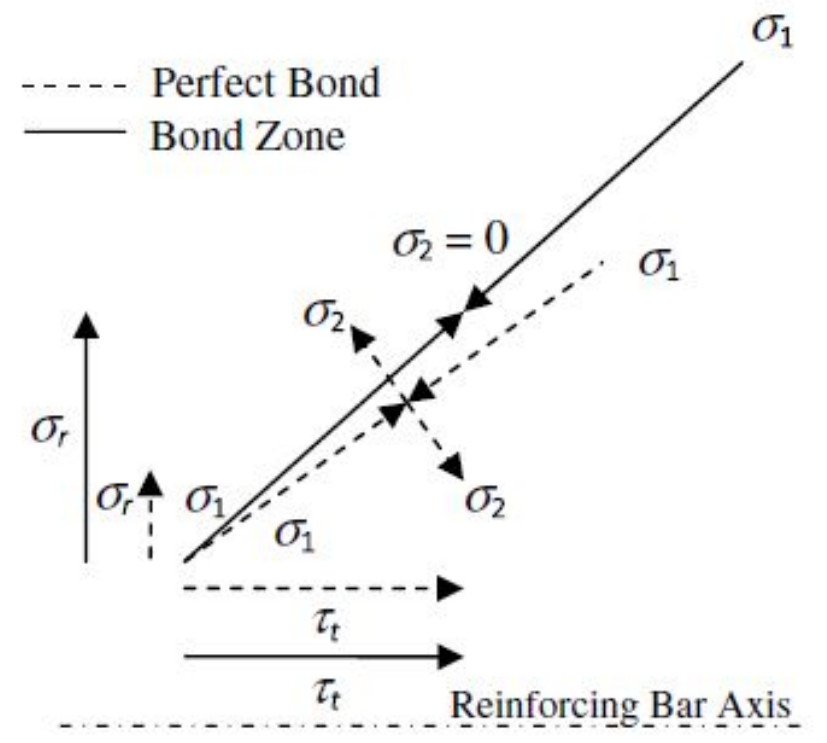

Figure 2-10 Principal stresses in concrete elements located in bond region for perfect bond and bond zone models (not to scale) (reproduced from Ziari and Kianoush 2014) 


\subsection{Need for Research}

The literature review showcases bond behaviour can be impaired by reinforcement corrosion. As reviewed, each mechanism contributing to bond is altered as the corrosion level increases. Although an initial increase in bond capacity is noticed in some experiments (see Figure 2-2), mainly attributed to the confinement increase due to the corrosion volumetric expansion at the concrete/steel interface, bond deterioration starts after the concrete cover cracks.

From the review of the literature, numerous experiments have contributed to today's knowledge on the loss of bond interaction between concrete and steel due to reinforcement corrosion. There have also been several studies to capture this bond deterioration in finite element modelling following different approaches, e.g., direct contact, linkage element and bond zone. The link element has been successfully used to model bond deterioration along the reinforcement in pullout test simulations, if the bond stress-bond slip constitutive behaviour is known a priori. However, there has been limited effort in applying link elements wherein the normal and transversal bond components are decoupled and evaluated using analytical modelling. This approach thus relates the level of concrete cover cracking (normal component) to bond degradation (transverse component). Therefore, this work attempts to implement this FE procedure by using link elements that simulate simultaneously the reduction of steel cross sectional area, the cracking of the concrete cover, and the loss of bonding between concrete and steel as a result of reinforcement corrosion. Procedures are implemented for a two-dimensional analysis of reinforced concrete flexural members. 


\section{Analytical Model for Bond Stress}

\subsection{Introduction}

When the corrosion level increases in reinforced concrete, the physical properties for concrete, steel bar and contact interface are altered, which changes the bond behaviour between steel and concrete. This chapter presents an analytical model for bond behaviour at different levels of reinforcing steel corrosion by first investigating the frictional stress, which can be expressed by the total corrosion pressure times the friction coefficient, followed by the evaluation of adhesive and mechanical interlocking stresses.

\subsection{Bond mechanism}

The bond capacity between concrete and reinforcement is mainly from (1) chemical adhesion, (2) friction, (3) and mechanical interlock due to the ribs of rebars. According to the frictional model proposed by Tastani and Pantazopoulou (2013), the bond capacity $\tau_{\max }$ can be written as:

$$
\tau_{\max }=f_{a d h}+\mu \cdot \sigma_{t c}+f_{i} \quad \text { Eq } 3-1
$$

where $f_{a d h}$ is the chemical adhesion, $\mu$ is the friction coefficient, $\sigma_{t c}$ is the corrosion pressure due to the accumulation of corrosion by-products around the reinforcing bar, and $f_{i}$ is mechanical interlock stress due to the rebar sliding against the concrete. Each of these mechanisms is explored further in the next sections.

\subsection{Corrosion pressure $\sigma_{t c}$}

Corrosion occurs at the surface of the steel bar, and the resulting oxides start to accumulate as the 
corrosion processes. Since iron oxides have lower density (e.g., $5.24 \mathrm{~g} / \mathrm{cm}^{3}$ for $\mathrm{Fe}_{2}(\mathrm{OH})_{3}$ ) than the virgin steel $\left(7.86 \mathrm{~g} / \mathrm{cm}^{3}\right)$, the rust product resulting from steel consumption due to corrosion has a larger volume than the original steel, and this volumetric expansion causes a pressure at the interface between the reinforcement and the concrete.

Tepfers (1979) first evaluated the confining stress at this interlayer by modelling the concrete as a thick-wall cylinder subjected to pressure at the inner surface (Figure 3-1), where the thickness corresponds to the concrete cover. In Tepfers' model, the pressure $P$ starts to build up at the inner surface of the thick-wall cylinder, whose inner radius is $r_{b}$ and outer radius is $R_{c}$. Radial cracks are created if the pressure $P$ induces tensile stress above the tensile capacity of the concrete cover. Once the cylinder is partially cracked, the model can be divided into two parts: an elastic uncracked part (from $R_{i}$ to outer edge of cylinder $R_{c}$ ) and a cracked inner ring (from the edge of the corroded rebar $r_{b}-x+t_{r}$ to crack front $R_{i}$ ), where $r_{b}$ is the radius of the uncorroded steel, $t_{r}$ is the thickness of the rust layer, $R_{i}$ is the radius of the crack front, and $x$ is the attack penetration, which is used to measure the corrosion level and can be calculated if the corrosion current and the corrosion period are known, or obtained from on-site observation.

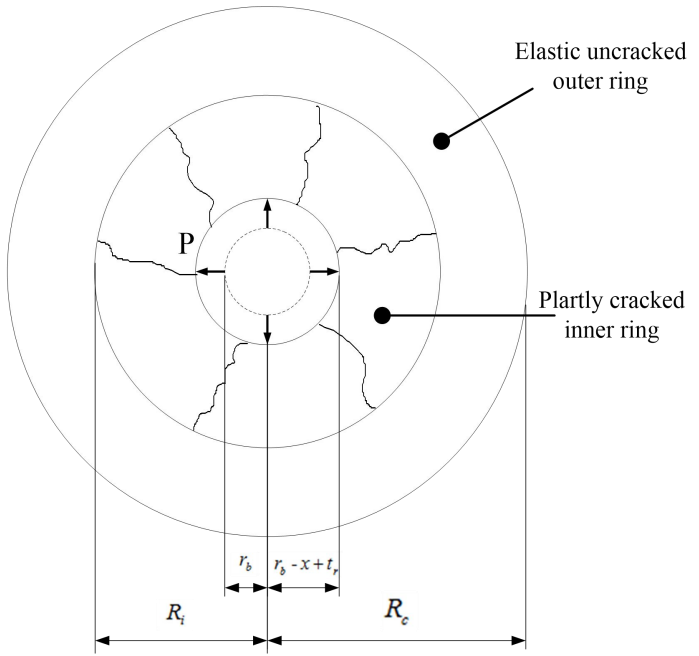

Figure 3-1 Concrete cover idealized as a thick-wall cylinder 
Wang et al. (2004) also adopted this methodology to evaluate the confinement pressure resulting from corrosion build-up. By assuming corrosion buildup is uniformly distributed around the reinforcing bar, the corresponding volume of consumed steel per unit length is given as:

$$
\Delta V_{s}=\pi r_{b}^{2}-\pi R_{s}^{2}=2 \pi r_{b} x-\pi x^{2}
$$

where $r_{b}, R_{s}$ are the radii of the virgin rebar and corroded bar, respectively.

As oxides products have lower density compared to sound steel, the corresponding volume of accumulated iron oxides can be obtained from:

$$
\Delta V_{r}=n \Delta V_{s}
$$

where $n$ is the ratio between the volume of oxide products and virgin steel. According to Rosenberg et al. (1989), the ratio $n$ can be taken from 2 to 6.4 for different corrosion products (see Figure 3-2). The approximation of the value $n$ should be based on the assessment of oxide products, and it is assumed to be 2 in Lundgren (2007).

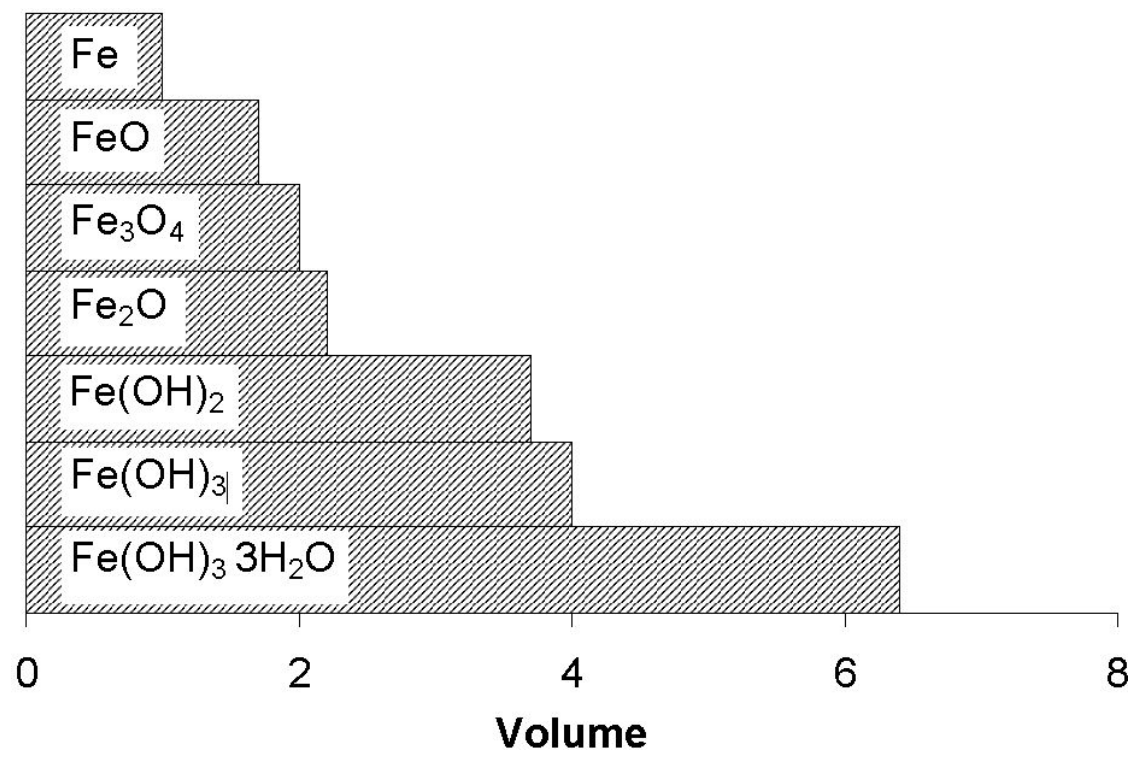

Figure 3-2 Values of $n$ representing different corrosion products

The stress in the concrete cover due to corrosion expansion $\sigma_{t c}$ results from the confining 
behaviour of the concrete itself, denoted here as $\sigma_{c}$, and from the existing stirrups, denoted as $\sigma_{s}$. The following sections present how to calculate each component contributing to $\sigma_{t c}$.

\subsubsection{Confining stress from concrete $\sigma_{c}$}

\subsubsection{Partially-cracked thick wall cylinder}

When the cylinder model is partly cracked, i.e., the crack front $R_{i} \leq R_{c}$, the confining stress contribution comes from elastic and inelastic regions in the concrete cover. Thus, the confinement stress can be evaluated by establishing the equilibrium condition according to Figure 3-3.

$$
\sigma_{c} \cdot r_{b}=\int_{r_{b}}^{R_{c}} \sigma_{\theta} d r=\int_{r_{b}}^{R_{i}} \sigma_{\theta} d r+\int_{R_{i}}^{R_{c}} \sigma_{\theta} d r=P_{p}+P_{e} \quad \text { Eq 3-4 }
$$

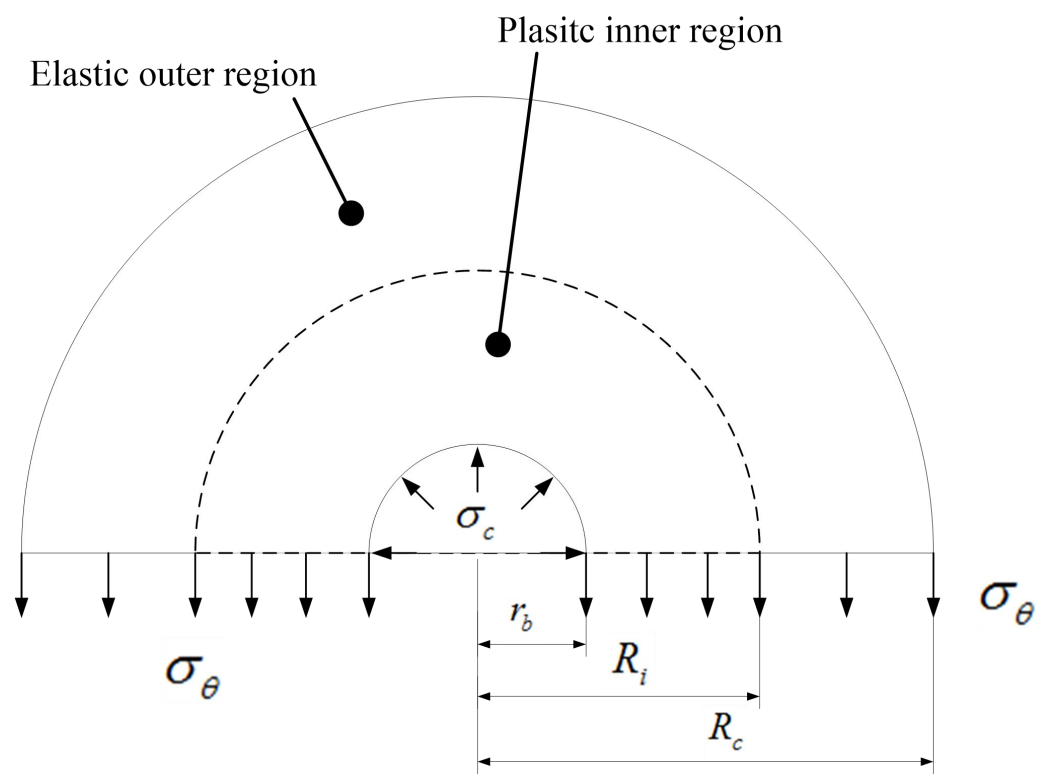

Figure 3-3 Equilibrium condition in the cylinder model 
where $P_{p}$ is the stress contribution from the inner cracked ring, $P_{e}$ is the stress contribution from the outer uncracked ring, and $\sigma_{\theta}$ is the tensile stress in concrete.

\subsection{Confining stress from inner cracked ring $P_{p}$}

Once cracks in concrete are initiated, rust products can diffuse and fill the space. According to Pantazopoulou and Papoulia (2001), cracks can be assumed to form in triangular shape (Figure $3-4)$, whose volume per unit length is written as $w \cdot\left(R_{i}-R_{r}\right) / 2.0$, where $w$ is the crack width opening around the perimeter of the rust front $R_{r}$ for each crack.

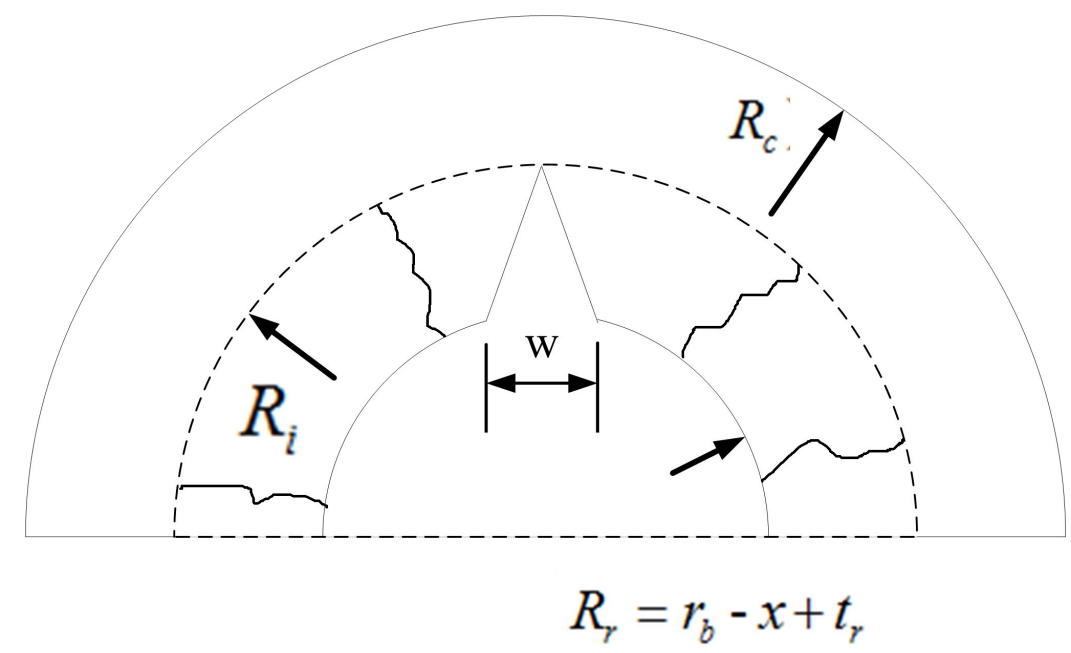

Figure 3-4 Crack shape in concrete cover

It is assumed that the corrosion products are free to expand, i.e., the volume of accumulated corrosion products $\Delta V_{r}$ does not reduce under pressure $P$, which is rewritten as:

$$
\Delta V_{r}=n \Delta V_{s}=\pi \cdot t_{r}\left(2 R_{s}+t_{r}\right)+\sum w \cdot\left(R_{i}-R_{r}\right) / 2.0 \quad \text { Eq } 3-5
$$

where $\sum w$ is the total amount of crack width openings, given by $\sum w=2 \pi \cdot u\left(r_{b}\right)=2 \pi \cdot\left(R_{r}-r_{b}\right)$, 
and $u\left(r_{b}\right)$ is the radial displacement at $r=r_{b}$ caused by corrosion, written as:

$$
u\left(r_{b}\right)=t_{r}-x=\frac{(n-1) \cdot\left(2 r_{b} x-x^{2}\right)}{R_{i}+r_{b}}
$$

To obtain the analytical solution for tensile stresses in the thick-wall cylinder, the theory of elasticity is adopted, which is given by:

$$
\sigma_{\theta}(r)=f_{s} \cdot \frac{\left(R_{c} / r\right)^{2}+1}{\left(R_{c} / r_{s}\right)^{2}+1}
$$

where $r_{s}$ is the radial position, and $f_{s}$ is the corresponding tensile stress in the cylinder at $r=r_{s}$ (Figure 3-5). If the tensile stress $f_{s}$ at $r=r_{s}$ in the thick-wall cylinder is known, the tensile stress $\sigma_{\theta}(r)$ within the elastic ring can be evaluated.

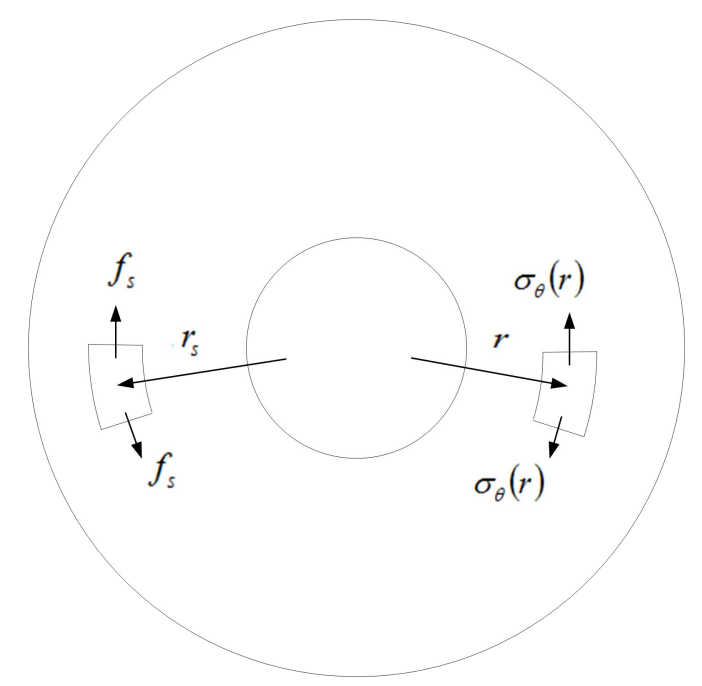

Figure 3-5 Tensile stresses in the thick-wall cylinder

Because the concrete reaches its tensile strength at the crack front $R_{i}$, i.e., $r_{s}=R_{i}$ and $f_{s}=f_{t}^{\prime}$, Eq 3-7 can be rewritten as: 


$$
\sigma_{\theta}(r)=f_{t}^{\prime} \cdot \frac{\left(R_{c} / r\right)^{2}+1}{\left(R_{c} / R_{i}\right)^{2}+1}
$$

where $f_{t}^{\prime}$ is the tensile strength of concrete.

In Wang et al. (2004), the authors assume elastic behaviour in the inner cracked zone and neglect Poisson's effect. Therefore, a radial displacement distribution for an elastic thick-wall cylinder is used for both regions in the concrete cover (cracked and uncracked), i.e., from $r_{b}$ to $R_{c}$, and it is given by:

$$
\begin{gathered}
\varepsilon(r)=\frac{\sigma_{\theta}(r)}{E_{c}}=\frac{f_{t}^{\prime}}{E_{c}} \cdot \frac{\left(R_{c} / r\right)^{2}+1}{\left(R_{c} / R_{i}\right)^{2}+1} \\
u(r)=\varepsilon(r) \cdot r=\frac{f_{t}^{\prime}}{E_{c}} \cdot r \cdot \frac{\left(R_{c} / r\right)^{2}+1}{\left(R_{c} / R_{i}\right)^{2}+1} \\
\text { for } r_{b}<r<R_{c}
\end{gathered}
$$

where $\varepsilon(r)$ is the hoop strain at position $r$, and $E_{c}$ is the initial elastic modulus of concrete.

However, in the inner cracked ring, the cracking strain $\varepsilon_{c r}$ has been attained. Therefore, the total tensile strain in the cracked region $\varepsilon_{t}$, which can be expressed as $\varepsilon_{t}=\varepsilon_{c r}+\varepsilon_{e}$, where $\varepsilon_{e}$ is the elastic hoop strain, should be larger than the hoop strain (Eq 3-9) evaluated by Wang et al. (2004), where only the elastic strain $\varepsilon_{e}$ is considered in the inner region $\left(r_{b} \leq r \leq R_{i}\right)$. In other words, for a partially cracked cylinder, the radial displacement $u(r)$ within the cracked ring (left side in Figure 3-6) should be larger than the radial displacement at the same radial position $r$ where the inner cylinder is not cracked (right side in Figure 3-6) and the deformation of the entire concrete cover is assumed to be elastic. 


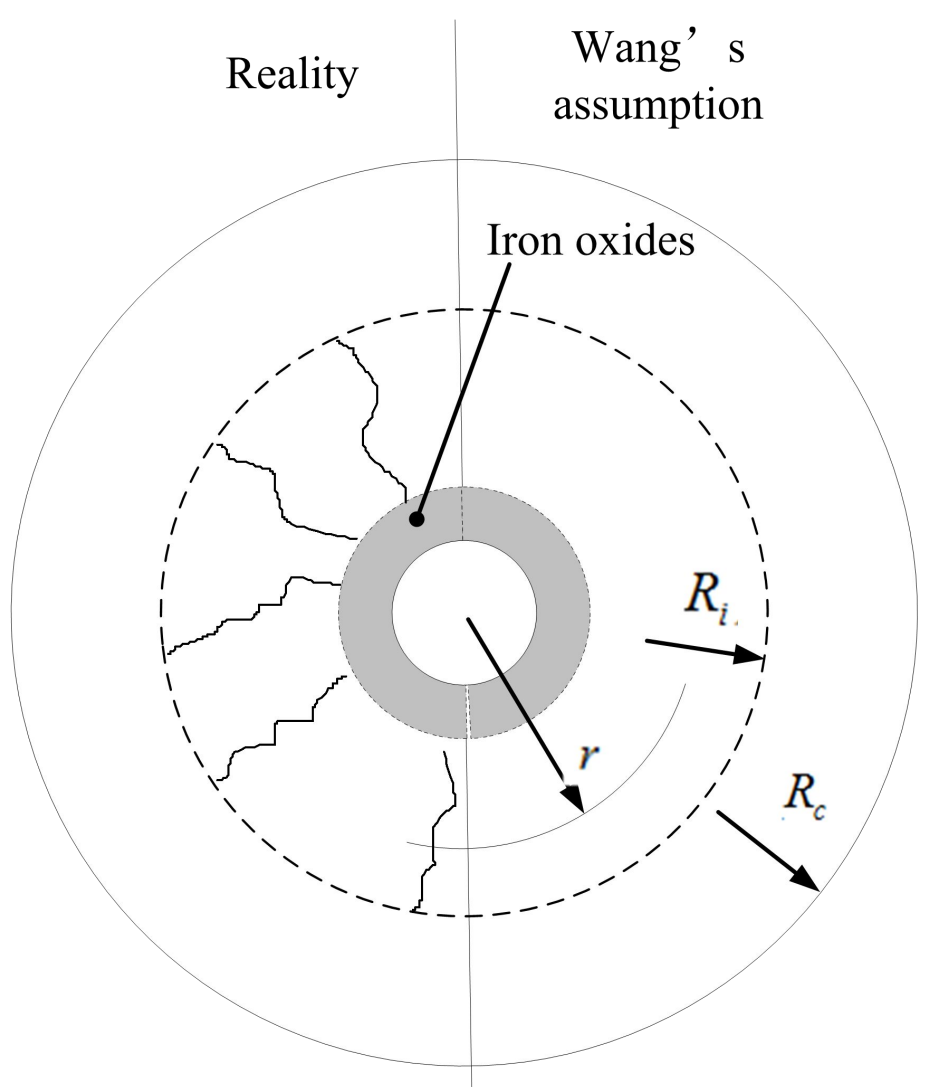

Figure 3-6 Comparison of thick wall cylinder with different displacement assumptions

The drawback of the elastic distribution assumption for the whole cylinder is that the stiffness of the cylinder is overestimated, leading to a higher confinement stress $\sigma_{c}$. As pointed out by Gambarova et al. $(1997,1998)$, the assumption made in the choice of concrete softening model and displacement field along the concrete cover is a significant modelling consideration, since the confinement capacity in the plastic region depends on the concrete strength after cracking. Therefore, other assumptions of radial displacement in the inner ring (from $r_{b}$ to $R_{i}$ ) leading to larger displacements should be made.

Since for a cracked cylinder model, the only variable in Wang's evaluation of radial displacement (Eq 3-9) is the radial position $r$, from a mathematical prospective, it can be simplified as: 


$$
u(r)=\frac{f_{t}^{\prime}}{E_{c}} \cdot r \cdot \frac{\left(R_{c} / r\right)^{2}+1}{\left(R_{c} / R_{i}\right)^{2}+1}=A \cdot r+\frac{B}{r}
$$

where coefficients $A=\frac{f_{t}^{\prime}}{E_{c} \cdot\left[\left(R_{c} / R_{i}\right)^{2}+1\right]}$ and $B=\frac{f_{t}^{\prime} \cdot R_{c}^{2}}{E_{c} \cdot\left[\left(R_{c} / R_{i}\right)^{2}+1\right]}$ are constants derived from the original equation.

In order to obtain an approximation of larger displacements in the inner region, the rational function whose order is equal to -1 , i.e., $u(r)=\frac{C}{r}$, where $C$ is a coefficient, is used in this research to describe $u(r)$ from $r_{b}$ to $R_{i}$. Therefore, the displacement field is written as:

$$
\begin{array}{cc}
u(r)=\frac{C}{r} & \text { for } r_{b}<r<R_{i} \quad \text { Eq 3-12 } \\
u(r)=\varepsilon_{r} \cdot r=\frac{f_{t}^{\prime}}{E_{c}} \cdot r \cdot \frac{\left(R_{c} / r\right)^{2}+1}{\left(R_{c} / R_{i}\right)^{2}+1} & \text { for } R_{i}<r<R_{c} \quad \text { Eq 3-13 }
\end{array}
$$

Due to continuity, i.e., Eq 3-12 and Eq 3-13 both pass $\left(R_{i}, \frac{f_{t}^{\prime}}{E_{c}} \cdot R_{i}\right)$, the coefficient $C$ can be solved, and Eq 3-12 and Eq 3-13 should be rewritten as:

$$
\begin{array}{cc}
u(r)=\frac{f_{t}^{\prime} \cdot R_{i}^{2}}{E_{c}} \cdot \frac{1}{r} & \text { for } r_{b}<r<R_{i} \quad \text { Eq 3-14 } \\
u(r)=\frac{f_{t}^{\prime}}{E_{c}} \cdot r \cdot \frac{\left(R_{c} / r\right)^{2}+1}{\left(R_{c} / R_{i}\right)^{2}+1} & \text { for } R_{i}<r<R_{c} \quad \text { Eq 3-15 }
\end{array}
$$

The hoop strain can then be rewritten as:

$$
\varepsilon_{\theta}(r)=\frac{u(r)}{r}=\frac{f_{t}^{\prime} \cdot R_{i}^{2}}{E_{c}} \cdot \frac{1}{r^{2}} \quad \text { for } r_{b}<r<R_{i} \quad \text { Eq 3-16 }
$$




$$
\varepsilon_{\theta}(r)=\frac{f_{t}^{\prime}}{E_{c}} \cdot \frac{\left(R_{c} / r\right)^{2}+1}{\left(R_{c} / R_{i}\right)^{2}+1} \quad \text { for } R_{i}<r<R_{c} \quad \text { Eq } 3-17
$$

The evaluation of radial displacement according to Eq 3-14 and Eq 3-15 is plotted on the right side of

Figure 3-7, and it is compared to Eq 3-10 obtained from Wang et al. (2004) on the left side of the figure.

Combining Eq 3-6 and Eq 3-14, the following equation is obtained:

$$
\frac{f_{t}^{\prime} \cdot R_{i}^{2}}{E_{0} \cdot r_{b}}=\frac{(n-1) \cdot\left(2 r_{b} x-x^{2}\right)}{R_{i}+r_{b}}
$$

which can be rearranged as:

$$
\varepsilon_{c r} \cdot R_{i}^{3}+\varepsilon_{c r} r_{b} \cdot R_{i}^{2}+(1-n)\left(2 r_{b} x-x^{2}\right) r_{b}=0
$$

The value of the crack front $R_{i}$ can be solved from Eq 3-19, and the regions for cracked and uncracked concrete along the concrete cover can be established.

The solution of Eq 3-19 is obtained by applying the general formula for the root of a cubic function $a x^{3}+b x^{2}+c x+d=0$ (William et al. 1992), i.e.,

$$
x=-\frac{1}{3 a}\left(b+C+\frac{\Delta_{0}}{C}\right)
$$


where

$$
\begin{gathered}
C=\sqrt[3]{\frac{\Delta_{1}+\sqrt{\Delta_{1}^{2}-4 \Delta_{0}^{3}}}{2}} \\
\Delta_{0}=b^{2}-3 a c \\
\Delta_{1}=2 b^{3}-9 a b c+27 a^{2} b
\end{gathered}
$$

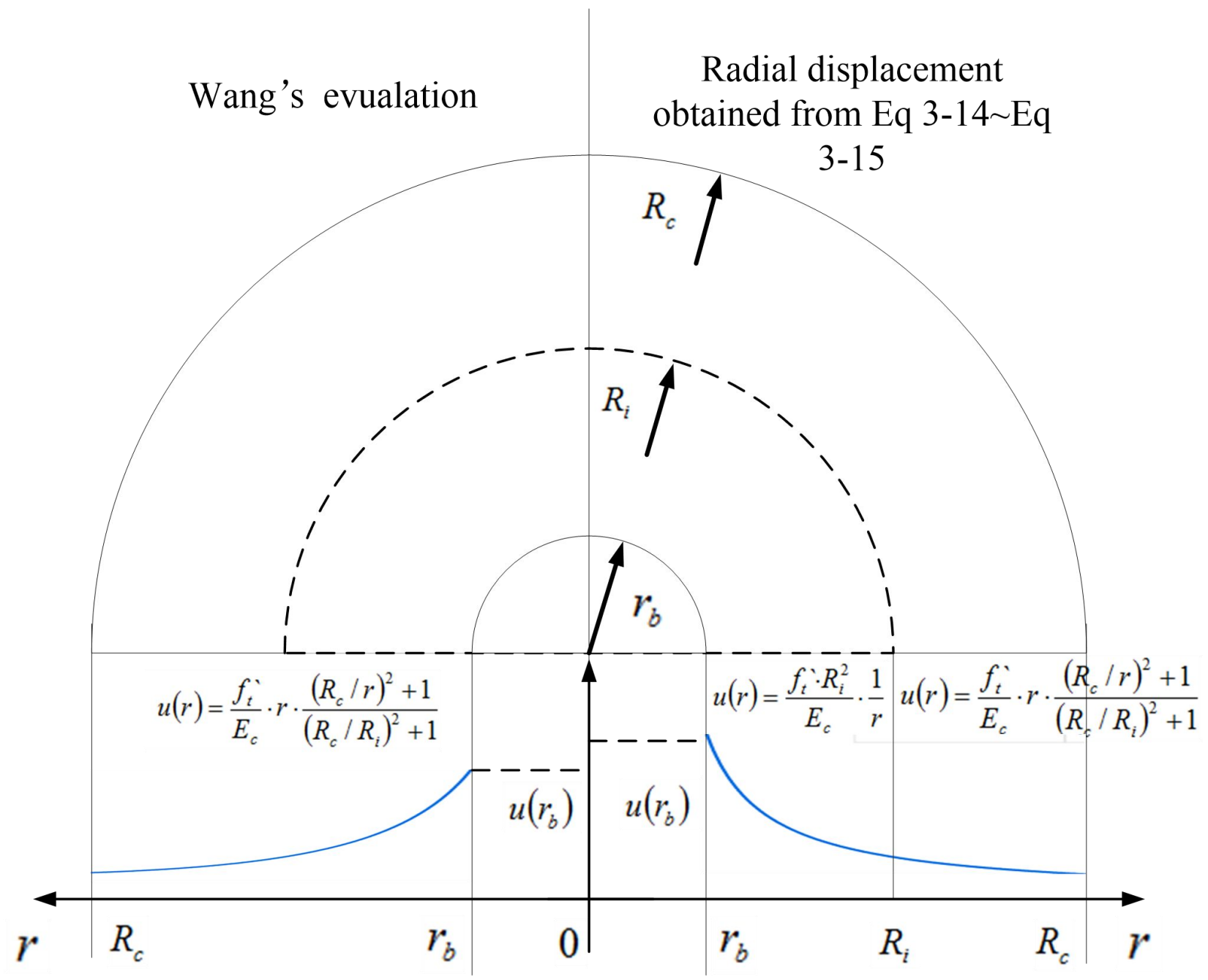

Figure 3-7 Comparison of radial displacement obtained from Wang's evaluation and modified distribution 
The solution for Eq 3-19 is therefore written as:

$$
R_{i}(x)=R_{i a}+\sqrt[3]{-R_{i b}+\sqrt{R_{i b}^{2}+R_{i c}^{3}}}+\sqrt[3]{-R_{i b}-\sqrt{R_{i b}^{2}+R_{i c}^{3}}}
$$

where the corresponding mathematical coefficients are written as:

$$
\begin{gathered}
R_{i a}=-\frac{r_{b}}{3} \\
R_{i b}=\frac{27(1-n)\left(2 r_{b} x-x^{2}\right) r_{b}+2 \varepsilon_{c r} r_{b}^{3}}{54 \varepsilon_{c r}} \\
R_{i c}=-\frac{r_{b}^{2}}{9}
\end{gathered}
$$

To evaluate the stress contribution from the inelastic region, a bi-linear curve is adopted to describe the strain-stress relation in tension, i.e., after reaching the tensile strength $f_{t}^{\prime}$ at strain $\varepsilon_{c r}$, the tensile stress decreases linearly to zero at ultimate strain $\varepsilon_{u}$, and the expressions are given by:

$$
\begin{array}{cl}
\sigma=E_{c} \varepsilon & \text { for } 0 \leq \varepsilon \leq \varepsilon_{c r} \\
\sigma=f_{t}-E_{t}\left(\varepsilon-\varepsilon_{c r}\right) & \text { for } \varepsilon_{c r}<\varepsilon \leq \varepsilon_{u} \\
\sigma=0 & \text { for } \varepsilon_{u}<\varepsilon
\end{array}
$$

The value of the ultimate tensile strain $\varepsilon_{u}$ can be evaluated from the fracture energy $G_{f}$, which is the energy dissipation due to localized cracking per unit area of plane, and its evaluation is presented in the CEB-FIP Model Code (2010) as:

$$
G_{f}=73\left(f_{c}^{\prime}\right)^{0.18}(\mathrm{~N} / \mathrm{m})
$$


where $f_{c}^{\prime}$ is the compressive strength of concrete. Therefore, the fracture energy is a material property dependent on the concrete strength.

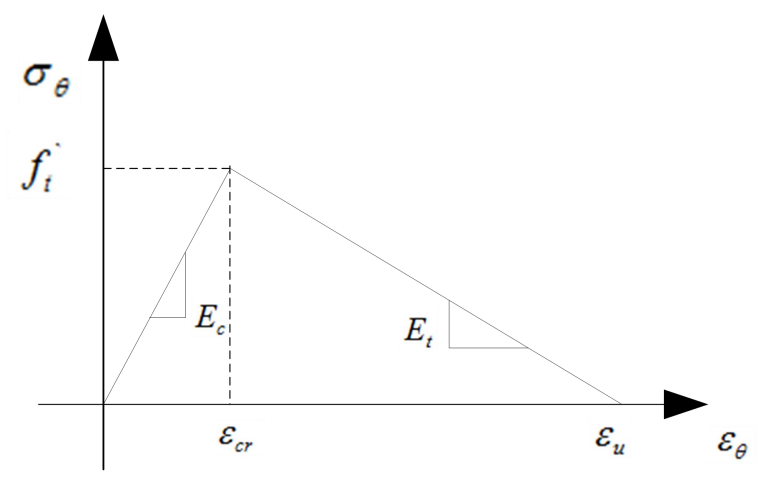

Figure 3-8 Tensile stress-strain model for concrete

The fracture energy is equal to the area under the uniaxial tensile stress-crack opening curve (Bazant 1986). Once $G_{f}$ is determined, the final tensile strain can be calculated by ensuring the same energy dissipation in the tensile softening stage. Therefore, the value of $\varepsilon_{u}$ is written as:

$$
\varepsilon_{u}=\frac{2 G_{f}}{f_{t}^{\prime} w_{c}}
$$

where $w_{c}$ is the characteristic width of the advancing micro cracking zone, which Bazant and Oh (1983) suggested to be equal to $3 d_{a}$, where $d_{a}$ is the maximum aggregate size in the concrete.

Once the ultimate strain $\varepsilon_{u}$ is obtained, the softening modulus in Eq 3-29 can be expressed as:

$$
E_{t}=\frac{f_{t}^{\prime}}{\varepsilon_{u}-\varepsilon_{c r}}
$$


where $f_{t}^{\prime}$ is the tensile strength of concrete, and $\varepsilon_{c r}$ is the strain at the maximum tensile strength.

Concrete loses its tensile strength if its hoop strain is larger than the ultimate strain $\varepsilon_{u}$. To estimate the range over which concrete has lost its tensile strength, $\varepsilon=\varepsilon_{u}$ is substituted into Eq 3-14 and, noting that the hoop strain and the displacement are related by $\varepsilon=u \cdot r$, the ultimate strain in the analytical model is written as $\varepsilon_{u}=\frac{\varepsilon_{c r} \cdot R_{i}^{2}}{R_{u 1}^{2}}$, where $R_{u 1}$ is the radial position in which the hoop strain reaches ultimate strain $\varepsilon_{u}$, given by:

$$
R_{u 1}=\sqrt{\frac{\varepsilon_{c r}}{\varepsilon_{u}}} \cdot R_{i}
$$

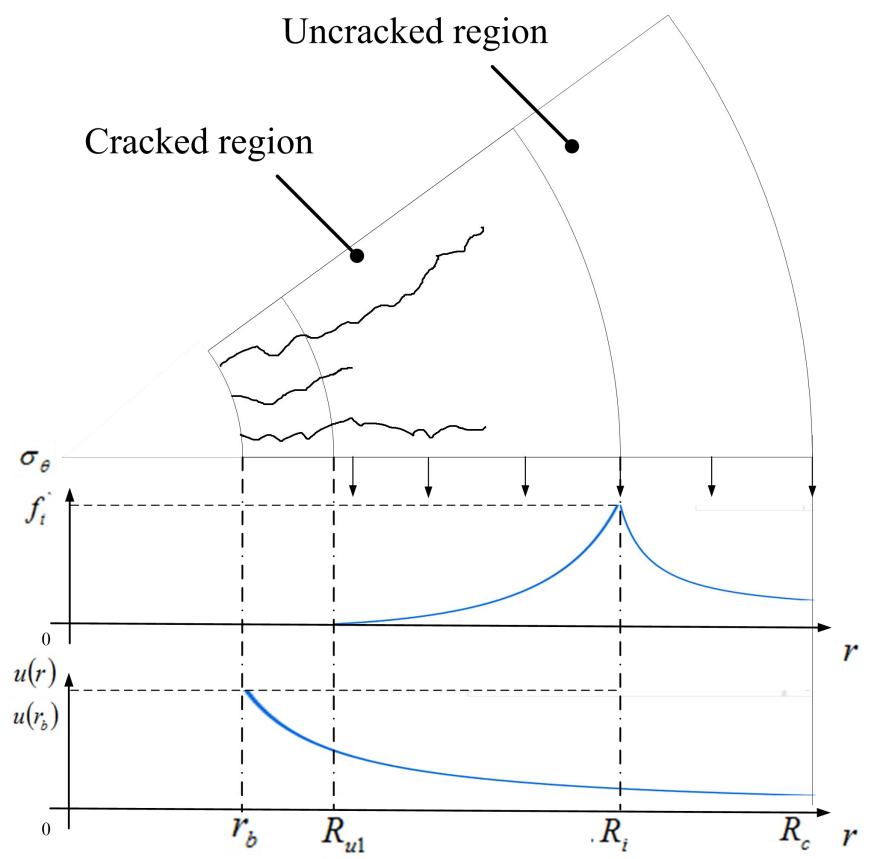

Figure 3-9 Hoop stress and radial displacement distributions in the thick-wall cylinder model

Therefore, when $R_{u 1}>r_{b}$, the region of concrete cover from $r_{b}$ to $R_{u 1}$ loses its tensile capacity 
(Figure 3-9). By setting $R_{a}=\max \left(r_{b}, R_{u 1}\right)$, the confining stress from the cracked region $P_{p}$ can be obtained from:

$$
\begin{aligned}
& P_{p}=\int_{R_{a}}^{R_{i}}\left[f_{t}^{\prime}-E_{t}\left(\varepsilon_{r}-\varepsilon_{c r}\right)\right] d r=\int_{R_{a}}^{R_{i}}\left[f_{t}^{\prime}-E_{t}\left(\frac{\varepsilon_{c r} R_{i}(x)^{2}}{r^{2}}-\varepsilon_{c r}\right)\right] d r \\
& =\left(f_{t}^{\prime}+E_{t} \varepsilon_{c r}\right)\left(R_{i}-R_{a}\right)+\frac{E_{t} \varepsilon_{c r} \cdot R_{i} \cdot\left(R_{a}-R_{i}\right)}{R_{a}}
\end{aligned}
$$

Eq 3-35

\subsection{Confining stress from outer uncracked ring $P_{e}$}

The confinement stress $P_{e}$ can be evaluated by solving the equilibrium condition illustrated in Figure 3-10 based on the cylinder model developed by Wang et al. (2004), since the tensile strain is not modified in the elastic region, where the hoop strain $\varepsilon_{\theta}$ can be evaluated from Eq 3-17.

$$
\begin{aligned}
& P_{e}=\int_{R_{i}}^{R_{c}} \sigma_{\theta} d r=\int_{R_{i}}^{R_{c}} E_{c} \cdot \varepsilon_{\theta} d r=\int_{R_{i}}^{R_{c}}\left(f_{t}^{\prime} \cdot \frac{\left(R_{c} / r\right)^{2}+1}{\left(R_{c} / R_{i}\right)^{2}+1}\right) d r \\
& =\frac{f_{t}^{\prime}}{\left(R_{c} / R_{i}\right)^{2}+1}\left(-\frac{R_{c}^{2}}{r}+r\right)_{R_{i}}^{R_{c}} \\
& =\frac{f_{t}^{\prime}\left(R_{c}^{2}-R_{i}^{2}\right) R_{i}}{R_{c}^{2}+R_{i}^{2}}
\end{aligned}
$$

Thus, the total confining stress is obtained by substituting Eq 3-35 and Eq 3-36 into Eq 3-4, which is rewritten as:

$$
\sigma_{c}=\left(P_{p}+P_{e}\right) / r_{b}
$$




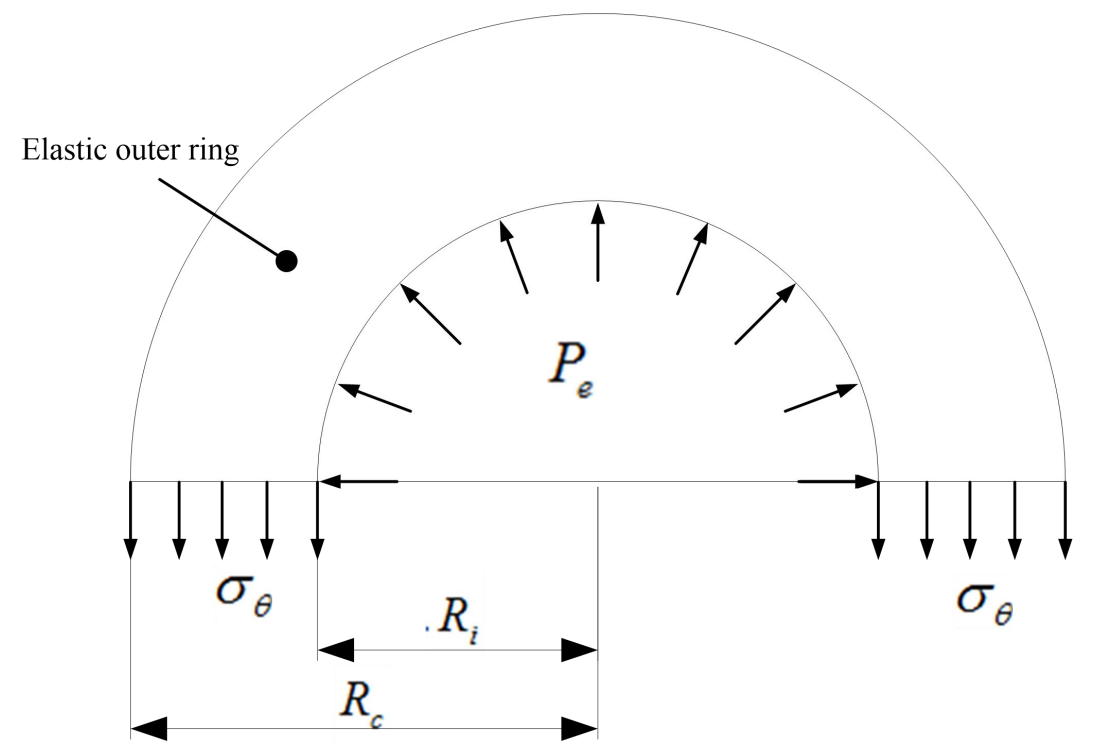

Figure 3-10 Equilibrium condition in the outer region of the thick-wall cylinder

\subsubsection{Fully cracked concrete cover $\left(R_{i}>R_{c}\right)$}

If the concrete cover is fully cracked, i.e., the crack front $R_{i}$ reaches the outer surface $R_{c}$; there is no elastic ring in the analytical model. The radial displacement at the steel/concrete surface and the equilibrium equation are respectively rewritten as:

$$
\begin{aligned}
& u(r)=\frac{(n-1) \cdot\left(2 r_{b} x-x^{2}\right)}{R_{c}+r_{b}} \\
& \sigma_{c} \cdot r_{b}=\int_{r_{b}}^{R_{c}} \sigma_{\theta}(r) d r=P_{p}
\end{aligned}
$$

As discussed in the previous section, the radial displacement field along the cracked region is modified the one in the cylinder model proposed by Wang et al. (2004) and assumed as a rational function, which is written as:

$$
u(r)=\frac{C}{r} \quad \text { for } \quad r_{b} \leq r \leq R_{c}
$$


where $C$ can be solved by combining Eq 3-6 and Eq 3-40, which results in:

$$
u\left(r_{b}\right)=\frac{C}{r_{b}}=\frac{(n-1) \cdot\left(2 r_{b} x-x^{2}\right)}{R_{c}+r_{b}}
$$

Thus, the radial displacement $u(r)$ and hoop $\varepsilon d(r)$ strain for the fully cracked cylinder are rewritten as:

$$
\begin{gathered}
u(r)=\frac{U(x)}{r} \\
\varepsilon_{\theta}(r)=\frac{u(r)}{r}=\frac{U(x)}{r^{2}} \quad \text { for } r_{b} \leq r \leq R_{c}
\end{gathered}
$$

where the coefficient $C$ is substituted by $U(x)$, which is given by:

$$
U(x)=\frac{(n-1) \cdot\left(2 r_{b} x-x^{2}\right) \cdot r_{b}}{\left(R_{c}+r_{b}\right)}
$$

Similar to the previous section, to determine the effective thickness of the thick-wall cylinder which has tensile stress capacity (Figure 3-9), the radial position $r=R_{u 2}$ where the tensile strain reaches $\varepsilon_{u}$ is obtained. By substituting $\varepsilon_{\theta}=\varepsilon_{u}$ into Eq 3-43, $R_{u 2}=\sqrt{\frac{U(x)}{\varepsilon_{u}}}$ is obtained. If the value of $R_{u 2}$ is less than the radius of the steel bar, there is no loss of concrete tensile strength. When $R_{u 2}>r_{b}$, by setting $R_{b}=\max \left(r_{b}, R_{u 2}\right)$, the confining stress of the cracked thick-wall cylinder $P_{p}$ with a modified tensile strain is given by: 


$$
\begin{aligned}
& P_{p}=\int_{R_{b}}^{R_{c}}\left[f_{t}^{\prime}-E_{t}\left(\varepsilon_{\theta}(r)-\varepsilon_{c r}\right)\right] d r=\int_{R_{b}}^{R_{c}}\left[f_{t}^{\prime}-E_{t}\left(\frac{U_{c}(x)}{r^{2}}-\varepsilon_{c r}\right)\right] d r \\
& =\left(f_{t}^{\prime}+E_{t} \varepsilon_{c r}\right)\left(R_{c}-R_{b}\right)+\frac{E_{t}\left(R_{b}-R_{c}\right)}{R_{c} R_{b}} \cdot U_{c}(x)
\end{aligned}
$$

\subsubsection{Confining stress from stirrups $\sigma_{s}$}

If transverse reinforcement is provided, the confinement capacity in the concrete is enhanced. Noghabai (1996) evaluated the confinement stress from transverse reinforcement based on the thick-wall cylinder model proposed by Tepfers (1979). The author idealized and modelled the stirrups as spiral reinforcement in the cylinder, as illustrated in Figure 3-11, located at a distance $r_{s}$ from the center of the tension rebar. It is realized that in reality the confinement provided by stirrups in flexural members would be less than the formulation proposed by Noghabai (1996).

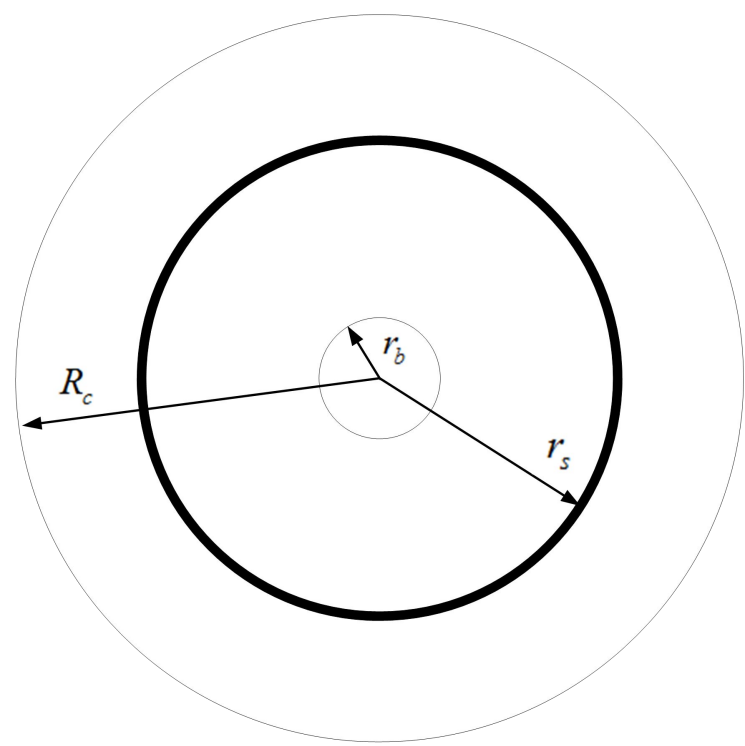

Figure 3-11 Thick-wall cylinder model with stirrup

In order to obtain the confining stress per unit length due to spiral reinforcement, equilibrium as 
shown in Figure 3-12 has to be established, where the stress $f_{s s}$ in the stirrup's cross section is assumed to be uniformly distributed.

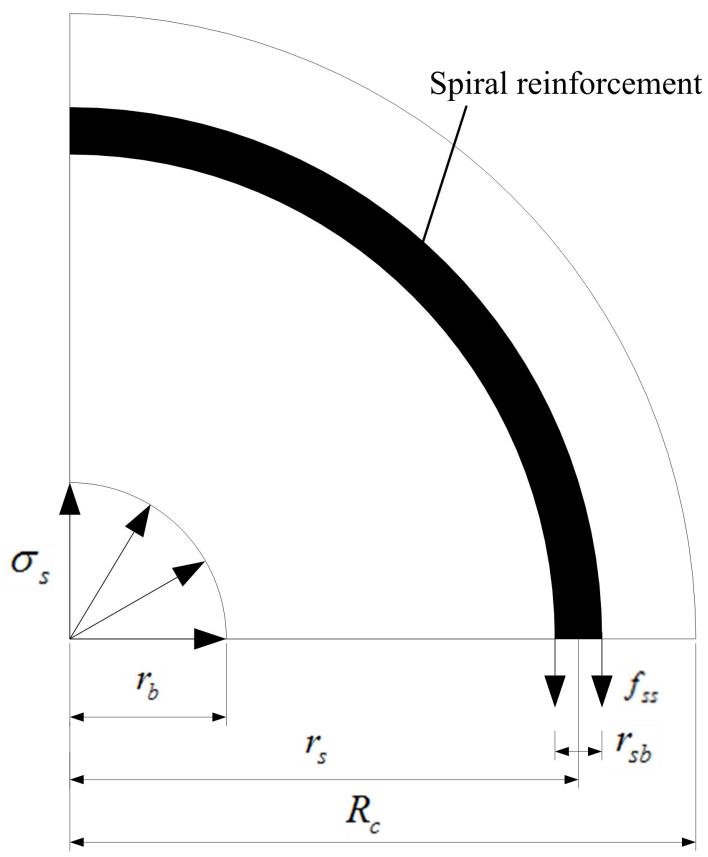

Figure 3-12 Equilibrium condition in the cylinder model reinforced by stirrups

Thus, equilibrium is written as:

$$
\int_{0}^{\frac{\pi}{2}} \sigma_{s} \cdot \sin \theta \cdot r_{b} d \theta+\int_{r_{s}-0.5 \cdot r_{s b}}^{r_{s}+0.5 \cdot r_{s b}} f_{s s} d r=0
$$

Thus,

$$
\sigma_{s}=\frac{f_{s s} \cdot r_{s b}}{r_{b}}
$$

where $\sigma_{s}$ is the confinement stress due to transverse reinforcement, and $f_{s s}$ is the tensile stress in the stirrups, which can be expressed as $f_{s s}=E_{s} \cdot \varepsilon_{s} \leq f_{y}$, where $E_{s}$ is the elastic modulus of steel, $\varepsilon_{s}$ is the strain in the spiral reinforcement, $f_{y}$ is the yielding stress of steel, $r_{s b}$ is the 
equivalent steel radius per unit length, given by $r_{s b}=A_{s} / L_{s}, A_{s}$ is the cross-sectional area of one stirrup leg, and $L_{s}$ is the spacing between adjacent stirrups.

In this work, assuming the spiral reinforcement does not influence the hoop strain distribution along the concrete cover in the analytical model, the strain field can be evaluated by Eq 3-16 Eq 3-17 or Eq 3-43 depending on whether or not the thick-wall cylinder model is fully cracked and on the position of the stirrups. Therefore, the strain in the stirrups can be obtained by substituting $r$ with the radial distance to the center of the transverse bar, i.e., $r=r_{s}$. The strain in the stirrups is therefore obtained as:

If $r_{s}<R_{i}$ and $R_{i} \leq R_{c}$

(The cylinder is partially cracked,

$$
\varepsilon_{s}=\frac{\varepsilon_{c r} \cdot R_{i}^{2}}{r_{s}^{2}}
$$

and the stirrups are in the inner

region.)

If $r_{s}<R_{i}$ and $R_{i}>R_{c}$

(The cylinder is fully cracked, and

$$
\varepsilon_{s}=\frac{U(x)}{r_{s}^{2}}
$$

the stirrups are in the inner region.)

If $r_{s} \geq R_{i}$

(The stirrups are in the outer $\quad \varepsilon_{s}=\varepsilon_{c r} \cdot \frac{\left(R_{c} / r_{s}\right)^{2}+1}{\left(R_{c} / R_{i}\right)^{2}+1}$ region.)

Using Eq 3-48 Eq 3-50, the corresponding expressions for the expansion stress resulting from the transverse reinforcement per unit length are given by: 


$$
\begin{array}{lc}
\text { If } r_{s}<R_{i} \text { and } R_{i} \leq R_{c} & \sigma_{s}=\frac{E_{s} \cdot r_{s b} \cdot \varepsilon_{c r} \cdot R_{i}^{2}}{r_{b} \cdot r_{s}^{2}} \\
\text { If } r_{s}<R_{i} \text { and } R_{i}>R_{c} & \sigma_{s}=\frac{E_{s} \cdot r_{s b} \cdot U(x)}{r_{b} \cdot r_{s}^{2}} \\
\text { If } r_{s} \geq R_{i} & \sigma_{s}=\frac{E_{s} \cdot r_{s b} \cdot \varepsilon_{c r}\left[\left(R_{c} / r_{s}\right)^{2}+1\right]}{r_{b} \cdot\left[\left(R_{c} / R_{i}\right)^{2}+1\right]}
\end{array}
$$

\subsubsection{Summary for evaluation of confinement stress}

The stress in the concrete cover due to corrosion expansion results from the confining behaviour from the concrete itself and the existing stirrups, i.e.,

$$
\sigma_{t c}=\sigma_{c}+\sigma_{s}
$$

where $\sigma_{c}$ and $\sigma_{s}$ are the confinement stresses from concrete and stirrups, respectively, whose analytical solutions are summarized below.

\subsubsection{Confining stress from concrete}

In order to evaluate the confining stress $\sigma_{c}$ at the inner surface of the concrete, the cracked front $R_{i}$ in the analytical model needs to be determined first:

$$
R_{i}=R_{i a}+\sqrt[3]{-R_{i b}+\sqrt{R_{i b}^{2}+R_{i c}^{3}}}+\sqrt[3]{-R_{i b}-\sqrt{R_{i b}^{2}+R_{i c}^{3}}} \quad \text { Eq 3-55 }
$$

where

$$
\begin{gathered}
R_{i a}=-\frac{r_{b}}{3} \\
R_{i b}=\frac{27(1-n)\left(2 r_{b} x-x^{2}\right) r_{b}+2 \varepsilon_{c r} r_{b}^{3}}{54 \varepsilon_{c r}}
\end{gathered}
$$




$$
R_{i c}=-\frac{r_{b}^{2}}{9}
$$

From the above equations, the crack front $R_{i}$ can be viewed as a function of $x$, i.e., $R_{i}(x)$. Note that the drawback of the analytical evaluation developed in the previous sections is the assumption that the cylinder is cracked. Therefore, to approximate the stress when the concrete is not cracked, for $R_{i}(x)<r_{b}$, a linear interpolation starting from zero pressure at $0 \%$ corrosion to the point where the cylinder is just cracked $\left(R_{i}(x)=r_{b}\right)$ is assumed (Figure 3-13).

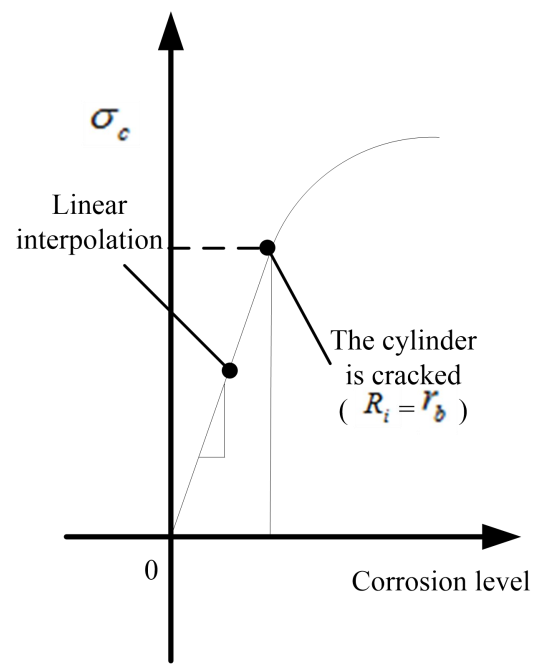

Figure 3-13 Linear interpolation for the confinement stress $\sigma_{c}$ evaluation

When $r_{b} \leq R_{i}(x) \leq R_{c}$ (partially-cracked concrete cover):

$$
\begin{gathered}
\sigma_{c}=\left(P_{p}+P_{e}\right) / r_{b} \\
P_{e}=\frac{f_{t}^{\prime}\left(R_{c}^{2}-R_{i}^{2}\right) R_{i}}{R_{c}^{2}+R_{i}^{2}} \\
P_{p}=\left(f_{t}^{\prime}+E_{t} \varepsilon_{c r}\right)\left(R_{i}-R_{a}\right)+\frac{E_{t} \varepsilon_{c r} \cdot R_{i} \cdot\left(R_{a}-R_{i}\right)}{R_{a}}
\end{gathered}
$$




$$
\begin{aligned}
& R_{a}=\max \left(r_{b}, R_{u 1}\right) \\
& R_{u 1}=\sqrt{\frac{\varepsilon_{c r}}{\varepsilon_{u}}} \cdot R_{i}(x)
\end{aligned}
$$

When $R_{i}(x)>R_{c}$ (fully-cracked concrete cover):

$$
\sigma_{c}=P_{p} / r_{b}
$$

where

$$
\begin{gathered}
P_{p}=\left(f_{t}^{\prime}+E_{t} \varepsilon_{c r}\right)\left(R_{c}-R_{b}\right)+\frac{E_{t}\left(R_{b}-R_{c}\right)}{R_{c} R_{b}} \cdot U_{c}(x) \\
R_{b}=\max \left(r_{b}, R_{u 2}\right) \\
R_{u 2}=\sqrt{\frac{U(x)}{\varepsilon_{u}}}
\end{gathered}
$$

Parameters in Eq 3-59 Eq 3-67 have already been defined in Section 3.3.1.

\subsubsection{Confining stress from stirrups}

The evaluation of expansion force resulting from the transverse reinforcement depends on the radial position of the stirrups, $r_{s}$, and the crack front, $R_{i}$, i.e.,

$$
\begin{array}{lc}
\text { If } r_{s}<R_{i} \text { and } R_{i} \leq R_{c} & \sigma_{s}=\frac{E_{s} \cdot r_{s b} \cdot \varepsilon_{c r} \cdot R_{i}(x)^{2}}{r_{b} \cdot r_{s}^{2}} \\
\text { If } r_{s}<R_{i} \text { and } R_{i}>R_{c} & \sigma_{s}=\frac{E_{s} \cdot r_{s b} \cdot U(x)}{r_{b} \cdot r_{s}^{2}} \\
\text { If } r_{s} \geq R_{i} & \sigma_{s}=\frac{E_{s} \cdot r_{s b} \cdot \varepsilon_{c r} \cdot\left[\left(R_{c} / r_{s}\right)^{2}+1\right]}{\left.r_{b} \cdot\left(R_{c} / R_{i}(x)\right)^{2}+1\right]} \\
\text { where } & U(x)=\frac{(n-1) \cdot\left(2 r_{b} x-x^{2}\right) \cdot r_{b}}{\left(R_{c}+r_{b}\right)}
\end{array}
$$


Parameters in Eq 3-68 Eq 3-71 have already been defined in Section 3.3.2.

\subsubsection{Procedure for confinement stress calculation}

The algorithm followed to evaluate the confinement stress provided by the concrete cover and transverse reinforcement and based on the procedures presented is shown in Figure 3-14, which can be briefly summarized as follows:

1) The attack penetration $x(\mathrm{~mm})$ due to corrosion needs to be determined first as input data to calculate the crack front $R_{i}$ (Eq 3-55 Eq 3-58). If the crack front $R_{i}$ is not greater than the radius of the outer layer of the cylinder model $\left(R_{i} \leq R_{c}\right)$, i.e., the cylinder is partially cracked, the procedure for the partly-cracked model should be selected. Otherwise $\left(R_{i}>R_{c}\right)$, the fully-cracked model should be utilized.

2) For the partly- and fully-cracked models, the confinement stress from the concrete $\sigma_{c}$ can be evaluated according to Eq 3-59 Eq 3-63 or Eq 3-64 Eq 3-67, respectively.

3) If there are no stirrups, the confining stress from stirrups $\sigma_{s}$ is equal to 0 . If there are stirrups, $\sigma_{s}$ should be evaluated. For the fully-cracked cylinder model, $\sigma_{s}$ can be obtained from Eq 3-69, whereas for the partly-cracked model, $\sigma_{s}$ should be evaluated from Eq 3-68 if the transverse reinforcement is located within the elastic region $\left(r_{s}<R_{i}\right)$,or from Eq 3-70 if the stirrups are in the region of cracked concrete.

4) The total confinement stress $\sigma_{t c}$ can be obtained by combining the confinement contribution from the concrete cover $\sigma_{c}$ and the transverse reinforcement $\sigma_{s}$. 


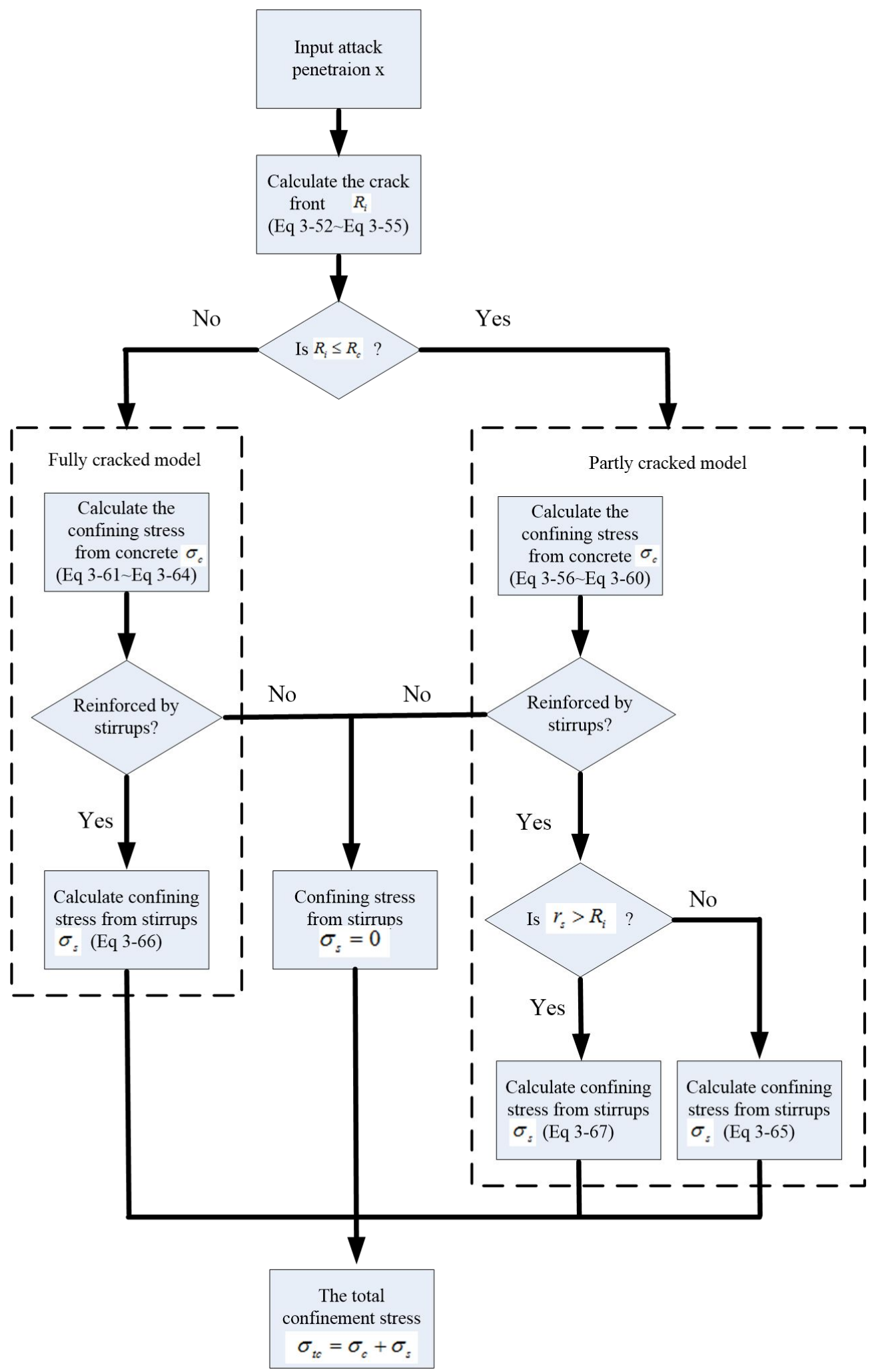

Figure 3-14 Procedure for confinement stress calculation 


\subsection{Friction coefficient $\mu$}

In order to evaluate the bond capacity according to Eq 3-1, the friction coefficient $\mu$ needs to be determined. For this work, the coefficient $\mu$ is defined according to the model proposed by Lundgren (2007) (see Eq 3-72), because this model captures a slight increase of friction at low levels of corrosion due to the increase of roughness when the corrosion products just start to accumulate, and a decrease again as the corrosion level increases, which results from the lubricant effect when the corrosion layer is formed. A lower limit was also set, which is not affected by the degree of reinforcement corrosion.

$$
\mu(x)=k\left(x / r_{b}\right) \cdot \mu_{0}
$$

where $\mu_{0}$ is the friction coefficient for an uncorroded bar, and $k\left(x / r_{b}\right)$ is a function of the attack penetration $x$. For a value of $x / r_{b}$ greater then 0.02, parameter $k$ is lower than 1 (see Figure 2-5).

As mentioned in the literature review chapter, the initial friction coefficient $\mu_{0}$ obtained in experimental studies has been measured as $0.3 \sim 0.6$. In the finite element pullout test performed by Lundgren (2007), the value of $\mu_{0}$ was taken as 0.9 and 1.0 for plain and ribbed bars, respectively, showing good agreement with experimental observations. Therefore, based on these published values, it is reasonable to choose the initial friction coefficient $\mu_{0}$ between 0.3 and 1.0.

\subsection{Adhesive stress}

Chemical adhesion between the steel reinforcement and concrete is not a reliable source of bond capacity. However, it is the main source of bond capacity of plain bars when there is no corrosion 
according to Eq 3-1. In the finite element pullout test performed by Lundrgen (2007), this stress was assumed not to vary with the corrosion level but changed with an increase in slippage between the steel and the concrete. In this work, a small constant value equal to $0.8 \mathrm{MPa}$ (obtained from the specimen with corrosion levels close to $100 \mu \mathrm{m}$ tested by Youlin 1992) is used if this value is not provided by published experimental data. Note that this value is assumed to remain constant for all levels of corrosion.

\subsection{Mechanical interlock}

Approximating the stress resulting from the mechanical interlock between the reinforcement and the concrete should consider the geometry of the rebar rib, such as the rib height and the distance between adjacent ribs, but these properties are not always available. The bond capacity for uncorroded ribbed and hot-rolled plain bars, as suggested by the CEB-FIP Model Code (2010), are respectively given by:

$$
\begin{gathered}
\tau_{u r_{-} \max }=2.5 \cdot \sqrt{f_{c}^{\prime}} \\
\tau_{u p_{-} \max }=0.3 \cdot \sqrt{f_{c}^{\prime}}
\end{gathered}
$$

where $\tau_{u r_{-} \max }$ and $\tau_{u p_{-} \max }$ are the maximum bonding stress for the ribbed bar and plain bar, respectively, and $f_{c}^{\prime}$ is the compressive strength of concrete.

According to the frictional model, for an uncorroded specimen reinforced with smooth bars, the only contribution to bond is that from chemical adhesion, whereas there is an extra bond contribution from the mechanical interlocking of ribbed rebars, i.e.,

$$
\tau_{u r_{-} \max }=f_{a d h}+f_{u_{-} i}
$$




$$
\tau_{\text {up_max }}=f_{\text {adh }}
$$

where $f_{u_{-} i}$ is the maximum interlock stress for uncorroded reinforcement bars.

Therefore, it is reasonable to obtain the initial interlocking stress by subtracting Eq 3-74 from Eq $3-75$, resulting in:

$$
f_{u_{-} i}=\tau_{u r_{-} \max }-\tau_{u p \_ \text {max }}=2.2 \cdot \sqrt{f_{c}^{\prime}}
$$

Chung et al. (2004) have reported that the elimination of mechanical interlock stress was observed at relatively low levels of corrosion (around 2\% diameter loss), where the rib no longer existed or only a small portion remained. Therefore, this work assumes that the mechanical interlock contribution to bond capacity decreases linearly from $f_{u-i}$ to zero at $2 \%$ corrosion, i.e.,

$$
f_{i}=f_{u_{-} i} \cdot \frac{0.02-\left(x / r_{b}\right)}{0.02} \quad \text { Eq 3-78 }
$$

where $f_{u \underline{i}}$ is the maximum interlock stress for a corroded ribbed rebar, $x$ is the attack penetration due to corrosion, and $r_{b}$ is the radius of the virgin reinforcement. It is realized that this assumption is based on the experimental results reported by Chung et al. (2004), and further investigation of the effect of corrosion on mechanical interlocking is warranted.

\subsection{Bond-slip relation}

For simplicity, in this work, the bond-slip behaviour of uncorroded and corroded reinforcement is assumed to adopt a bi-linear constitutive relation, which was also utilized in finite element tests carried out by Lee et al. (2002) and is illustrated in Figure 3-15. 


$$
\begin{array}{ccc}
\tau=\left(\tau_{\text {max }} / s_{y}\right) \cdot s \leq \tau_{\text {max }} & \text { for } s \leq s_{y} & \text { Eq 3-79 } \\
\tau=\tau_{\text {max }} & \text { for } s_{y}<s & \text { Eq 3-80 }
\end{array}
$$

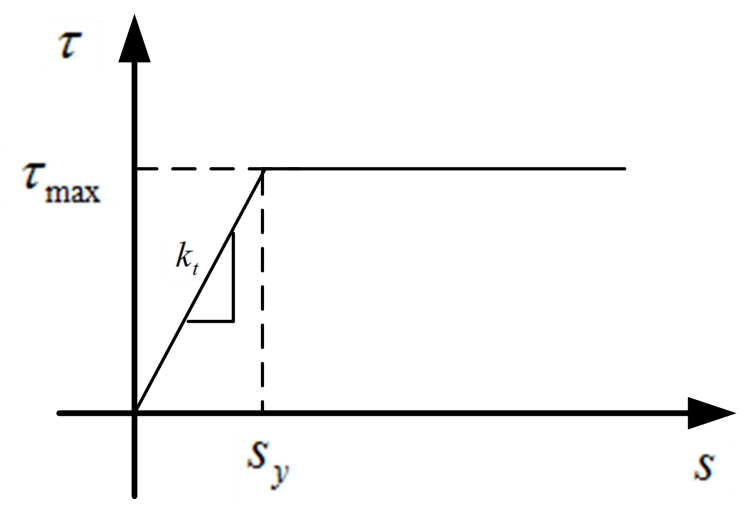

Figure 3-15 The bi-linear bond-slip relationship

where $s_{y}$ is the relative slip when the bonding stress reaches the bond capacity $\tau_{\max }$. Note that the value of $s_{y}$ is obtained from experimental observation conducted on specimens with similar physical properties. As the RC beams selected for validation in Chapter 5 had 10-mm diameter rebar and 20-mm thickness concrete cover, giving a ratio of concrete cover-to-rebar diameter of 2 , the value of $s_{y}=0.2$ provided by Tastani and Pantazopoulou. (2013) with similar concrete cover-to-rebar diameter ratio is adopted for the finite element validation.

By combining the frictional model expressed in Eq 3-1 and the bond-slip constitutive relation given in Eq 3-79, the bond stiffness $k_{t}$ along the reinforcement is written as:

$$
k_{t}=\frac{\tau}{s} \quad \text { for } \tau \leq \tau_{\max }
$$




\subsection{Summary}

This chapter presents the development of an analytical evaluation of bond capacity of corroded reinforcement by accounting for the affected mechanisms identified in the literature review, i.e., chemical adhesion, mechanical interlock and frictional stress. The analytical evaluation is based on the following:

1) If adhesive stress is not known, it is assumed to be a small value (0.8 MPa). Also, the adhesive stress is assumed to be constant for all corrosion levels.

2) The initial interlock stress is obtained by combining the analytical expressions of bond capacity for ribbed and plain bars, as given by the CEB-FIP Model Code (2010). A linear degradation is adopted for the mechanical interlock stress as the corrosion level increases.

3) The frictional stress is expressed as the product of the friction coefficient, whose deterioration can be described by the model provided by Lundgren (2007), and the confining stress, which is evaluated by a thick-walled cylinder model. The cylinder model is developed based on Wang et al. (2004). However, the tensile strain distribution in the plastic region, i.e., that corresponding the cracked concrete, is modified to improve the evaluation of confinement stress due to corrosion. 


\section{Finite Element Model}

\subsection{Introduction}

This chapter presents the implementation of corrosion-induced damages in a 2D finite element (FE) model to simulate the deterioration of flexural behaviour due to reinforcement corrosion. The finite element software ABAQUS has been used for this purpose due to the availablity of its user subroutine (UEL), where the analytical model that describes bond behaviour can be programmed. First, the chapter presents the FE model of a 2D control beam, with an investigation of the material models to be used and the selection of FE types. The link element representing the bonding interaction between the steel and the concrete is formulated according to the analytical evaluation of bond degradation presented in Chapter 3. It is followed by a presentation of the implementation of corrosion-induced damages (reduced cross-sectional area of steel, concrete cracking and degraded bond) in the FE modelling of affected RC flexural members.

\subsection{Selection of material models}

To simulate the material behaviour in the numerical model, the stress-strain relationships of concrete and steel were studied first, in order to input data for the FE material model in ABAQUS.

\subsubsection{Material behaviour of concrete}

\subsubsection{Compressive behaviour}

The model for compressive behaviour of concrete given in the CEB-FIP Model Code (2010) has been used in this work. The relation between stress $\sigma_{c}$ and strain $\varepsilon_{c}$ for short term uniaxial compression behaviour is expressed as: 


$$
\frac{\sigma_{c}}{f_{c}^{\prime}}=-\left(\frac{k \cdot \eta-\eta^{2}}{1+(k-2) \cdot \eta}\right) \quad \text { for }\left|\varepsilon_{c}\right|<\left|\varepsilon_{c, \lim }\right| \quad \text { Eq 4-1 }
$$

where $\eta=\varepsilon_{c} / \varepsilon_{c 1}, k=E_{c i} / E_{c 1}, \varepsilon_{c 1}$ is the strain at maximum compressive stress, $E_{c 1}$ is the secant modulus from the origin to the peak compressive stress, $k$ is the plasticity number, $\varepsilon_{c, \lim }$ is the ultimate strain, $f_{c}^{\prime}$ is the uniaxial compressive strength, and $E_{c i}$ is modulus of elasticity. The schematic representation of Eq 4-1 is shown in Figure 4-1.

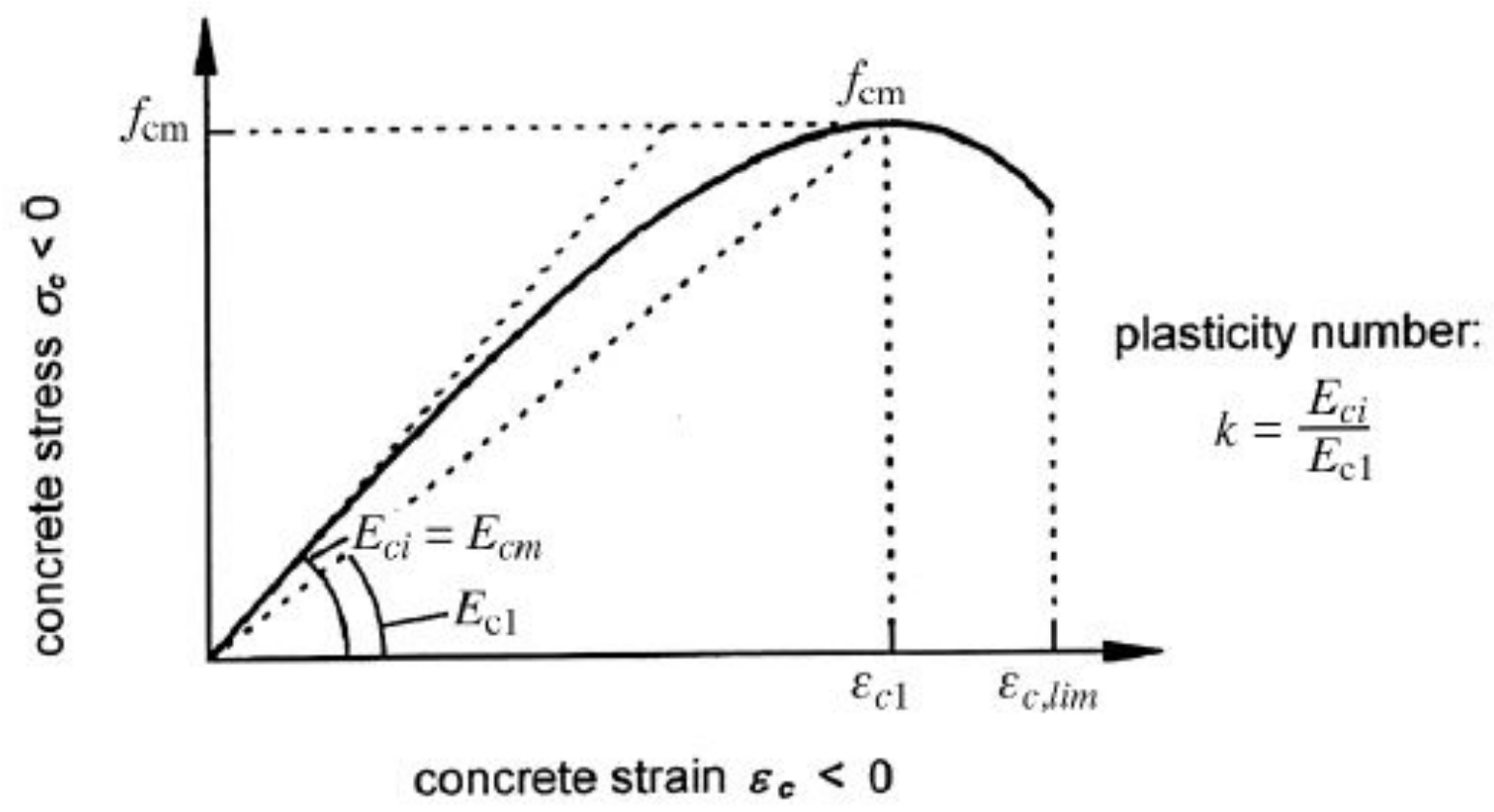

Figure 4-1 Compressive behaviour for concrete (reproduced from CEB-FIP 2010)

In the CEB-FIP Model Code (2010), the grades of concrete are classified by their compressive strength. For different grades of concrete, the material data are given in Table 4-1. 
Table 4-1 Material properties for different grades of concrete according to CEB-FIP (2010)

\begin{tabular}{l|c|c|c|c|c|c|c|c|c}
\hline $\begin{array}{l}\text { Concrete } \\
\text { grade }\end{array}$ & $\mathbf{C 1 2}$ & $\mathbf{C 1 6}$ & $\mathbf{C 2 0}$ & $\mathbf{C 2 5}$ & $\mathbf{C 3 0}$ & $\mathbf{C 3 5}$ & $\mathbf{C 4 0}$ & $\mathbf{C 4 5}$ & $\mathbf{C 5 0}$ \\
\hline$E_{c i}[\mathrm{GPa}]$ & 27.1 & 28.8 & 30.3 & 32.0 & 33.6 & 35.0 & 36.3 & 37.5 & 38.6 \\
$E_{c 1}[\mathrm{GPa}]$ & 11.1 & 12.2 & 13.3 & 14.9 & 16.5 & 18.2 & 20.0 & 21.6 & 23.2 \\
$\varepsilon_{c 1}[\%]$ & -1.9 & -2.0 & -2.1 & -2.2 & -2.3 & -2.3 & -2.4 & -2.5 & -2.6 \\
$\varepsilon_{c, l i m}[\%]$ & -3.5 & -3.5 & -3.5 & -3.5 & -3.5 & -3.5 & -3.5 & -3.5 & -3.4 \\
$k$ & 2.44 & 2.36 & 2.28 & 2.15 & 2.04 & 1.92 & 1.82 & 1.74 & 1.66 \\
\hline
\end{tabular}

\subsubsection{Tensile behaviour}

The bi-linear stress-strain relations (Eq 3-28 Eq 3-30) that were presented in Chapter 3 are adopted in the FE model to model concrete under uniaxial tension.

\subsubsection{Finite element material model of concrete}

There are three types of concrete models available in ABAQUS. In this work, the concrete damaged plasticity model, designed for applications in which concrete is subjected to monotonic load, is used in the numerical simulations. In the concrete damaged plasticity model, concrete is modelled using a continuum, plasticity-based, damage model (Abaqus Analysis User's Manual 2014). The model assumes that the main two failure mechanisms are tensile cracking and compressive crushing of the concrete material. The evolution of the yield (or failure) surface is controlled by two hardening variables, $\varepsilon_{t}^{p l}$ and $\varepsilon_{c}^{p l}$, linked to the failure mechanisms under tension and compression, respectively, where $\varepsilon_{t}^{p l}$ and $\varepsilon_{c}^{p l}$ are the tensile and compressive equivalent plastic strains, respectively.

In this material model, five parameters need to be specified: (1) the dilation angle, (2) the flow 
potential eccentricity, (3) the ratio of initial biaxial compressive yield stress to initial uniaxial compressive yield stress, (4) the ratio of the second stress invariant on the tensile meridian, and (5) the viscosity parameter. Also, to describe the stress-strain relationship for concrete, the plastic strain and corresponding stress are needed as input data to ABAQUS.

\subsubsection{Selection of parameters}

Since the calculations for these parameters involve complex mathematical derivations and assumptions using the yield surface of the concrete damage plasticity model, the proposed values in other researchers' work have been used here, and the verification of the model is performed by comparing the numerical results with published experimental data and is presented in Chapter 5.

(1) Dilation angle - A parametric study carried out by Malm et al. (2006) suggested that there is not significant difference between $20^{\circ}$ and $40^{\circ}$ dilation angle if a reinforced concrete beam is subjected to bending. The best agreement with experimental data was reached for a dilation angle between $30^{\circ}$ and $40^{\circ}$. Lee and Fenves (1998) also performed a verification of this material model with experimental data from Kupfer et al. (1969), where a dilation angle of $31^{\circ}$ was adjusted for uniaxial tensile and compressive failures, whereas a value of $25^{\circ}$ was used for biaxial compressive failure. Hence, the dilation angle is selected as $31^{\circ}$ in this work.

(2) Flow potential eccentricity -The flow potential eccentricity is a small positive number, which defines the rate at which the hyperbolic flow potential approaches its asymptote (Abaqus Analysis User's Manual 2014). In the finite element simulation done by Ren et al. (2014), the default value of 0.1 was used, which fitted the experimental test.

(3) Ratio of biaxial to uniaxial compressive yield stress -The biaxial stress ratio and the tensile-to-compressive meridian ratio were assumed to be equal to 1.16 and 0.667 , respectively, 
based on recommendations of Chen and Han (1995).

(4) Ratio of the second stress invariant on the tensile meridian -The ratio of the second stress invariant on the tensile meridian to that on the compressive meridian was taken as $2 / 3$ (Ren et al. 2014).

(5) Viscosity parameter -Since nonlinear material models with stiffness degradation often have convergence issues in ABAQUS, applying the technique of viscoplastic regularization is a common method to overcome this difficulty, which for sufficiently small amount of time increments, causes the consistent tangent stiffness of the softening material to become positive (Abaqus Analysis User's Manual 2014 ). However, as suggested by Lapczyk et al. (2007), the selection of the value for the viscosity parameter affects the stiffness model, and a low value of the viscosity parameter should be selected (small compared to the characteristic time increment). The authors also performed parametric studies, and they found that the specimens with a viscosity parameter ranging from 0.00025 to 0.001 had good agreement with experimental results.

Thus, the above parameters are tested and calibrated on a control beam before the corrosion-induced damage models are implemented, in order to capture experimental observations appropriately.

\subsubsection{Calculation of plastic strain}

In ABAQUS, the hardening or softening behaviour after yielding is described by the plastic strain. Thus, a set of a plastic strain and corresponding stress is needed to specify the plastic region of the elastic-plastic materials that use the Mises or Hill yield surface (ABAQUS User Manual 2014). Once the curve of stress-strain relationships in tension and compression are defined according to the previous sections, the plastic strain can be calculated by using the following equations: 


$$
\begin{gathered}
\varepsilon_{p l}=\varepsilon_{t}-\varepsilon_{e l} \\
\varepsilon_{e l}=\frac{f_{c}{ }^{\prime}}{E_{c}}
\end{gathered}
$$

Eq 4-2 whe

re

$\varepsilon_{t}$

is the total strain, $\varepsilon_{e l}$ is the elastic strain, $\varepsilon_{p l}$ is the plastic strain, $f_{c}{ }^{\prime}$ is the compressive stress, and $E_{c}$ is the elastic modulus of concrete.

\subsubsection{Material behaviour of steel}

For simplicity, the constitutive behaviour for steel is assumed to follow a bi-linear relationship in the finite element model. The ascending curve has a slope which is equal to Young's modulus $E_{s}$. Once the stress reaches the yielding stress $f_{y}$, the stress is maintained constant. Steel is assumed to behave the same in tension and compression (Figure 4-2).

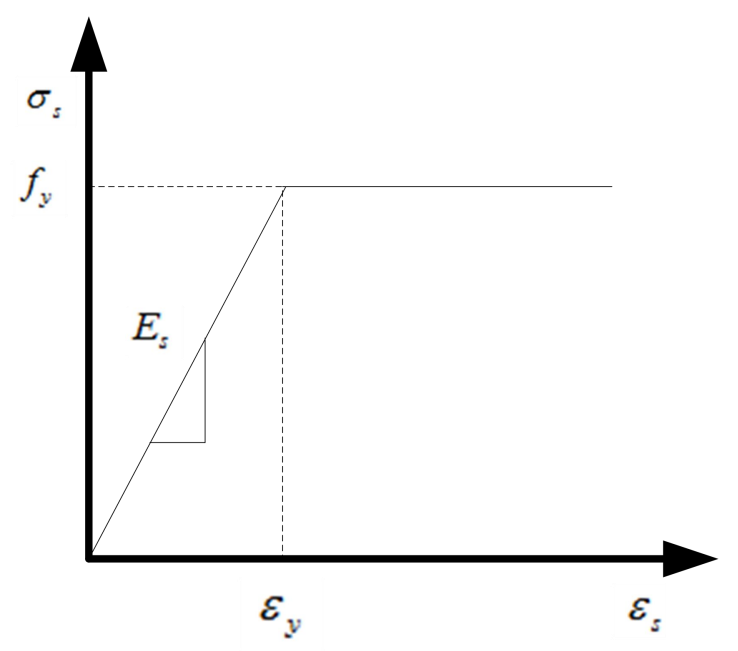

Figure 4-2 Bi-linear stress-strain relationship for steel 


\subsubsection{Finite element material model of steel}

The plastic model is adopted for steel elements. Similar to the concrete model, the definition of plastic strain is required. Once the material properties for steel are obtained from experimental data, the input data are also calculated according to Eq 4-2and Eq 4-3 .

\subsection{Selection of element types}

Since a structural member under bending does not experience external loading in the $z$ direction, the 2D 4-node plane stress elements (CPS4) are utilized to model concrete (Figure 4-3). Reinforcing bars are modelled as 2-node 2D truss elements (T2D2), which only have stiffness in one direction, rather than beam elements with stiffness in the $x$ and $y$ directions (see Figure 4-4). It is assumed that tension bars are not taking any shear force during the loading, i.e., dowel action is not modelled.

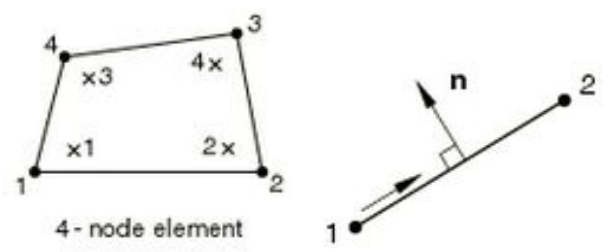

Figure 4-3 4-node plane-stress element and 2-node truss element (reproduced from ABAQUS User Manual 2014)

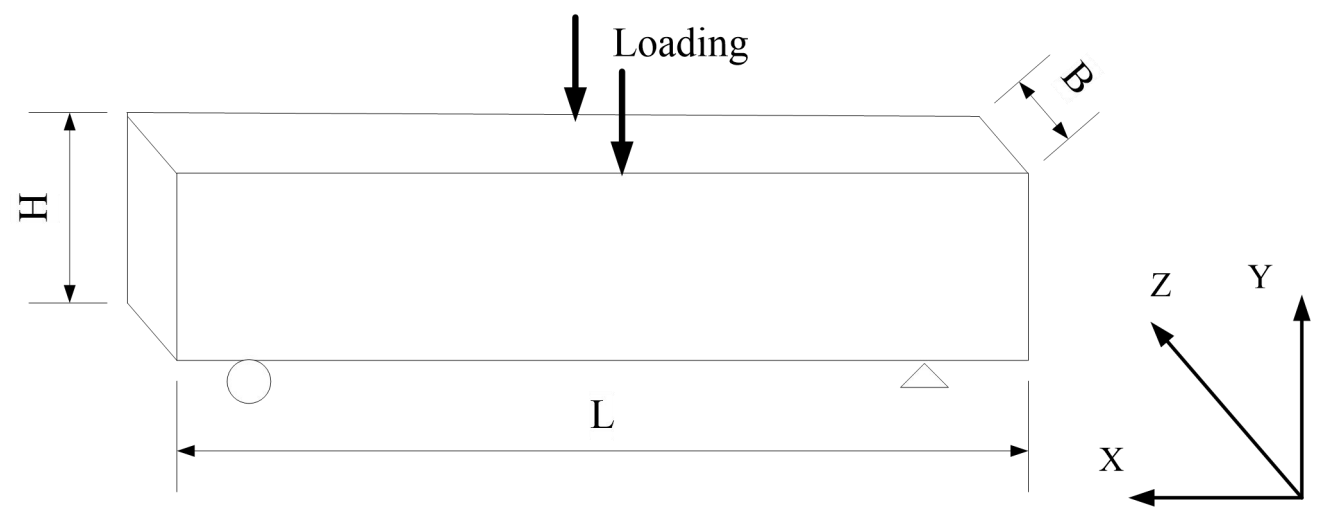

Figure 4-4 Structural member subjected to bending 


\subsection{Formulation of link element}

To model the bond interaction between concrete and reinforcing steel, link elements are used at the interlayer (Figure 4-5). The finite element link element to model bond behaviour in RC was first proposed by Ngo and Scordelis (1967), and it behaves similar to a nonlinear spring with stiffness $k_{t}$ in the longitudinal direction, providing the bond stiffness along the reinforcement.

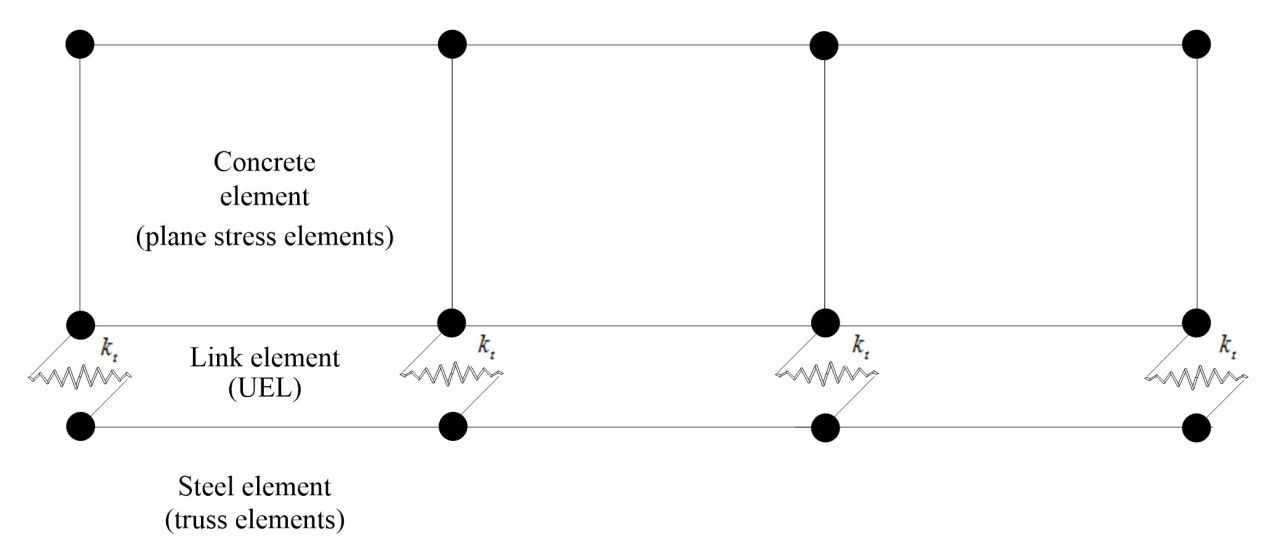

Figure 4-5 2D finite element model

The user-defined element subroutine (UEL) available in ABAQUS, which needs to be programmed in Fortran, is used to model the proposed link element, whose bond-slip behaviour, i.e., bond capacity $\tau_{\max }$ (Eq 3-1) and stiffness $k_{t}$ (Eq 3-81), has been developed in Chapter 3.

\subsection{Boundary conditions of 2D FE model}

After the selection of the finite element material models and the element types, the 2D FE beam can be built to evaluate the flexural response of an RC flexural member. Boundary conditions corresponding to the numerical simulation are presented in Figure 4-6.

Due to symmetry, only half of the specimen is analyzed to reduce the problem size. In order to model the boundary condition of a full length specimen, the symmetry plane was restrained 
against translation in the $x$ direction as shown in Figure 4-6, where $\mathrm{H}$ is the beam height, $\mathrm{B}$ is the beam width and $\mathrm{L}$ is the span of the beam.

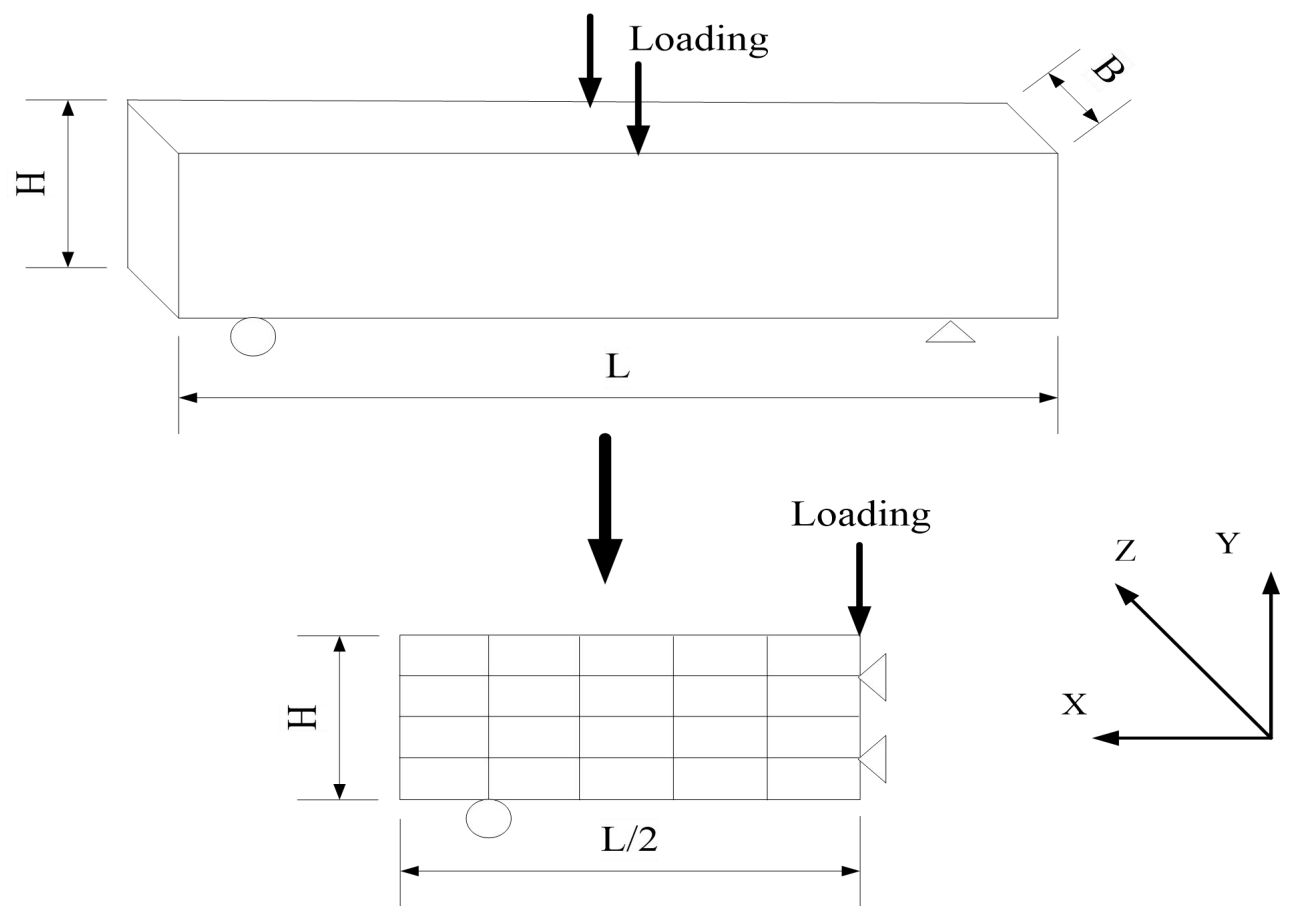

Figure 4-6 Boundary conditions of finite element model

\subsection{Corrosion-induced damage models}

\subsubsection{Damage on steel bar}

The cross section of the reinforcement decreases when the attack penetration $x$ increases, leading to degraded flexural stiffness and capacity. The expression for the effective area of rebar is given by:

$$
A_{\text {steel }}=\pi \cdot\left(r_{b}-x\right)^{2}
$$

Eq 4-4

where $r_{b}$ is the radius of the virgin bar and $x$ is the attack penetration. The reduced area of steel 
can be specified for the truss elements (T2D2) in the ABAQUS model.

\subsubsection{Damage on concrete}

In the 2D FE model, corrosion-induced cracking in the concrete due to the volumetric expansion of rust products is simulated by applying an equivalent expansion strain $\stackrel{\bar{\varepsilon}}{\bar{\varepsilon}}$ at the concrete elements surrounding the reinforcement.

As discussed in Chapter 3, the hoop strains for the partly- and fully-cracked thick-wall cylinder can be evaluated from Eq 3-48 Eq 3-50. Therefore, if the thick-wall cylinder is not fully cracked, i.e., $R_{i}<R_{c}$, the average tensile strain $\bar{\varepsilon}$ along the cylinder model can be evaluated from:

$$
\begin{aligned}
& \bar{\varepsilon}=\frac{1}{R_{c}} \int_{r_{b}}^{R_{c}} \varepsilon_{\theta}(r) d r=\frac{1}{R_{c}}\left[\int_{r_{b}}^{R_{i}} \varepsilon_{\theta}(r) d r+\int_{R_{i}}^{R_{c}} \varepsilon_{\theta}(r) d r\right] \\
& =\frac{1}{R_{c}}\left[\varepsilon_{c r} \cdot R_{i}^{2} \cdot\left(\frac{1}{r_{b}}-\frac{1}{R_{i}}\right)+\frac{\varepsilon_{c r}}{\left(R_{c} / R_{i}\right)^{2}+1} \cdot\left(\frac{R_{c}}{R_{i}}-1+R_{c}-R_{i}\right)\right]
\end{aligned}
$$

where $R_{c}$ is the radius of the thick-wall cylinder, $r_{b}$ is the radius of the reinforcing bar, $R_{i}$ is the radial displacement of the crack front, $\varepsilon_{\theta}$ is the tensile strain, and $\varepsilon_{c r}$ is the tensile strain corresponding to the tensile strength of the concrete.

For the case where the thick-wall cylinder is fully cracked, i.e., $R_{i} \geq R_{c}$, the average tensile strain $\bar{\varepsilon}$ is written as:

$$
\bar{\varepsilon}=\frac{1}{R_{c}} \int_{r_{b}}^{R_{c}} \varepsilon_{\theta}(r) d r=\frac{U(x)}{R_{c}}\left(\frac{1}{r_{b}}-\frac{1}{R_{c}}\right)
$$




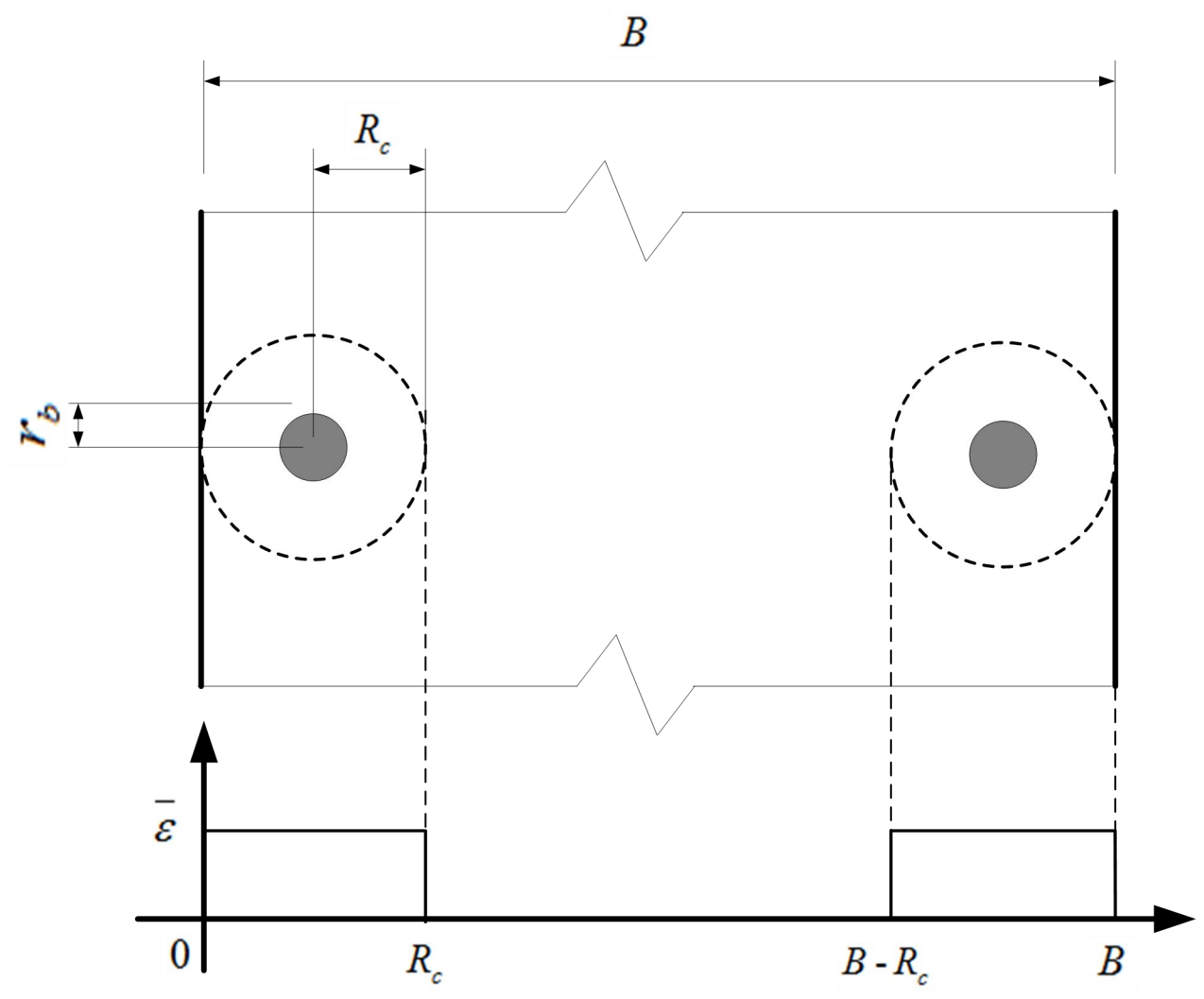

Figure 4-7 Corroded reinforcing bars in RC beam cross section

In the 2D model, it is assumed that the reinforcing bars at the same cross section have the same corrosion level. Thus, by averaging the tensile strains $\bar{\varepsilon}$ over the width $B$ of the beam (Figure 4-7), the resulting equivalent expansion strain $\stackrel{\bar{\varepsilon}}{\varepsilon}$ can be obtained from:

$$
\overline{\bar{\varepsilon}}=\sum_{i=1}^{n}\left(\bar{\varepsilon}_{n}\right) \times \frac{2 R_{c}}{B}
$$

where $\bar{\varepsilon}$ is the average strain for each reinforcing bar and is calculated according to Eq 4-5 or Eq 4-6, and $n$ is the number of steel bars in the cross section.

The simulation of expansion damage is accomplished by using thermal expansion elements, which are modelled as 2D truss elements (T2D2) with mechanical expansion. Those elements can expand 
and cause damage in concrete if the temperature in the elements rises. Thus, by setting the thermal

strain $\varepsilon_{t}$ equal to the equivalent expansion strain $\bar{\varepsilon}$, the simulation corrosion products build-up can be done, and the expansion elements can cause damage in the concrete surrounding the reinforcing bar.

\subsubsection{Damage on bond}

The deterioration of bond has been investigated in Chapter 3. By programming the relationship between attack penetration $x$ and degraded bond capacity $\tau_{\max }(\mathrm{Eq} 3-59 \sim \mathrm{Eq} 3-71)$ in the UEL subroutine, the deteriorated bonding behaviour corresponding to a certain attack penetration $x$ can be modelled in the FE model.

\subsubsection{Summary of development of FE model}

The procedure for developing a FE model of an RC flexural member with corrosion-induced damage incorporated is summarized in the flow chart shown in

Figure 4-8, which proceeds as follows:

1) The reduction of cross-sectional area of reinforcement is simulated by reducing the area of $2 \mathrm{D}$ truss elements according to Eq 4-4, when the attack penetration $x$ is given.

2) By applying an equivalent expansion strain, the cracking in concrete due to volumetric expansion is modelled. The equivalent expansion strain is obtained by averaging the tensile strain in concrete cross-section width (see Eq 4-7). 


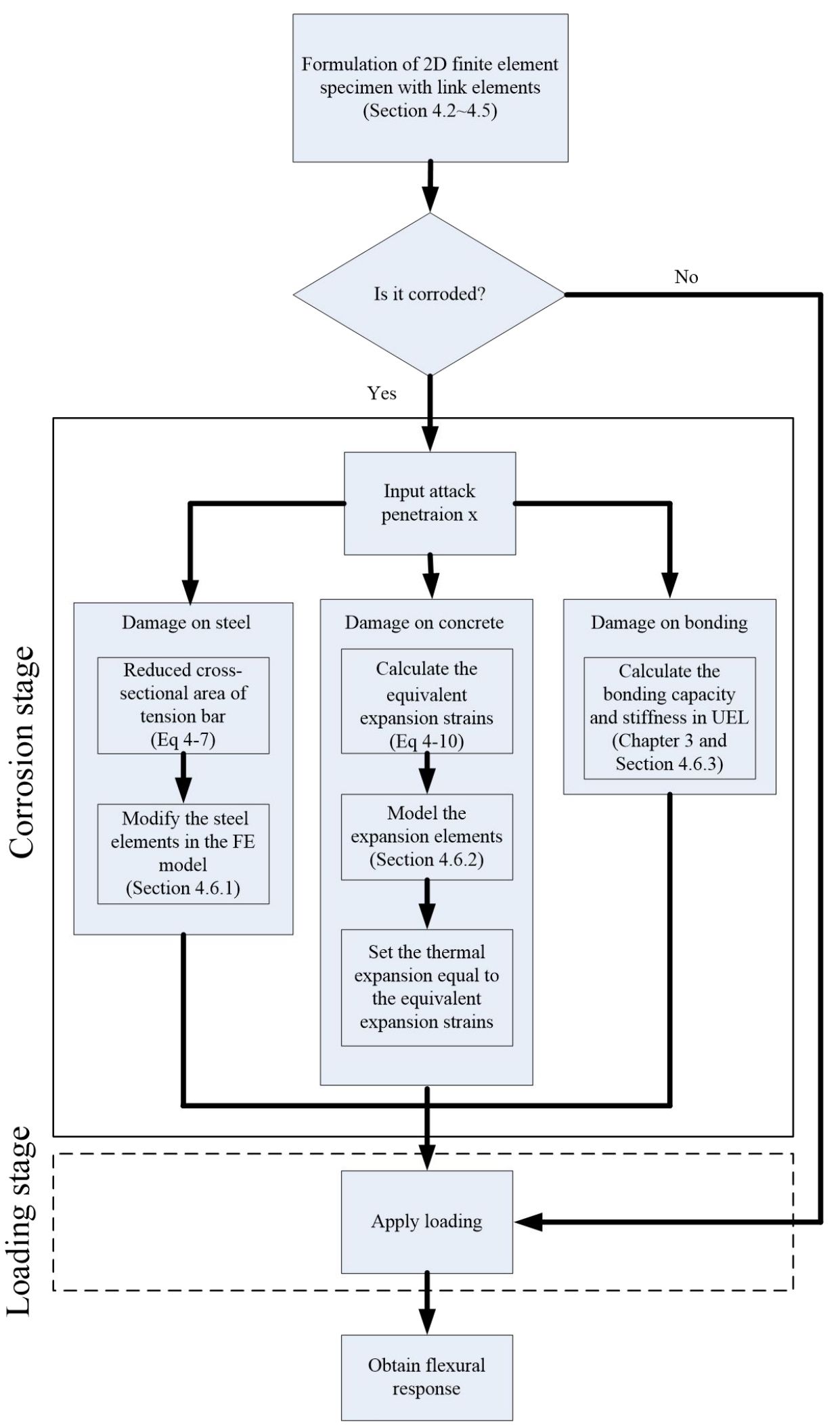

Figure 4-8 Procedure of FE model development 
3) The loss of bond is modelled in the finite element model by utilizing the link element, in which the analytical evaluation of bond degradation is programmed. The bi-linear bond-slip relation is adopted to describe bond behaviour.

Note that the corrosion stage and loading stage are two separate steps defined in ABAQUS, wherein the loading is applied after the corrosion stage is completed. 


\section{Model Validation}

\subsection{Introduction}

This chapter presents the validation of the analytical evaluation and 2D finite element models developed in Chapters 3 and 4. The verification of the analytical approximation of bond capacity is conducted first against the experimental and numerical pullout tests performed by Al-Sulaimani et al. (1990) and Lundgren (2007), respectively, to ensure the bond model can simulate the experimental and numerical observations properly.

Then, the application of the link element is tested by comparing three sets of bending experiments: (i) beams reinforced with ribbed bars (Mangat 1999), (ii) beams reinforced with plain bars (Cairns et al. 2008), and (iii) beams affected by uneven distribution of reinforcement corrosion (Du et al. 2007). Note that modelling bond for plain bars is the same as ribbed bars without accounting for mechanical interlock. To do so, control finite element models without corrosion-induced damage are first built. After the control models successfully capture the experimental responses, the link elements are applied for different corrosion levels, and the load-displacement curves from FE results are plotted to determine if the link element can reproduce the corrosion-induced bond damage realistically.

\subsection{Validation of analytical evaluation of bond stress}

\subsubsection{Comparison with Al-Sulaimani et al. (1990)}

In this section, the analytical bond model is validated against the experimental pullout tests performed by Al-Sulaimani et al. (1990), which were conducted on 150-mm cubic concrete specimens with 10,14, and 20-mm diameter ribbed bars embedded in the centre of the specimens 
to obtain a cover-to-rebar diameter $(C / d)$ ratios of $7.50,5.36$, and 3.75, respectively. Direct current was impressed on the embedded bar to simulate the corrosion process prior to the pullout test.

The properties of materials used in the validation are listed in Table 5-1. Note that not all material properties needed for the analytical model are provided in Al-Sulaimani et al. (1990) (e.g., properties at the interface). Thus, in order to determine those parameters, the material data suggested by the CEB-FIP Model Code (2010) and observations from other researchers were adopted, which were reviewed in Chapter 2. It is realized that some of these parameters are assumed due to the lack of available data. Further research on quantifying them is needed

Table 5-1 Material properties used in the analyses

\begin{tabular}{|c|c|}
\hline \multicolumn{2}{|l|}{ Concrete } \\
\hline Young's Modulus $E_{c}$ & $32 G P a$ \\
\hline Tensile strength $f_{t}^{\prime}$ & $2.6 \mathrm{MPa}$ \\
\hline \multicolumn{2}{|l|}{ Steel } \\
\hline Young's Modulus $E_{s}$ & $200 G P a$ \\
\hline \multicolumn{2}{|l|}{ Interface } \\
\hline *Initial friction coefficient $\mu_{0}$ & 0.8 \\
\hline *Chemical adhesion stress $F a$ & $0.8 \mathrm{MPa}$ \\
\hline \multicolumn{2}{|l|}{ Rust product } \\
\hline $\begin{array}{l}\text { *Ratio between the volume of oxides product } \\
\text { and virgin steel } n\end{array}$ & 2 \\
\hline
\end{tabular}

Note: Properties marked by * are determined according to the literature review.

The analytical calculations were obtained by inputting the material properties provided in Table 
5-1 into the analytical evaluation developed in Chapter 3. The results are compared with experimental data in Figure 5-1 to Figure 5-3. From the figures, it is observed that there is a good agreement between the analytical model and the experimental observation. Similar to the experimental results in Al-Sulaimani et al. (1990), it is observed that there is an initial increase in the bond capacity at low levels of corrosion for all results calculated from the analytical model, followed by continuously decreasing bond capacity as the percentage of corrosion-induced mass loss is increased. Both analytical and experimental results have similar bond degradation trend.

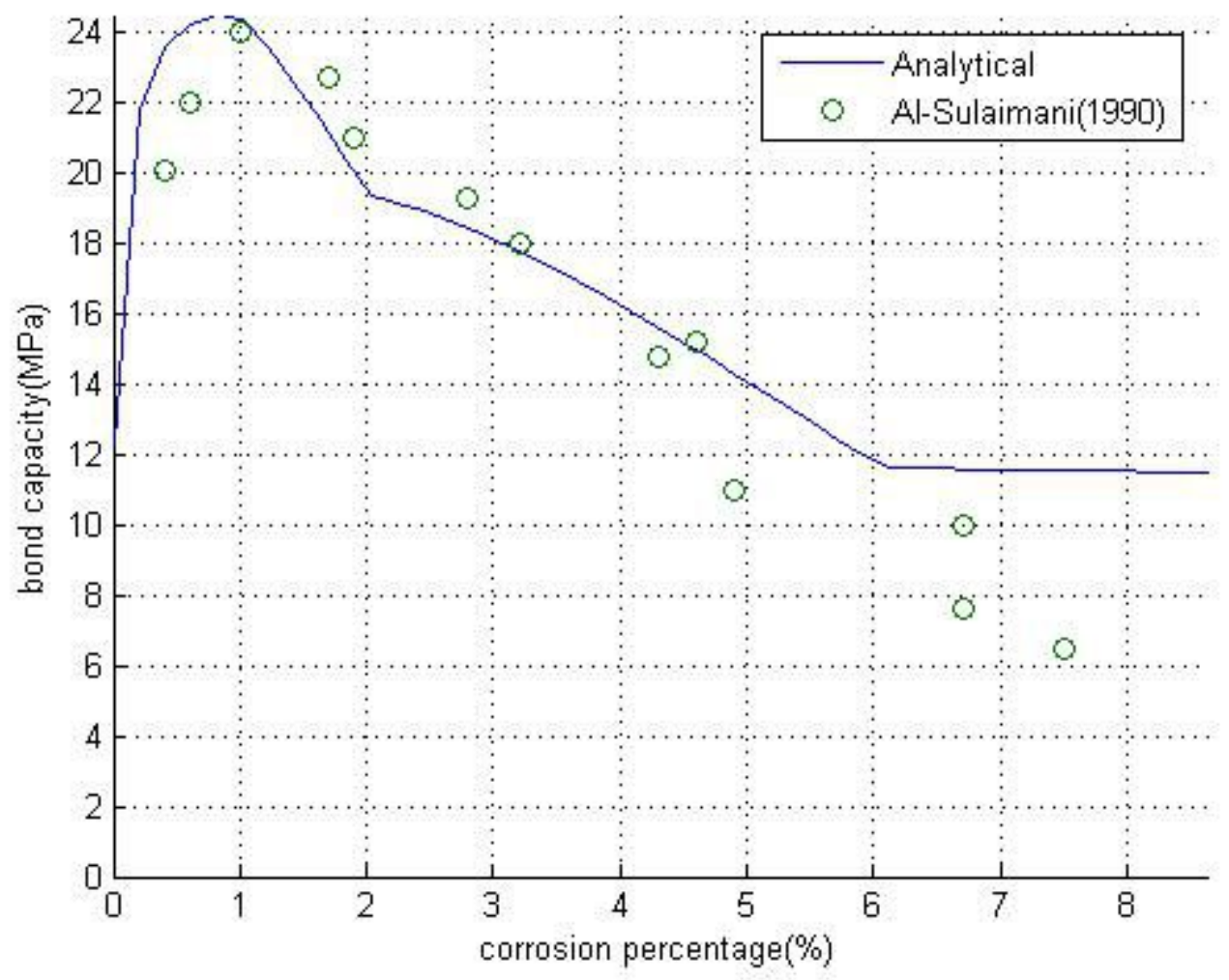

Figure 5-1 Comparison of analytical model to experimental results of specimen with 10-mm diameter reinforcement 


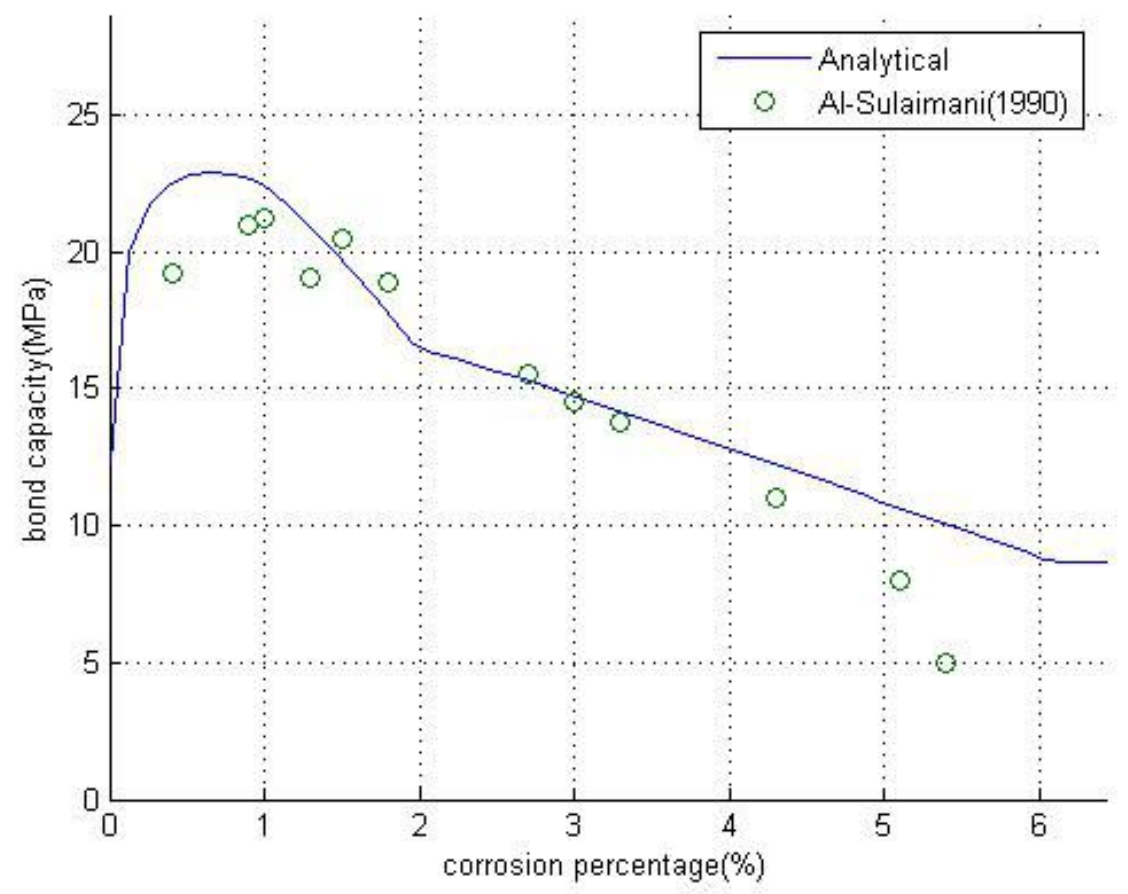

Figure 5-2 Comparison of analytical model to experimental results of specimen with 14-mm diameter reinforcement

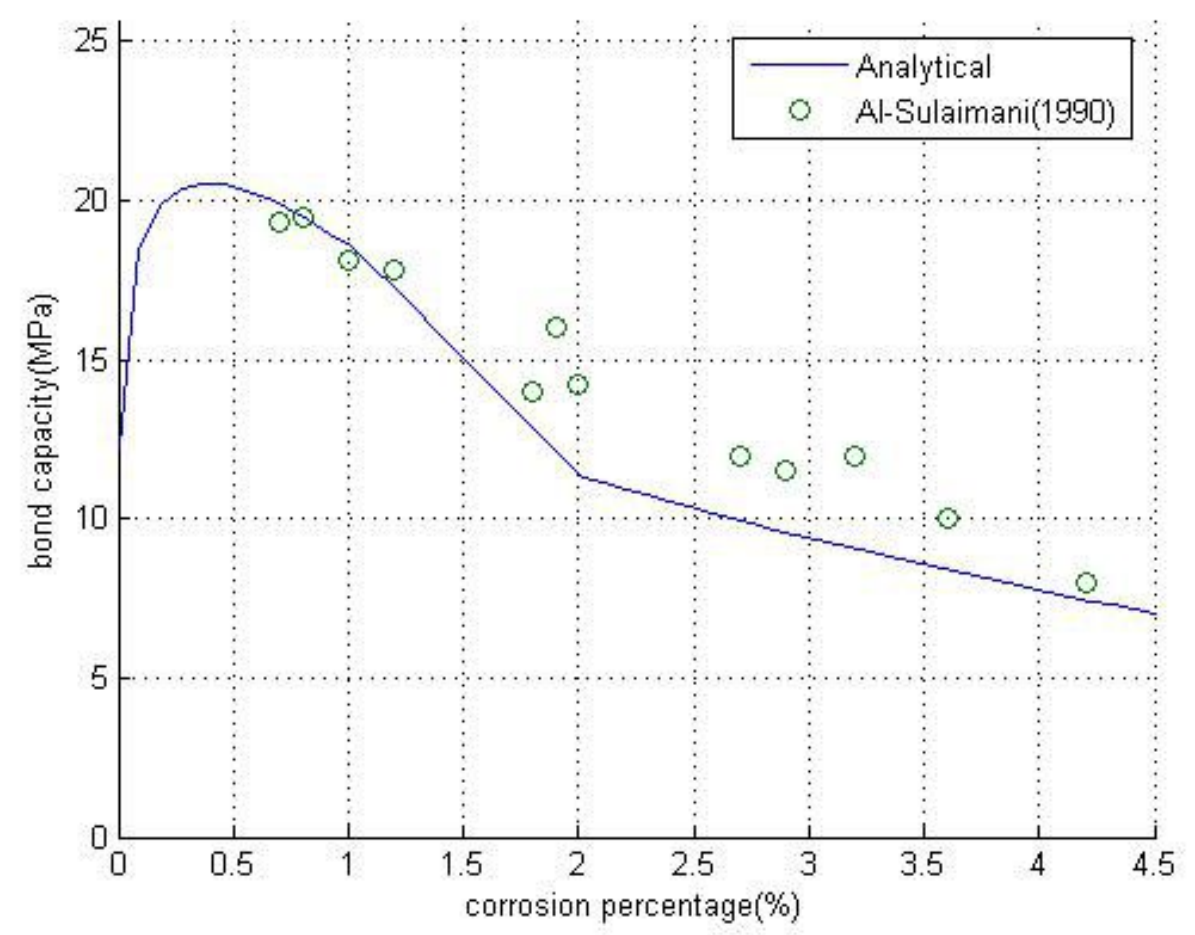

Figure 5-3 Comparison of analytical model to experimental results of specimen with 20-mm diameter reinforcement 
In addition, the specimens with higher cover-to-rebar diameter ratio $(C / d)$ tend to have a larger bonding capacity, since the thick-wall cylinder model used in Chapter 3 leads to higher cracking resistance when the concrete cover increases, providing, therefore, a higher confining stress and bonding resistance when the rust products accumulate around the reinforcing bar.

Notwithstanding, an overestimation of the maximum bond capacity predicted by the analytical model is noted at high levels of corrosion. Note that these divergences result from the selection of material models, such as the linear post-cracking model of concrete, since the confining capacity of the thick-wall cylinder model is significantly affected by the residual tensile stress after the cracking in concrete is initiated, or the assumption of radial displacement along the concrete cover, which is a crucial factor for the evaluation of strain in concrete.

\subsubsection{Comparison with Lundgren (2007)}

The validation for specimens reinforced with plain rebars was performed on the finite element (FE) pullout test conducted by Lundgren (2007), which was designed to investigate the degrading bond response of models with varying physical properties when the corrosion attack penetration increases. Specimens with different confinement conditions (with or without transverse reinforcement) and cover thickness (all summarized in Table 5-2) were modelled by axisymmetric elements in the FE tests conducted by Lundgren (2007). The analysis setup, shown in Figure 5-4, is a cylinder specimen with a 10-mm radius reinforcing bar centrally embedded in the specimen. The reinforcing bar was pulled out while the concrete was restrained, as illustrated in Figure 5-4. 


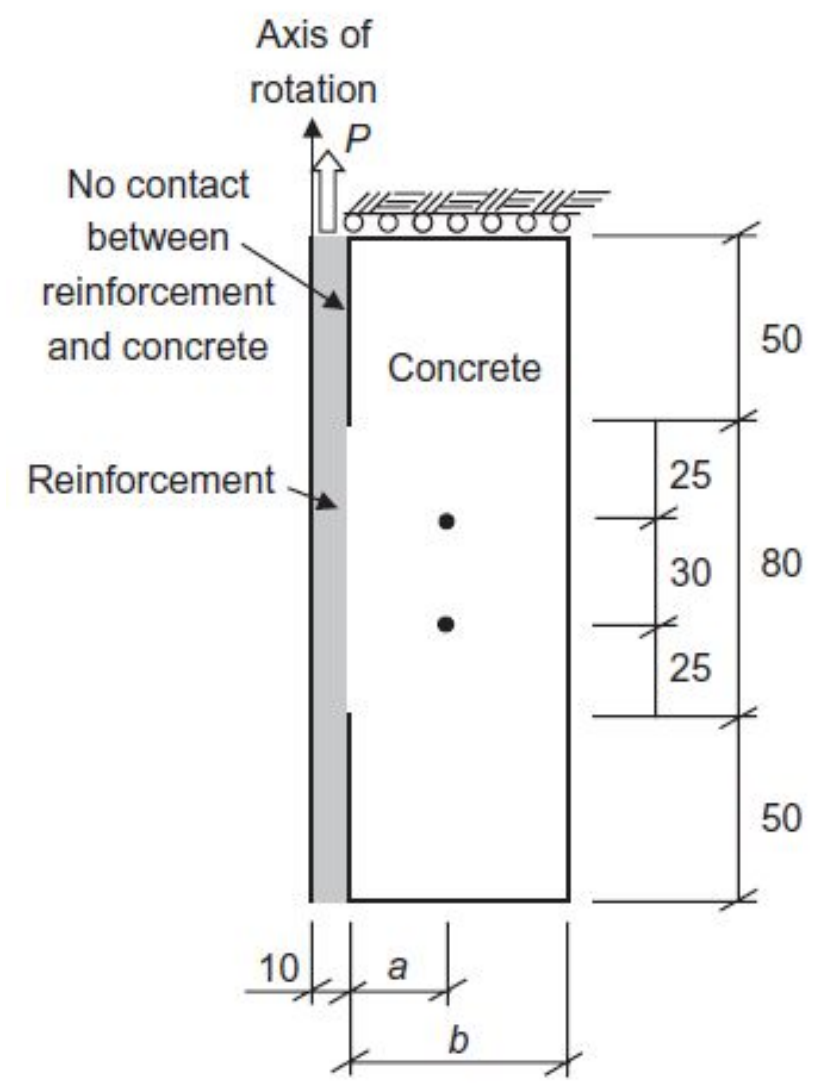

Figure 5-4 Setup of finite element model in Lundgren (2007) (all dimensions are in $\mathrm{mm}$ )

Table 5-2 Geometry of FE pullout test specimen

\begin{tabular}{|l|c|c|c|c|}
\hline Bar type & \multicolumn{3}{|c|}{ Smooth bar } \\
\hline Cover thickness $b(\mathrm{~mm})$ & 20 & 40 & 20 & 40 \\
\hline $\begin{array}{l}\text { Distance from the edge of tension bar to } \\
\text { stirrups } a(\mathrm{~mm})\end{array}$ & N/A & N/A* & 15 & 15 \\
\hline Specimen ref. \# & 1 & 2 & 3 & 4 \\
\hline
\end{tabular}

*N/A means no stirrup provided

The material properties used in the finite element analysis conducted by Lundgren (2007) are summarized in Table 5-3. As the yield strength for reinforcement was not specified in the finite element test, the yielding of the steel bar was taken as $500 \mathrm{MPa}$. Since physical properties in the 
interface, such as adhesive stress and initial friction coefficient, were provided by Lundgren (2007), those properties were used rather than being assumed according to the literature review.

Table 5-3 Material properties for FE pullout specimen

\begin{tabular}{|l|l|}
\hline Concrete & $34.2 \mathrm{GPa}$ \\
\hline Young's Modulus $E_{c}$ & $3 \mathrm{MPa}$ \\
\hline Tensile strength $f_{t}^{\prime}$ & $79.2 \mathrm{~N} / \mathrm{mm}$ \\
\hline Fracture energy $G_{f}$ & $500 \mathrm{MPa}$ \\
\hline Stirrups & $200 \mathrm{GPa}$ \\
\hline Yielding strength $f_{y}$ & $6 \mathrm{~mm}$ \\
\hline Young's Modulus $E_{s}$ & 2 \\
\hline Diameter $d_{b}$ & 0.8 \\
\hline Interface & $2 \mathrm{MPa}$ \\
\hline Initial friction coefficient $\mu_{0}$ & \multicolumn{2}{|l}{} \\
\hline Chemical adhesion stress $\mathrm{Fa}$ & \\
\hline Rust product & \multicolumn{2}{|l|}{} \\
\hline Ratio between the volume of oxides product & 2 \\
\hline
\end{tabular}

Figure 5-5 to Figure 5-8 show the comparisons between the bond capacity degradation obtained from the analytical model and the numerical results obtained by Lundgren (2007) for each of the four types of specimens. Figure 5-5 and Figure 5-6 show results for unconfined specimens, whereas results for confined specimens are illustrated in Figure 5-7 and Figure 5-8. 


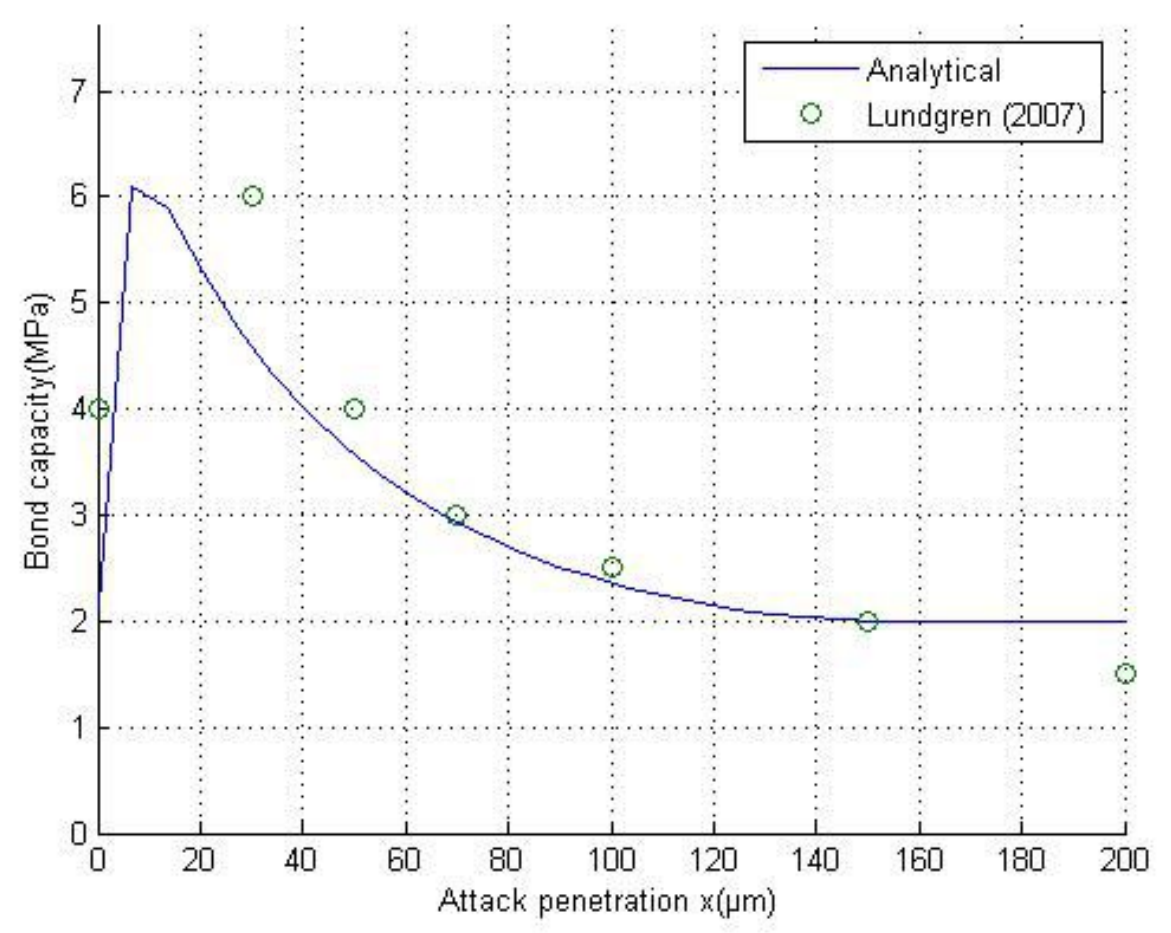

Figure 5-5 Maximum bond stress versus corrosion penetration for specimen \#1

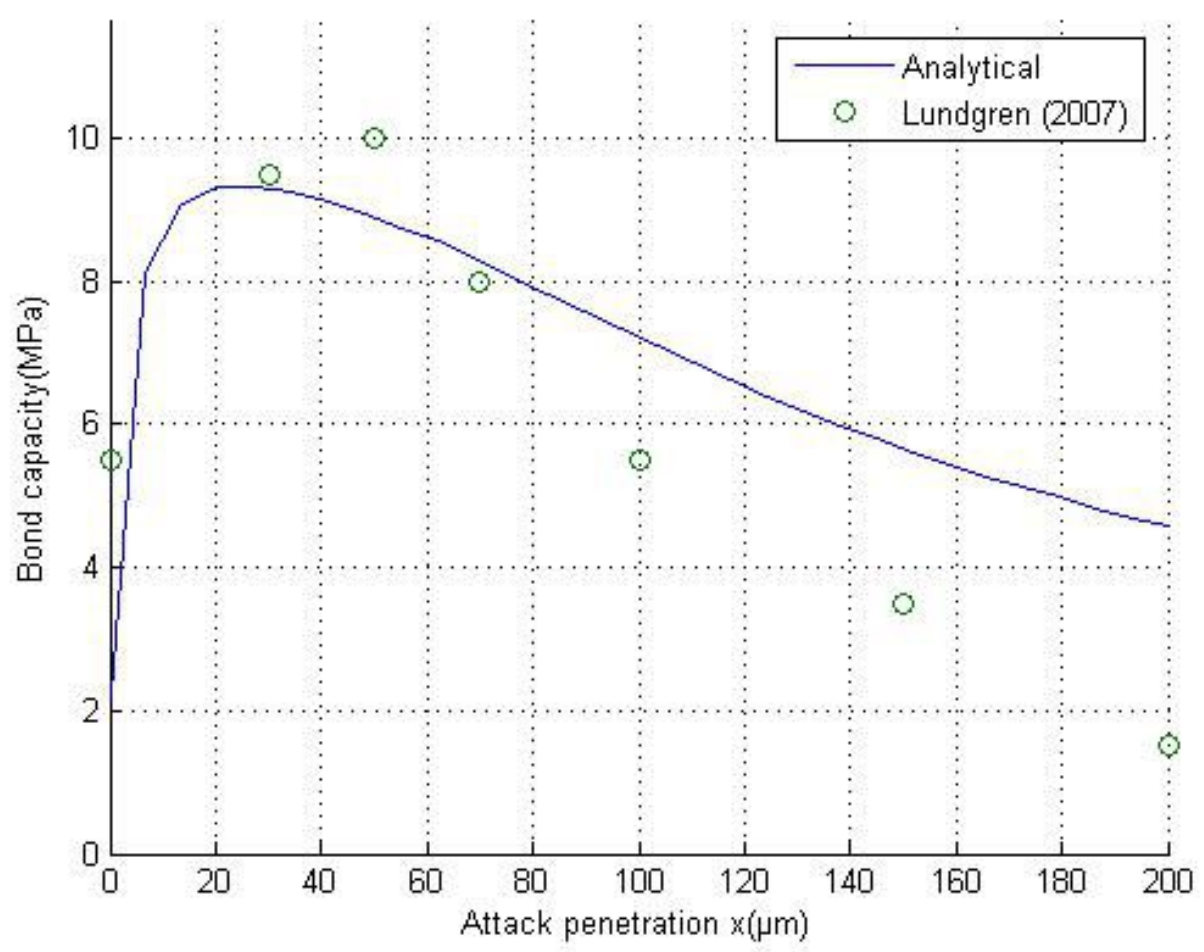

Figure 5-6 Maximum bond stress versus corrosion penetration for specimen \#2 


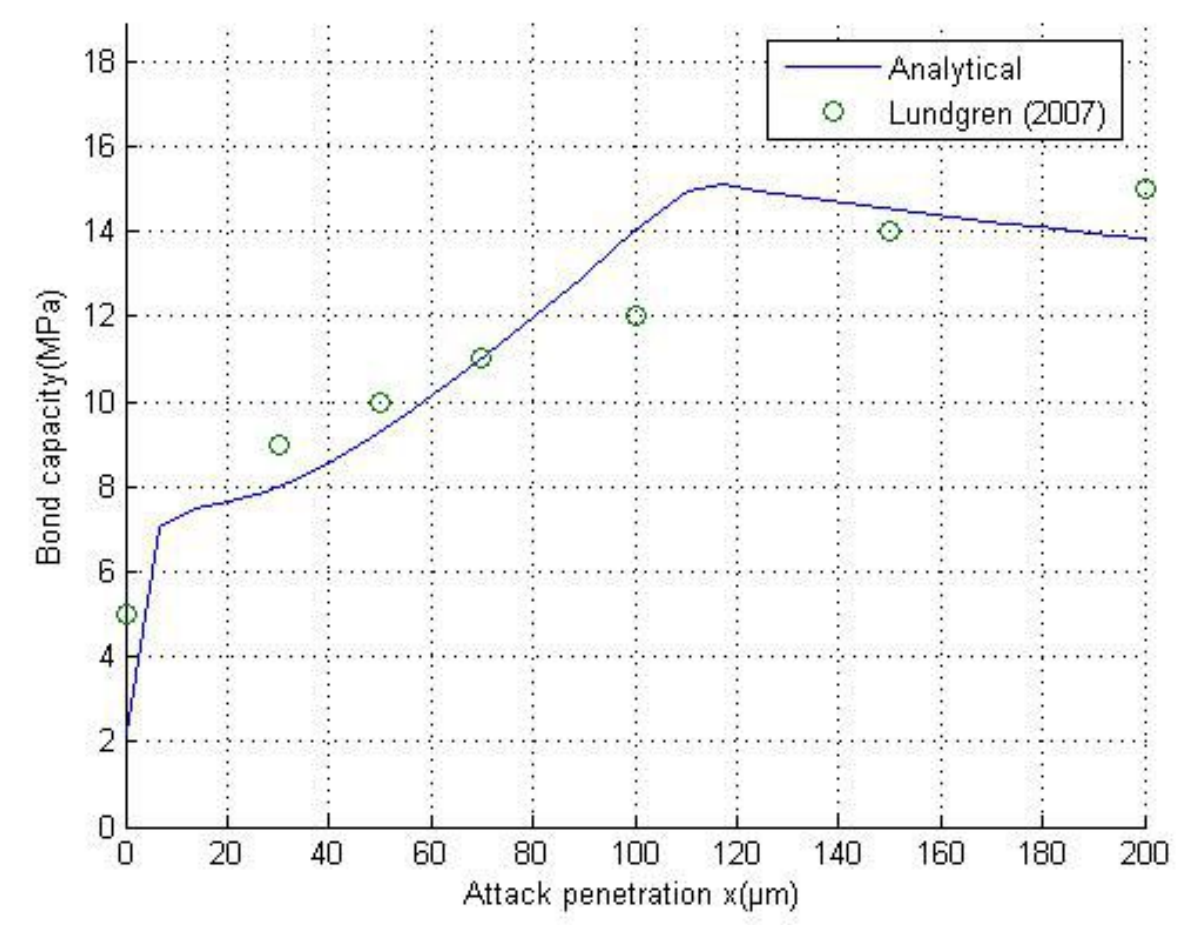

Figure 5-7 Maximum bond stress versus corrosion penetration for specimen \#3

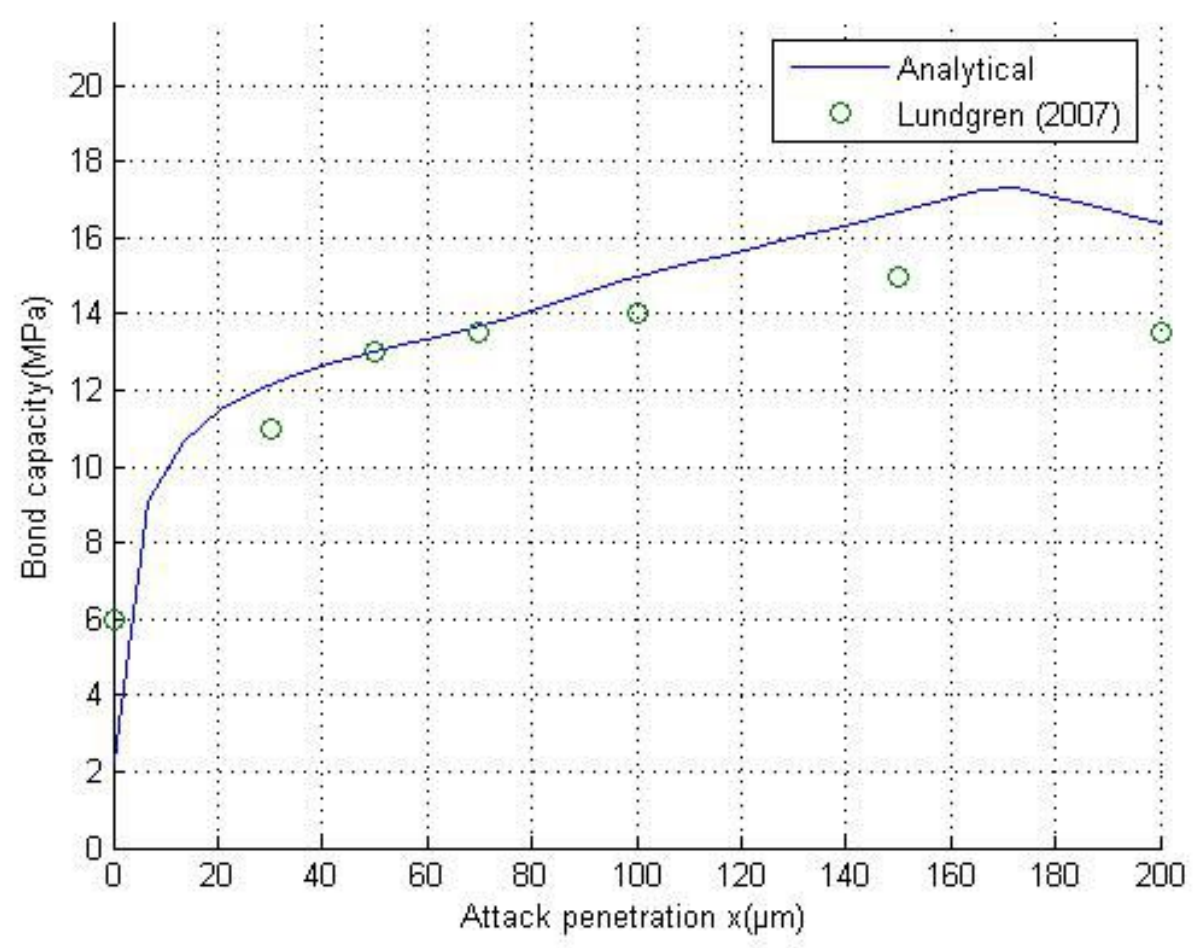

Figure 5-8 Maximum bond stress versus corrosion penetration for specimen \#4 
Overall, the comparisons shown in Figure 5-5 to Figure 5-8 indicate that the analytical approximations capture the finite element results obtained by Lundgren (2007), since similar values of maximum bond capacity and increasing/decreasing trends are noted when the attack penetration $x$ increases. Also, the models that are able to account for the confining stress, i.e., specimens with higher cover-to-diameter ratio $(C / d)$ and transverse reinforcement, tend to predict higher maximum bond capacity.

However, some differences between the two sets of results are also found in the comparisons. In groups \#1 and \#2, both sets of analytical results reach their maximum values at lower levels of attack penetration than the numerical results. The FE results for specimen \#2 degrade more rapidly as the corrosion level increases compared to the analytical model's results. As for results of groups \#3 and \#4, where specimens were reinforced by transverse rebars, although the differences are smaller than in groups \#1 and \#2, some divergences are noticed, for instance, in groups \#3 bond degradation as given by the analytical model starts at $120 \mu \mathrm{m}$ of attack penetration as opposed to that predicted by the FE analysis, in which the bond capacity keeps increasing up to $200 \mu \mathrm{m}$ of attack penetration.

Like the validation against the experimental results reported by Al-Sulaimani et al. (1990), the differences between the two sets of results in Figures 5-8 can result from the different material models used in the analytical evaluation. Hence, the major factors that affect the results of the analytical model, such as the tensile strength of the concrete and the selection of the volume ratio between oxides and virgin steel $n$, are investigated through a parametric study in Chapter 6 . 


\subsection{Validation of finite element model}

\subsubsection{Comparison with Mangat (1999)}

Mangat (1999) conducted 4-point flexural testing of a total of 111 under-reinforced concrete beams reinforced with ribbed bars and subjected to different attack penetrations. The beams were $150 \mathrm{~mm} \times 100 \mathrm{~mm}$ in cross section, and $910 \mathrm{~mm}$ in length. Two ribbed bars $(10-\mathrm{mm}$ diameter $)$ were used as tension reinforcement, protected by a 20-mm concrete cover (Figure 5-9). The reinforcement in the beams was subjected to an accelerated corrosion process before loading, wherein a mass loss ranging from 1.25 to $10 \%$ was induced. The authors reported the load-displacement responses for each of the tested beams. In order to develop full flexural capacity, one beam was reinforced with stirrups, while the other beams were reinforced in shear with external steel collars. The required material parameters for the finite element analysis are summarized in Table 5-4. Note that the average compressive strength of the concrete cubes after 28 days was $40 \mathrm{MPa}$ in the experiment. Other material properties, e.g., the uniaxial tensile strength for concrete, were determined from the CEP-FIP Model Code (2010).

\subsubsection{Control beam}

A control beam without corrosion-induced damage and without link elements was first analyzed, as illustrated in Figure 5-10. The FE mesh consists of 1,904 nodes, 1,732 concrete elements (plane-stress elements CPS4), whose dimension is $6.25 \times 6.25 \mathrm{~mm}$, and 68 2-node truss elements to represent the reinforcing bars. The external steel collar was modelled using 180 2-node truss (T2D2) elements. 
Table 5-4 Material properties for beams tested by Mangat (1999)

\begin{tabular}{|l|l|}
\hline Concrete & $40 \mathrm{MPa}$ \\
\hline Compressive strength $f_{c}^{\prime}$ & $33.6 \mathrm{GPa}$ \\
\hline Young's modulus $E_{c}$ & $2.9 \mathrm{MPa}$ \\
\hline Tensile strength $f_{t}^{\prime}$ & $10 \mathrm{~mm}$ \\
\hline Maximum coarse aggregate size $d_{a}$ & $520 \mathrm{MPa}$ \\
\hline Steel & $206 \mathrm{GPa}$ \\
\hline Yielding strength $f_{y}$ & 2 \\
\hline Young's modulus $E_{s}$ & 0.8 \\
\hline Interface & $0.8 \mathrm{MPa}$ \\
\hline *Initial friction coefficient $\mu_{0}$ & \\
\hline *Chemical adhesion stress $\mathrm{Fa}$ & \\
\hline Rust product & \\
\hline *Ratio between the volume of oxides & \\
\hline
\end{tabular}

Note: Properties marked by * are selected according to the literature review.

Perfect bond was assumed in the analysis of the control beam. The assumption of perfect bond is widely applied in normal analysis and design of $\mathrm{RC}$, so it is reasonable to use it to represent the bond behaviour between concrete and uncorroded ribbed bars.

The load vs mid-span displacement curve from the experimental and numerical results is highlighted in Figure 5-11. As it is observed from the figure, the finite element analysis successfully models the experimental results of the control beam reported by Mangat (1999), although the overestimation of flexural strength at large deflections (around 8\%) is noticed. 


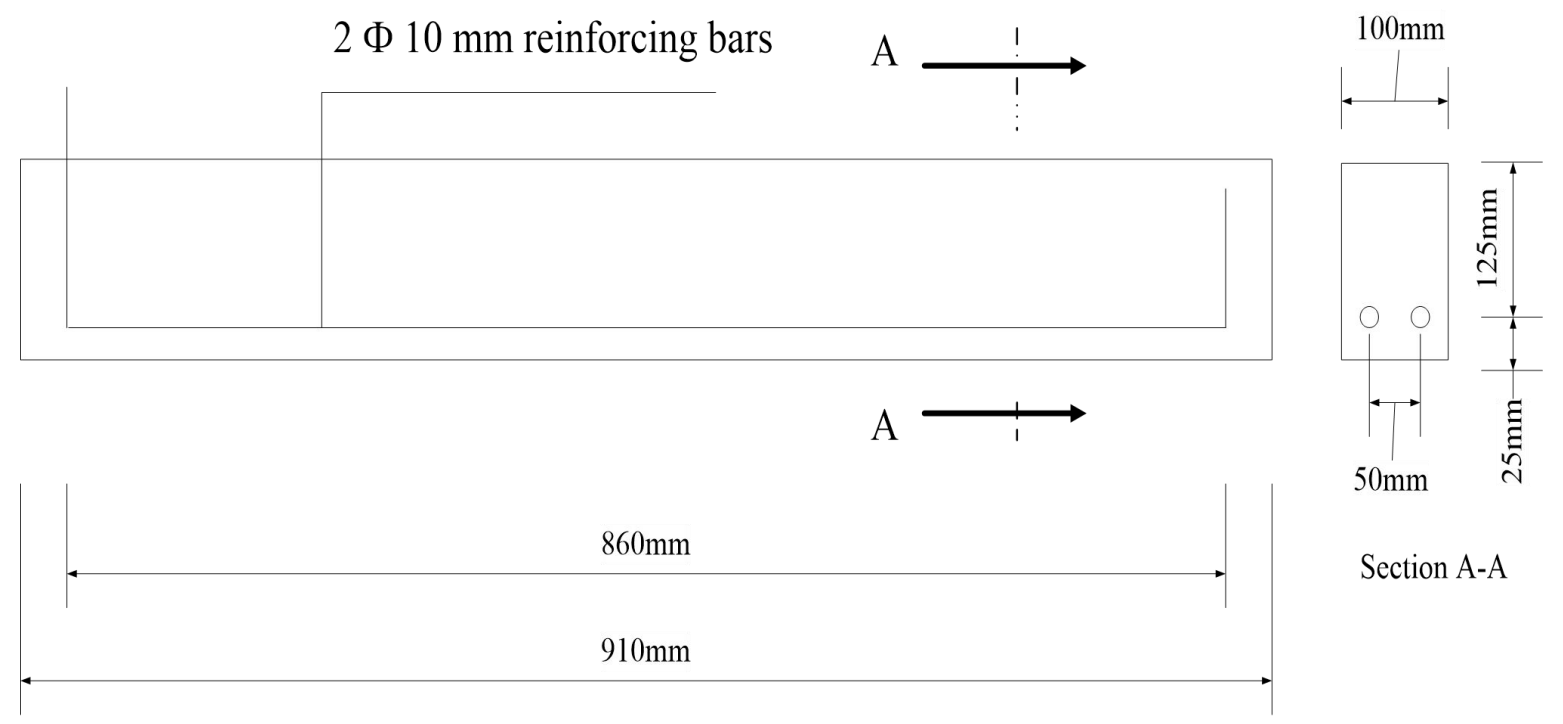

Figure 5-9 Geometry of beams tested by Mangat (1999)

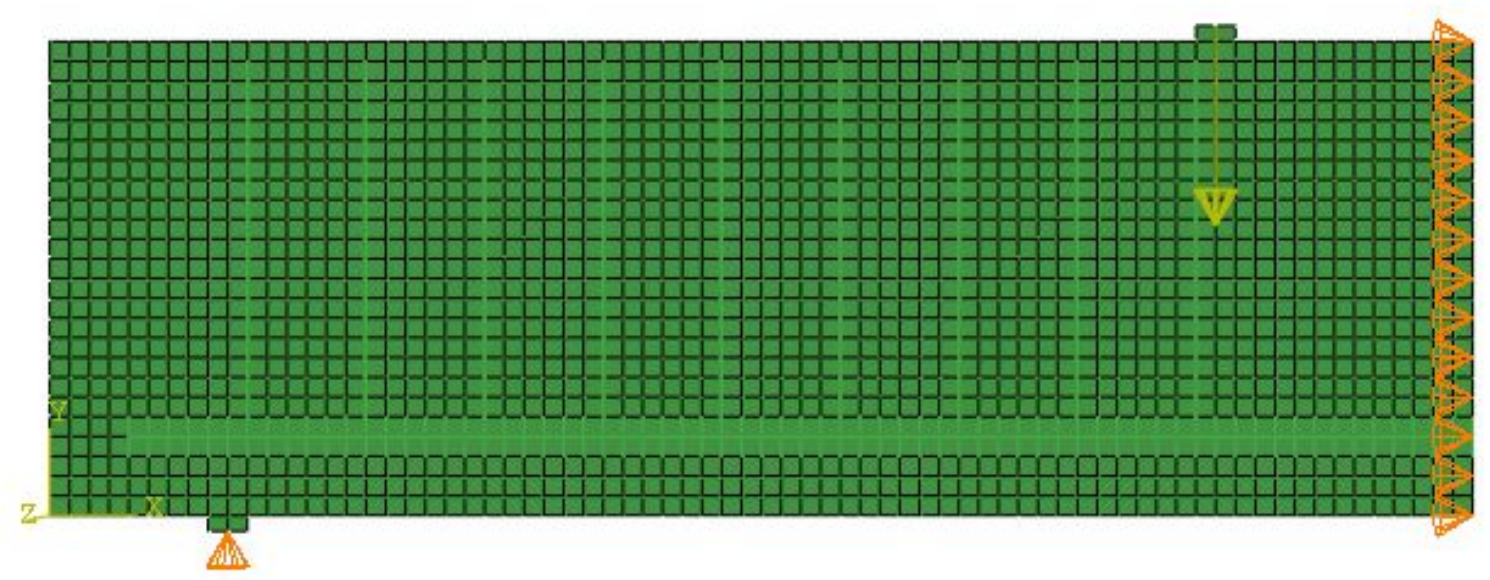

Figure 5-10 FE mesh of control beam as displayed in ABAQUS 


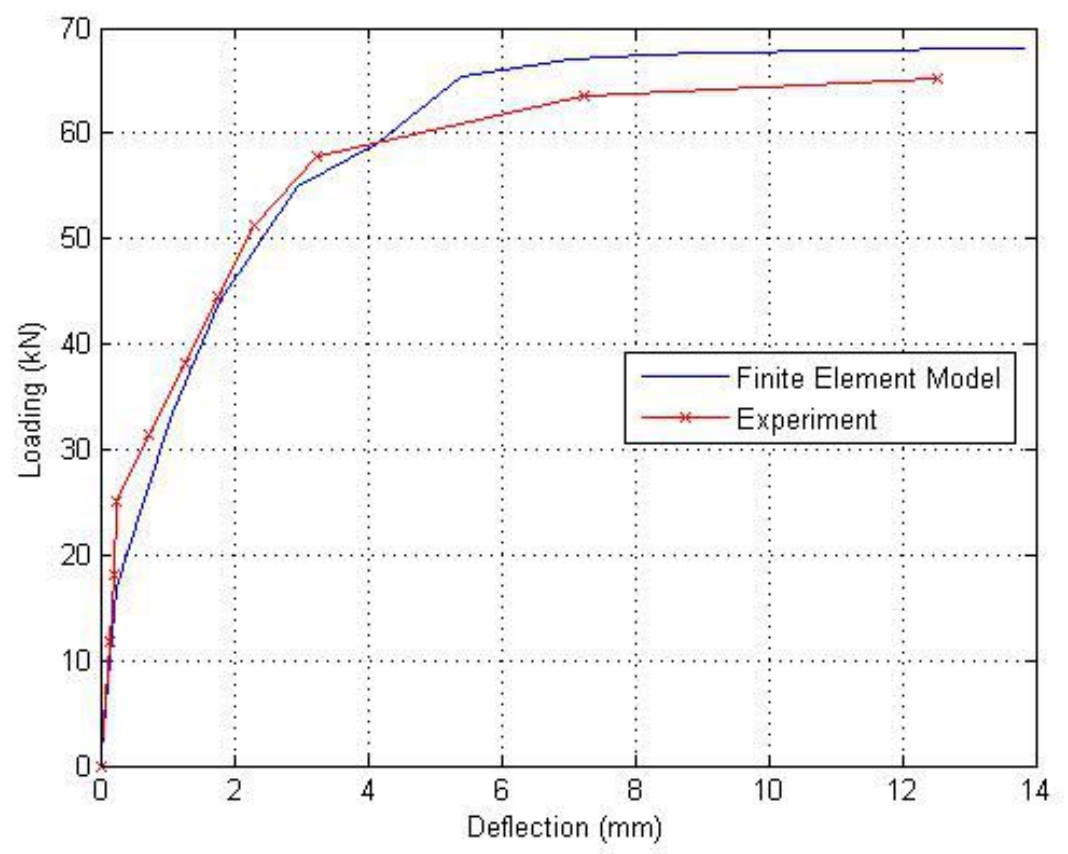

Figure 5-11 Load-displacement response for control beam with perfect bond

\subsubsection{Application of link element for uncorroded beam}

Once the verification of the finite element model had been done, the validation of the link element for an uncorroded beam was conducted. The link elements, where $0 \%$ corrosion was specified, were placed at the interface between the concrete elements and the truss elements representing the reinforcing bars (Figures 4-5 in Chapter 4).

Using the same meshing as shown in Figure 5-10, the FE specimen was subjected to a 4-point load analysis. Figure 5-12 shows the resulting flexural response. Comparing both experimental and numerical responses, the FE results captures the overall load-deformation response, although the FE model slightly underestimates the strength and stiffness up to a 6-mm mid-span deflection. 


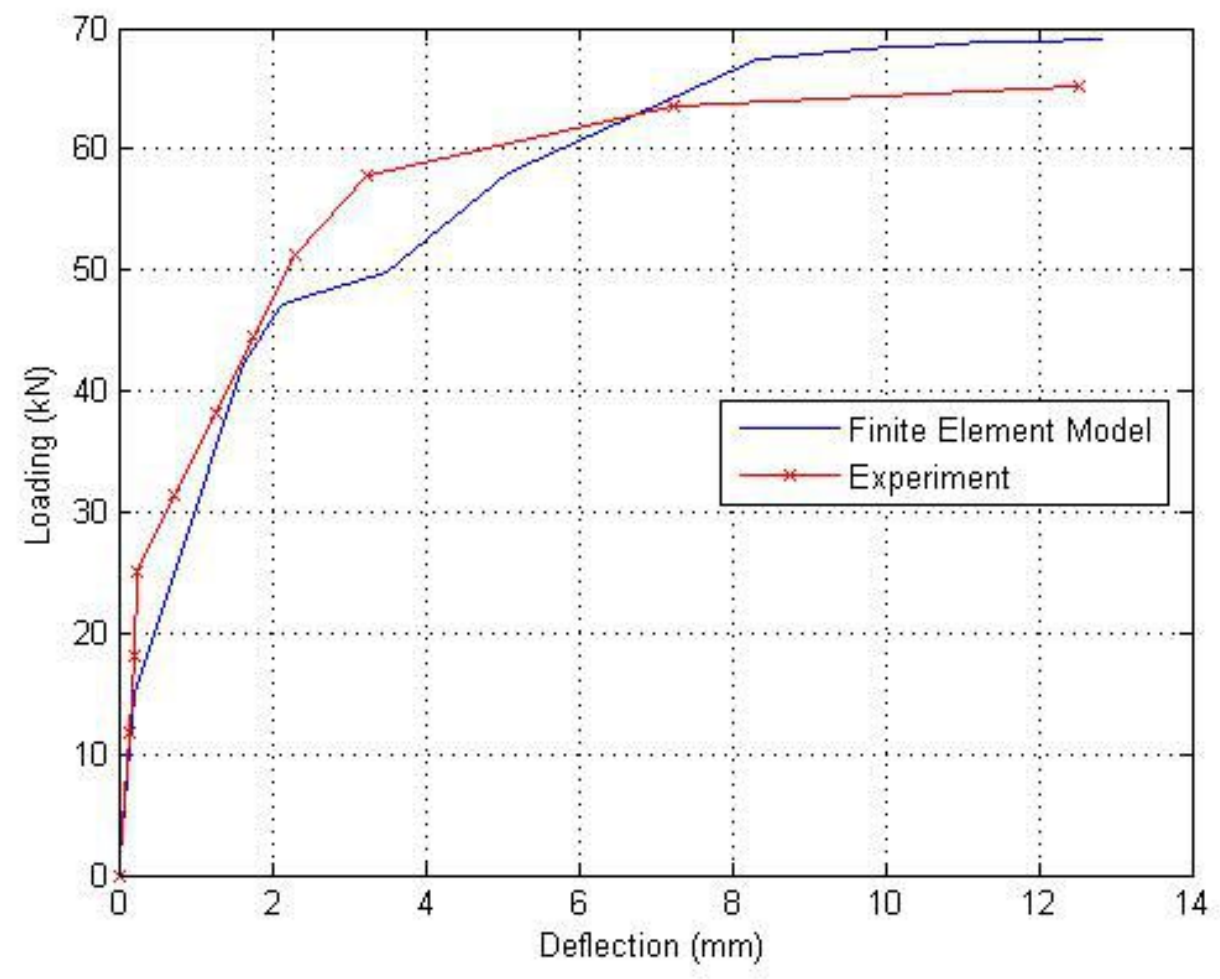

Figure 5-12 Load-displacement response for control beam with link elements

Figure 5-13 shows the comparison of the load-displacement curves for FE results with the assumption of perfect bond and using link elements to simulate bonding action. The use of link elements results in a softer response, with a slightly lower stiffness and strength. The reason for this variation is that at $0 \%$ corrosion, the link elements still have limited stiffness along the reinforcing bar, differing from perfect bond where no slip is allowed between nodes, and this results in a lower bond stress than a specimen modelled under the assumption of perfect bond. 


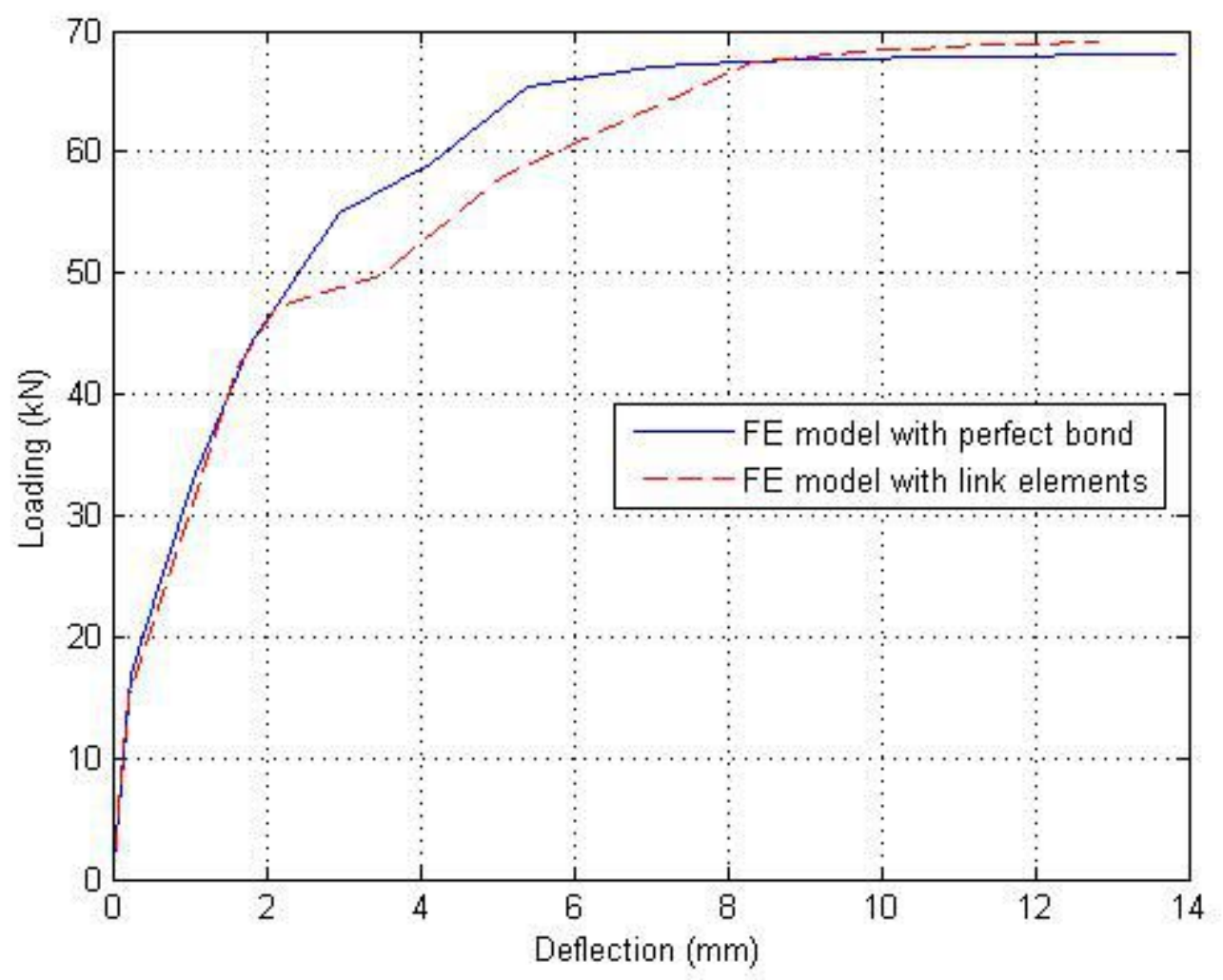

Figure 5-13 Comparison of load-displacement response for both sets of control beams

\subsubsection{Application of link element for corroded beam}

Corrosion-induced damage was modelled according to the development of analytical and numerical model presented in Chapters 3 and 4, respectively. The reduced cross-section area was considered according to Eq 4-4. Bond behaviour was modelled with the link elements. Finally, corrosion-induced cracking of the concrete cover resulting from the corrosion products accumulation around the reinforcing bar was modelled using expansive elements (see Section 4.6.2). Figure 5-14 illustrates the load-displacement curves from the numerical model using link elements at a level of corrosion of $0 \%, 1.25 \%, 2.5 \%, 5 \%$ and $10 \%$ (measured by the ratio of attack penetration $x$ to radius of reinforcement $r_{b}$ ). 


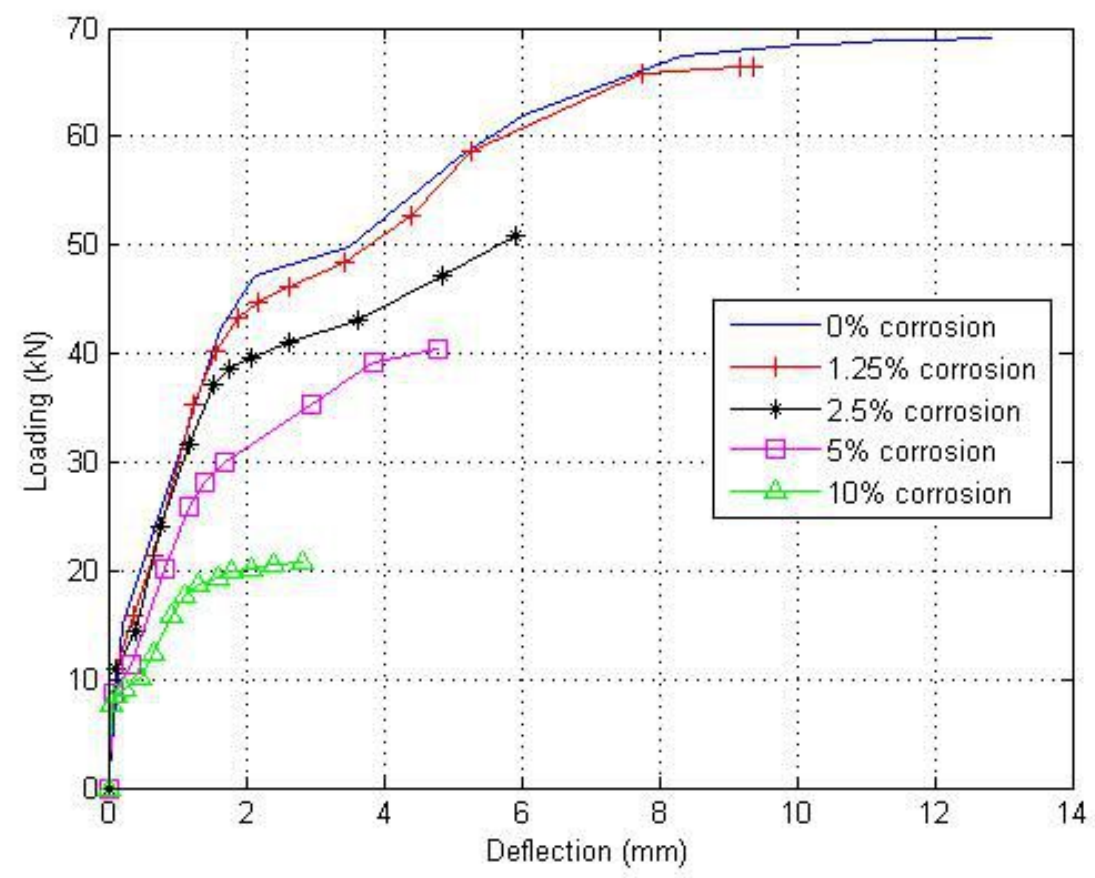

Figure 5-14 Load-displacement responses from finite element models
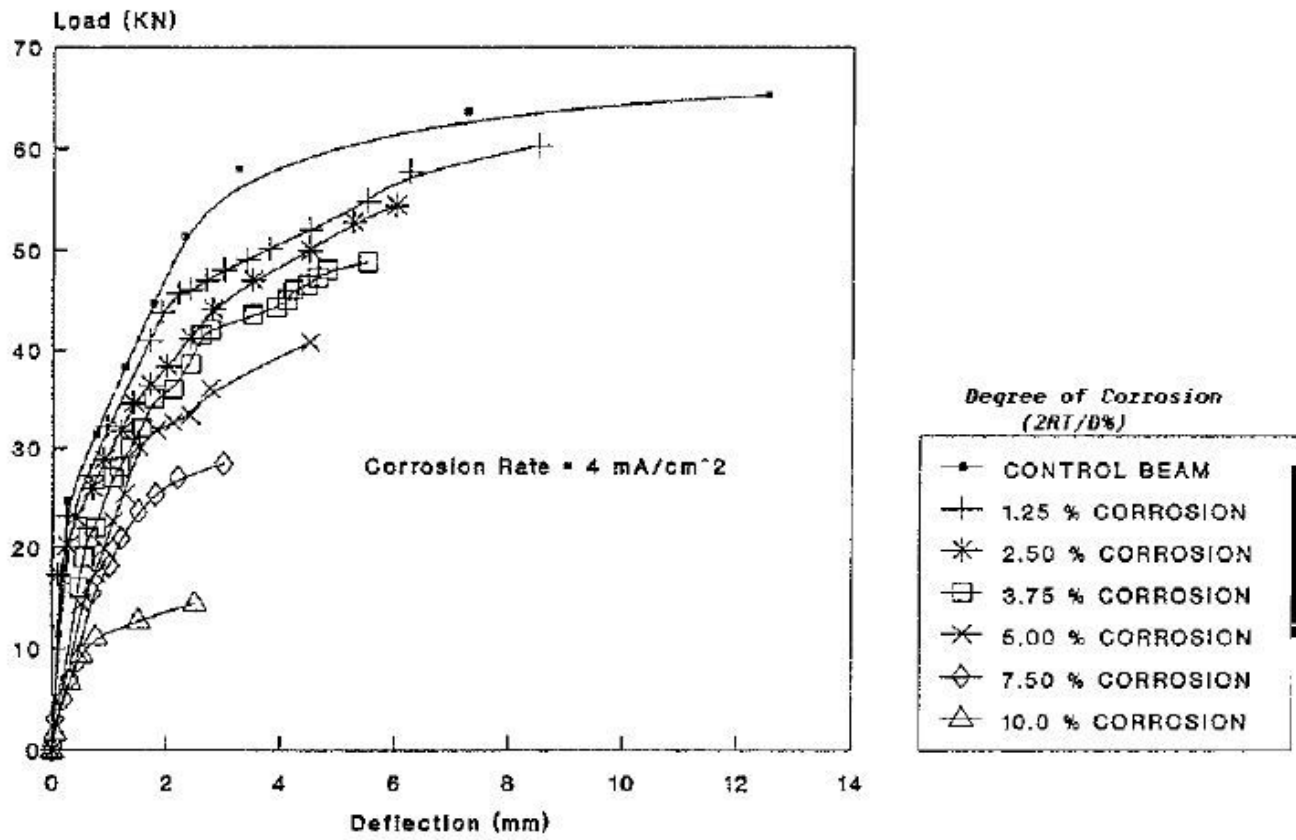

Figure 5-15 Load-displacement responses for tested specimens (reproduced from Mangat (1999))

From Figure 5-14, it is observed that flexural behaviour in beams degrades as the corrosion level 
in the tension reinforcement increases. Under the same level of loading, the corroded specimens displayed a larger mid-span deflection, this degradation being more severe in beams with higher corrosion attack penetration. Similar observations were noted in Mangat (1999), as shown in Figure 5-15, which indicates the FE model is able to simulate corrosion-induced flexural deterioration, and the FE model with link elements is sensitive to the degree of tensile reinforcement corrosion.

The comparisons of the finite element model results against the experimental results by Mangat (1999) are also presented in Figure 5-16 to Figure 5-19 for $0 \%, 1.25 \%, 2.5 \%, 5 \%$ and $10 \%$ corrosion, respectively. Both numerical results correlate well with the experimental flexural response, although the specimen with $10 \%$ corrosion shows the largest differences, wherein the flexural strength is overestimated, which might result from the overestimation of bond capacity at high corrosion levels. Since the comparisons show that the finite element model using link elements can reproduce the degradation of the overall structural behaviour of the corroded beams reasonably well, it can also be used as a practical tool to predict the flexural strength of RC beams with corroded reinforcement.

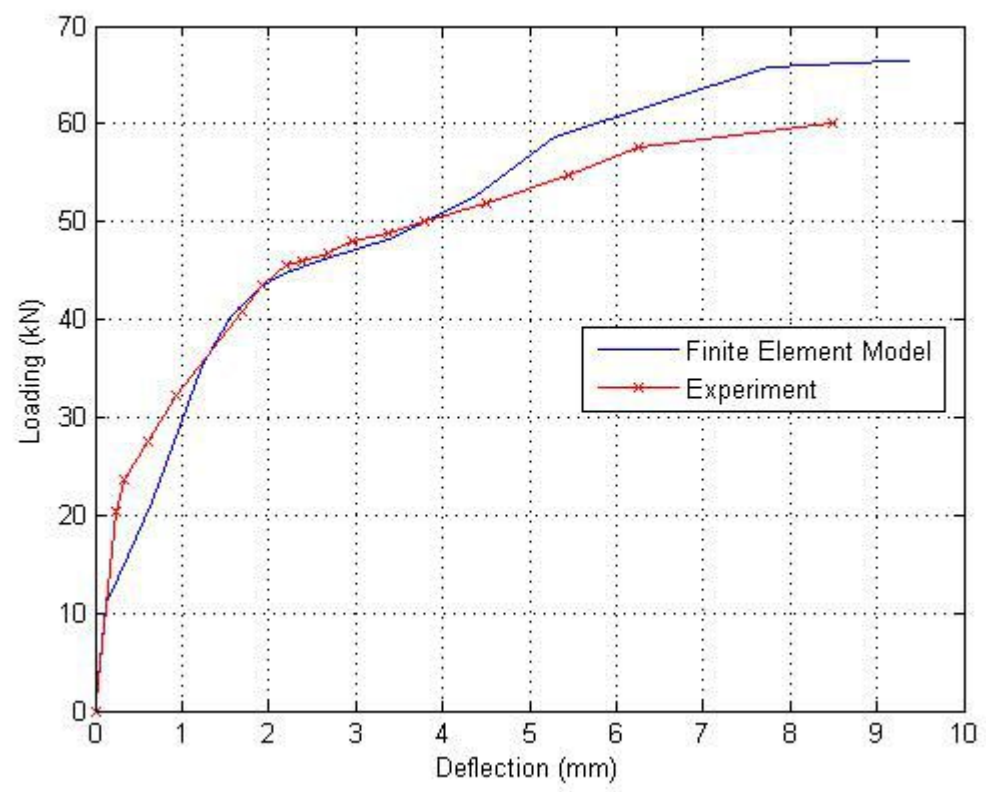

Figure 5-16 Load-displacement response for beams with $1.25 \%$ corrosion 


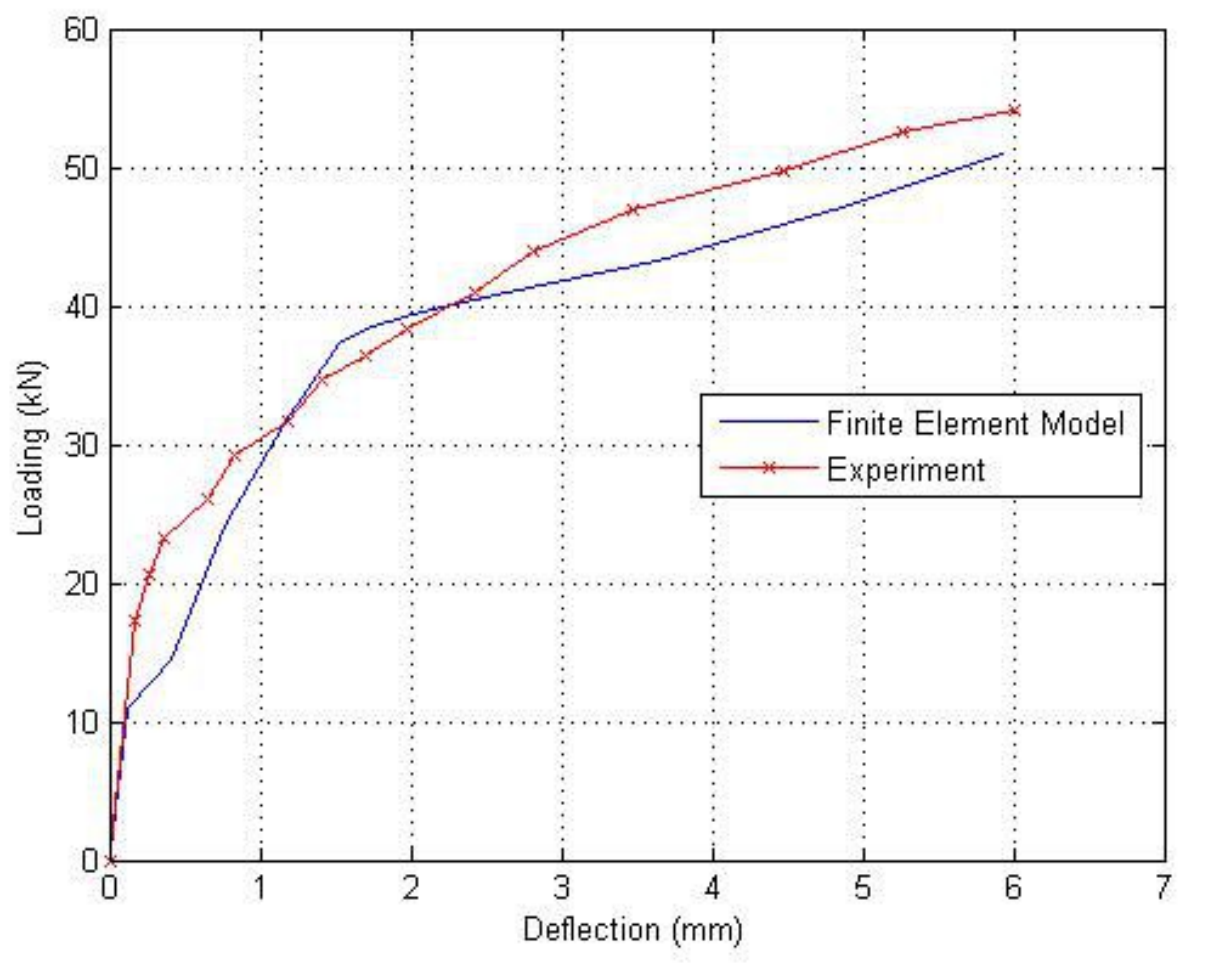

Figure 5-17 Load-displacement response for beams with 2.5\% corrosion

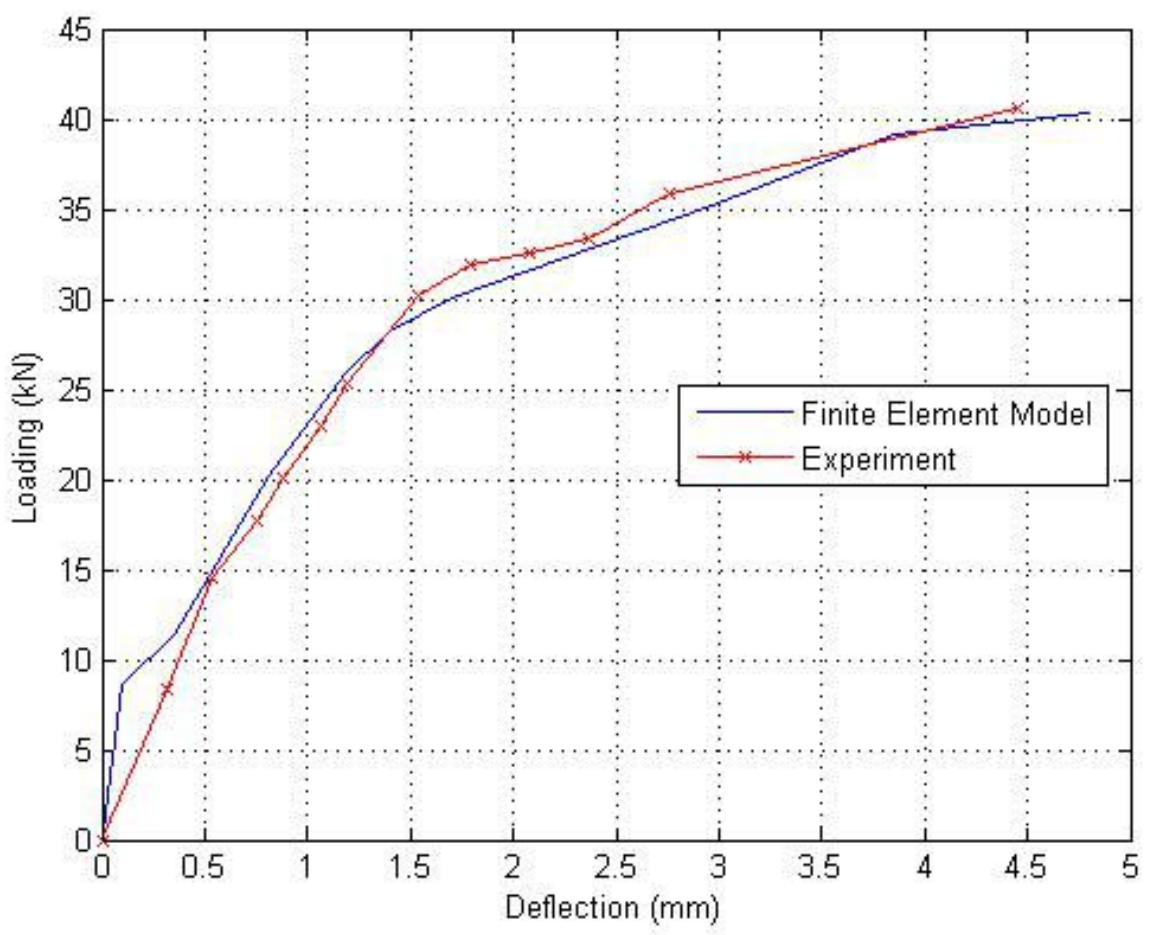

Figure 5-18 Load-displacement response for beams with 5\% corrosion 


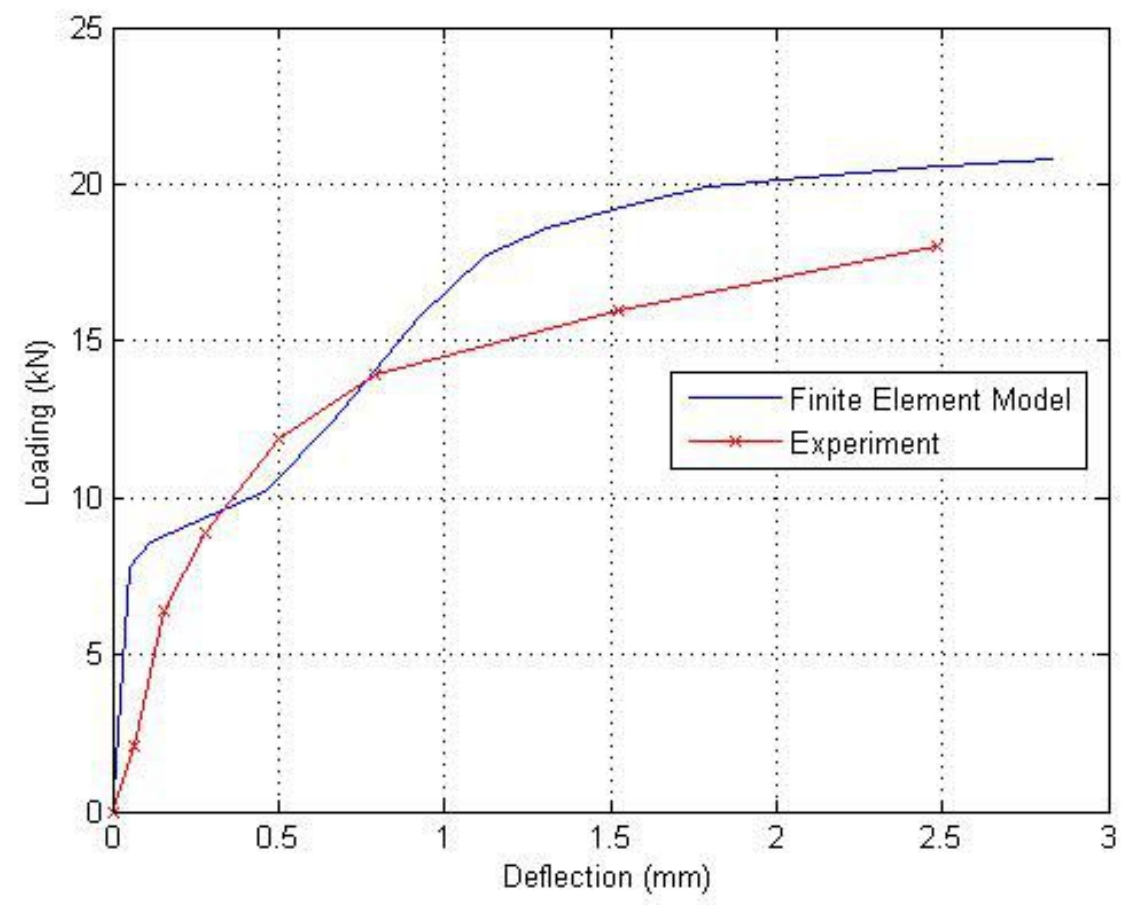

Figure 5-19 Load-displacement response for beams with 10\% corrosion

\subsubsection{Comparison with Cairns et al. (2008)}

Since some aged buildings were constructed and reinforced with plain bars before the application of ribbed bars, further validation was conducted by analyzing tests performed by Cairns et al. (2008), in which the specimens were reinforced with plain round steel bars and stirrups. The bonding capacity of corroded plain reinforcement rises to a noticeable extent even at relatively large attack penetrations (Lundgren 2007), although it is still lower than that of deformed bars due to the lack of mechanical interlocking. This is because for uncorroded plain rebars, the friction stress is equal to zero as no confinement stress is introduced according to the analytical model in Chapter 3, and the bond capacity only results from the chemical adhesion between the steel and the concrete, whereas for corroded plain rebars, the bond capacity increases as the friction increases due to the accumulation of corrosion products at the steel/concrete interface. This results in an increase in the overall flexural stiffness and strength, even though corrosion-induced 
damages, such as reduced cross-sectional area of steel and corrosion products expansion, are introduced. Cairns et al. (2008) observed this enhanced response for corroded beams as well. Therefore, the verification of the link element with plain reinforcement can be done by observing if the finite element model is able to capture this increased in flexural response as the corrosion level increases.

Cairns et al. (2008) tested four types of beams: (i) simply-supported beams lightly reinforced $(0.6 \%$ reinforcement ratio) in flexure (denoted as sbf), (ii) simply-supported beams heavily reinforced (2.3\% reinforcement ratio) in flexure (denoted as sbs), (iii) two-span continuous beams with continuous reinforcement (cbf), and (iv) two-span continuous beams with reinforcement lapped near points of contra flexure (dbf). All these beams were subjected to different corrosion levels before being tested in bending.

The validation is conducted by modelling the specimen type sbf, whose geometric details are illustrated in Figure 5-20. The beam specimen had overall section dimensions of $150 \mathrm{~mm} \times 200$ $\mathrm{mm}$, and it was reinforced with plain round mild steel. The concrete cover to flexural reinforcement was $20 \mathrm{~mm}$. There were two $10-\mathrm{mm}$ diameter top bars and two $10-\mathrm{mm}$ diameter bottom bars placed at the corners of the specimens. Six-mm diameter shear reinforcing bars with a spacing of $125 \mathrm{~mm}$ were also provided to prevent shear failure. Note that concrete cube strength reached 43.2 MPa by the time the first load tests were carried out. Other material parameters used in the FE analysis are obtained from the CEB-FIP code (identified as C35 grade concrete), and they are listed in Table 5-5. 
Table 5-5 Material properties for sbf beam

\begin{tabular}{|c|c|}
\hline \multicolumn{2}{|l|}{ Concrete } \\
\hline Compressive strength $f_{c}^{\prime}$ & 43.2 $\mathrm{MPa}$ \\
\hline Young's modulus $E_{c}$ & $35 \mathrm{GPa}$ \\
\hline Tensile strength $f_{t}^{\prime}$ & $3.21 \mathrm{MPa}$ \\
\hline \multicolumn{2}{|l|}{ Steel } \\
\hline \multicolumn{2}{|l|}{ Tension bar } \\
\hline Yielding strength $f_{y}$ & 342.7 MPa \\
\hline Young's modulus $E_{s}$ & $200 G P a$ \\
\hline \multicolumn{2}{|l|}{ Stirrups } \\
\hline Yielding strength $f_{y}$ & $328.5 \mathrm{MPa}$ \\
\hline Young's modulus $E_{s}$ & $200 G P a$ \\
\hline \multicolumn{2}{|l|}{ Interface } \\
\hline *Initial friction coefficient $\mu_{0}$ & 0.8 \\
\hline *Chemical adhesion stress $\mathrm{Fa}$ & $0.8 \mathrm{MPa}$ \\
\hline \multicolumn{2}{|l|}{ Rust product } \\
\hline $\begin{array}{l}\text { * Ratio between the volume of oxides } \\
\text { product and virgin steel } n\end{array}$ & 2 \\
\hline
\end{tabular}

Note: Properties marked by * are selected according to the literature review. 


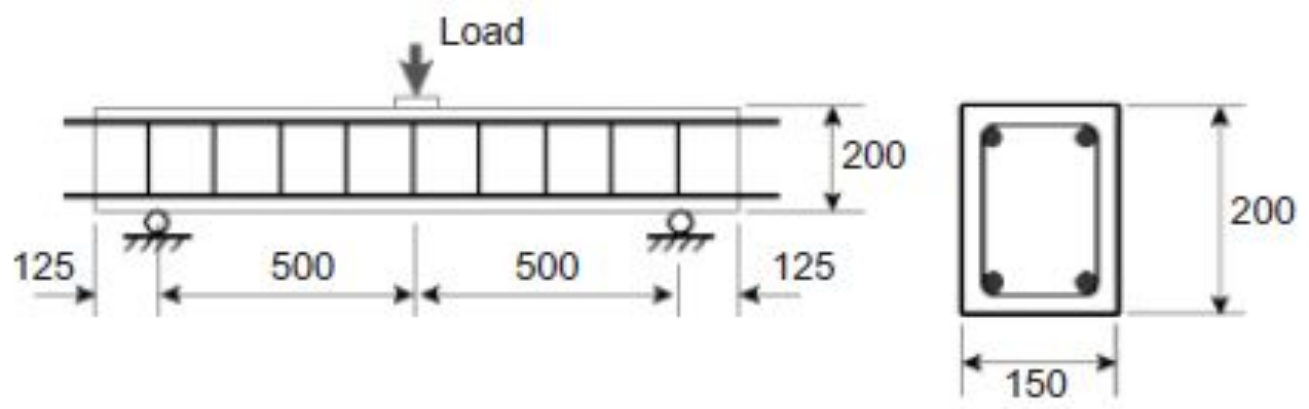

Figure 5-20 Geometry of specimen sbf (in mm) (reproduced from Cairns et al. 2008)

\subsubsection{Control specimen}

A similar modelling technique to the one used in the validation of beams with ribbed reinforcement is also adopted here. The 2D control beam with $0 \%$ corrosion is modelled first. However, since the beam reinforced by plain bars has lower bond capacity, the perfect bond assumption cannot be used. Therefore, the control specimen is modelled using the link elements but without any corrosion-induced damage (Figure 5-21).

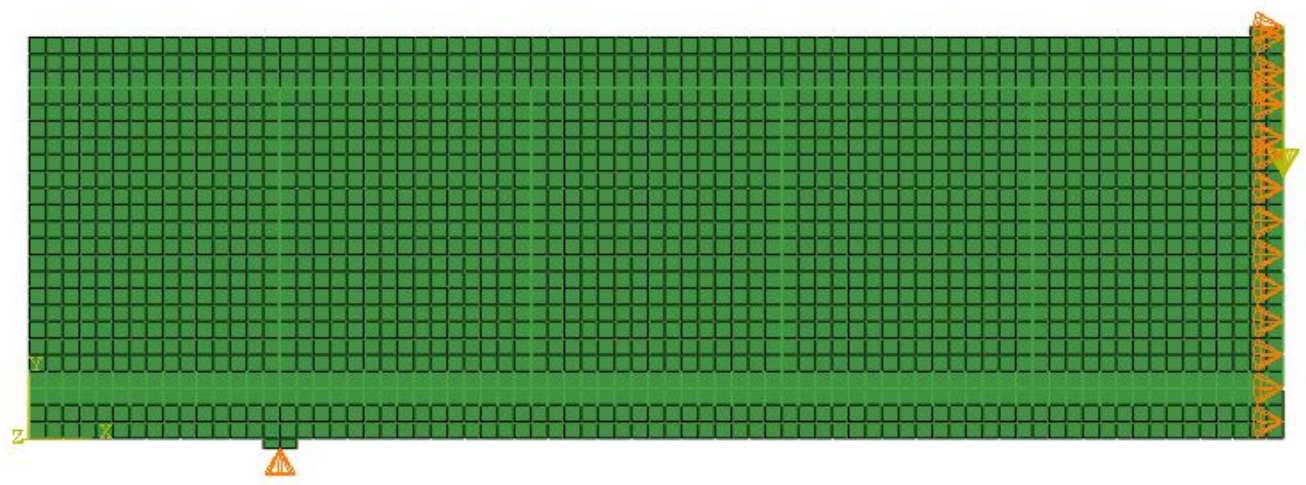

Figure 5-21 FE mesh of control beam as displayed in ABAQUS

The comparison between experimental and numerical results for the control beam is presented (see Figure 5-22). Note that only two significant points in the load-deflection curve were provided by Cairns et al. (2008): yielding of reinforcement and ultimate capacity. In Figure 5-22, the FE model 
underestimates the flexural capacity at yielding point. However, as the mid-span deflection increases, the response stiffens, which leads to a small overestimation of flexural strength (around $5 \%)$ at large levels of deformation.

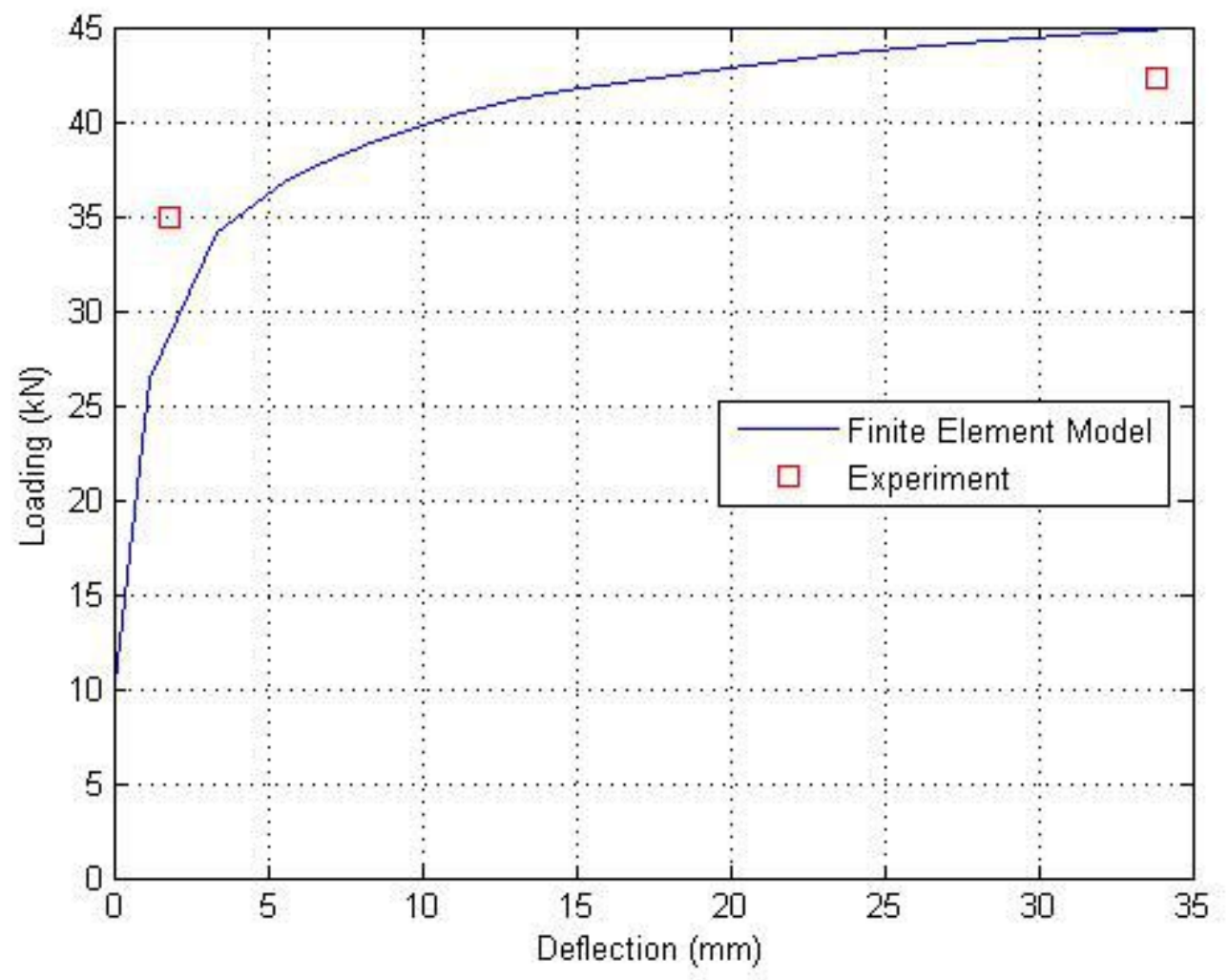

Figure 5-22 Load-displacement response for specimen sbf-00

\subsubsection{Corroded specimen}

The experimental results for group sbf are presented in Table 5-6. In this table, the corroded beams, i.e., sbf-01 and sbf-05, show similar responses, although the latter beam (sbf-05) has slightly stiffer performance, since larger flexural stiffness is observed. Also, the corroded specimens have higher flexural stiffness than the uncorroded one (sbf-00), which may result from the initial increase of bond strength due to the accumulation of corrosion by-products at the concrete/steel interface. 
Table 5-6 Experimental results for group sbf

\begin{tabular}{|c|c|c|c|c|c|c|}
\hline $\begin{array}{l}\text { Specimen } \\
\text { ref. }\end{array}$ & $\begin{array}{l}{ }^{*} \text { Flexural } \\
\text { stiffness } \\
(\mathrm{kN} / \mathrm{mm})\end{array}$ & $\begin{array}{l}\text { Yield } \\
\text { load } \\
(k N)\end{array}$ & $\begin{array}{l}\text { Deflection } \\
\text { at yield } \\
(\mathrm{mm})\end{array}$ & $\begin{array}{l}\text { Maximum } \\
\text { load } \\
(k N)\end{array}$ & $\begin{array}{l}\text { Deflection at } \\
\text { max load } \\
(\mathrm{mm})\end{array}$ & $\begin{array}{l}\text { Mean attack } \\
\text { penetration } \\
(\mathrm{mm})\end{array}$ \\
\hline sbf-00 & 17.7 & 35 & 1.8 & 42.3 & 33.8 & 0 \\
\hline sbf-01 & 33.4 & 39 & 1.3 & 51.8 & 37.0 & 0.22 \\
\hline sbf-05 & 34.9 & 43 & 1.8 & 53.1 & 56.8 & 0.3 \\
\hline
\end{tabular}

*measured by overall deformations

Using the FE model that accounts for corrosion-induced damages, the load-deflection responses for sbf-01 and sbf-05 are illustrated in Figure 5-23 and Figure 5-23, respectively.

Figure 5-23 showcases good agreement between the numerical and experimental results of specimen sbf-01, since the FE model for sbf-01 captures the two significant points provided by the experimental results. Also, both sets of results have a similar flexural stiffness before yielding of the specimen. In Figure 5-24, although a reasonably good correlation is noted in the comparison, the FE analysis of specimen with $0.3 \mathrm{~mm}$ attack penetration (sbf-05) tends to slightly underestimate the flexural response (for both yielding and maximum points). Overall, the finite element models were able to reproduce the experimental data. 


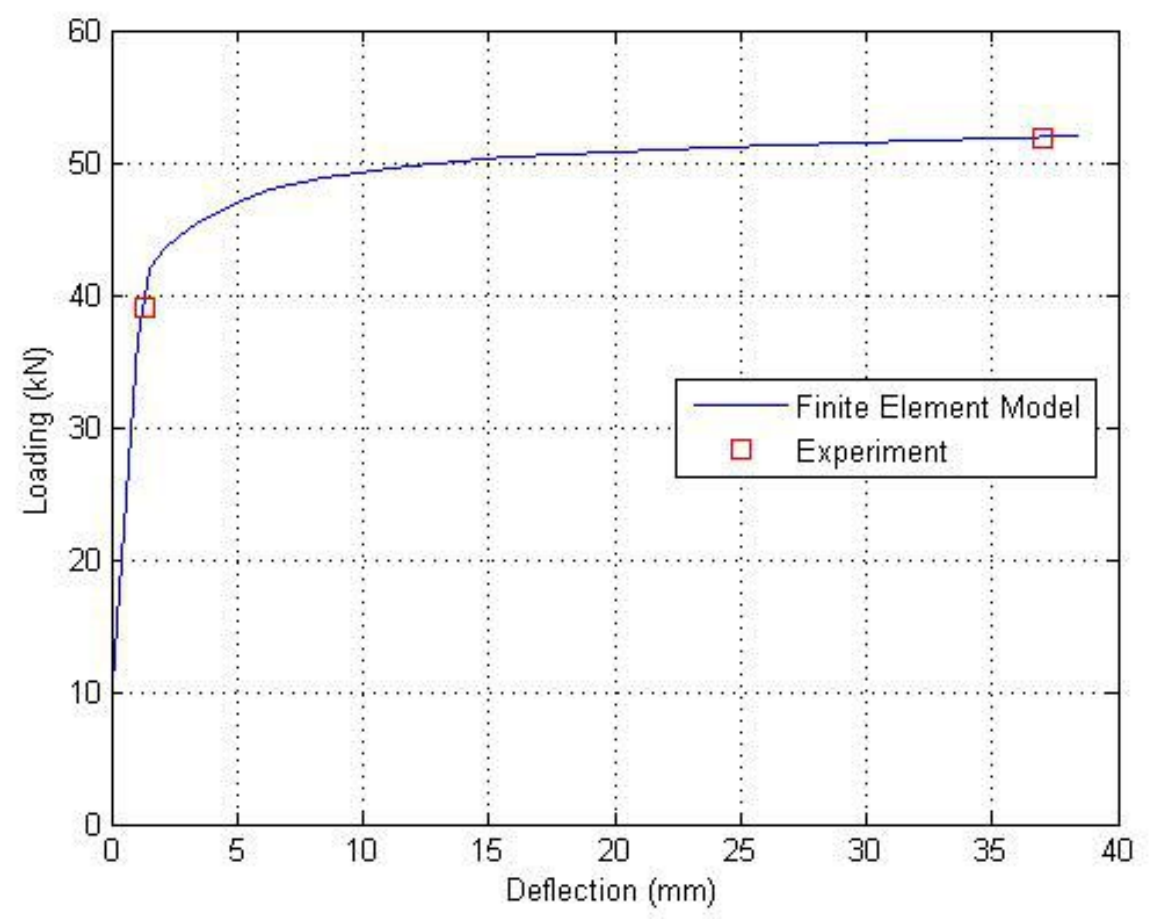

Figure 5-23 Load-displacement response for specimen sbf-01

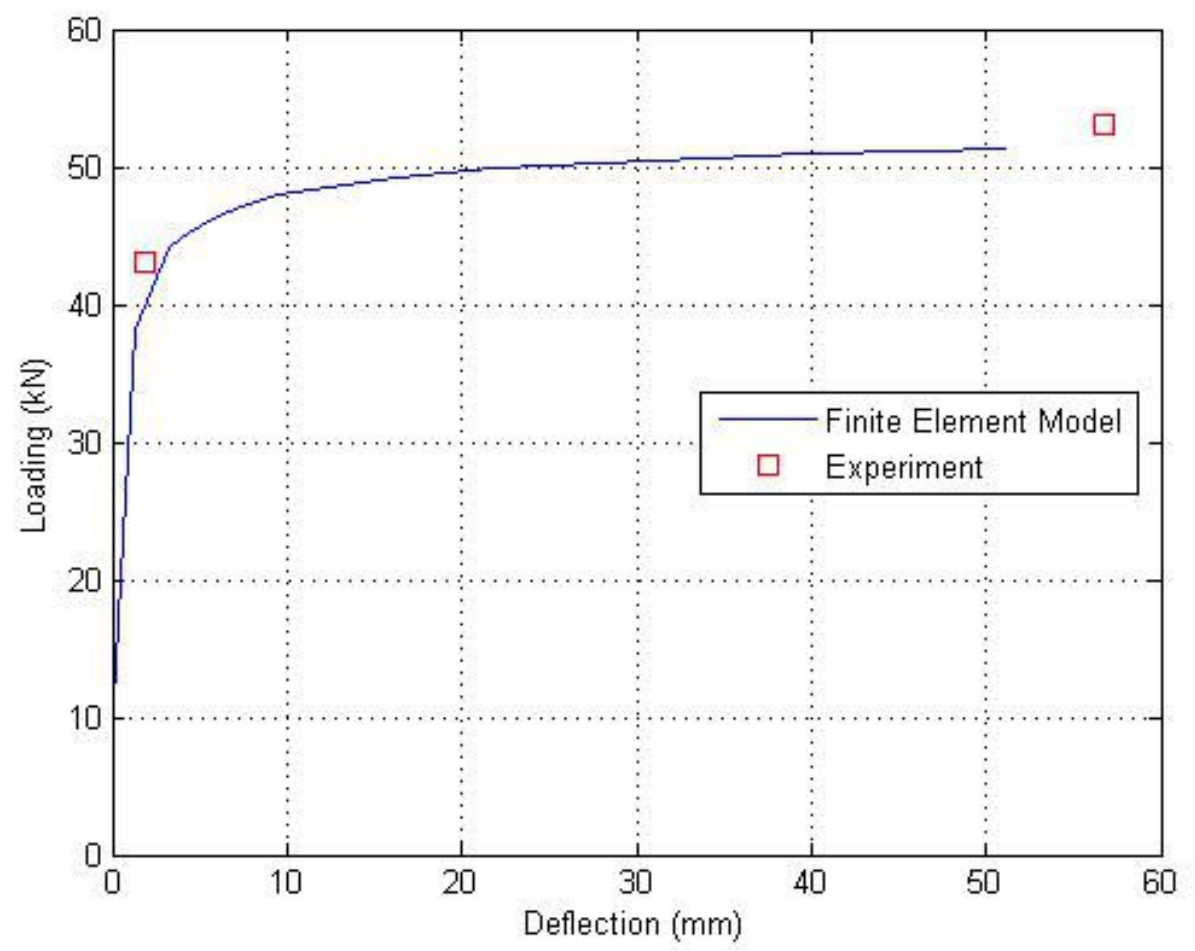

Figure 5-24 Load-displacement response for specimen sbf-05 
The three sets of numerical results (sbf-00, sbf-01 and sbf-05) are compared in Figure 5-25. Although corrosion-induced damages are included in the analyses, a stiffer flexural response as corrosion increases is still observed; this is due to a higher bond stress resulting from the enhancement of confining stress at the interface and reflects the experimental observations reported by Cairns et al. (2008)

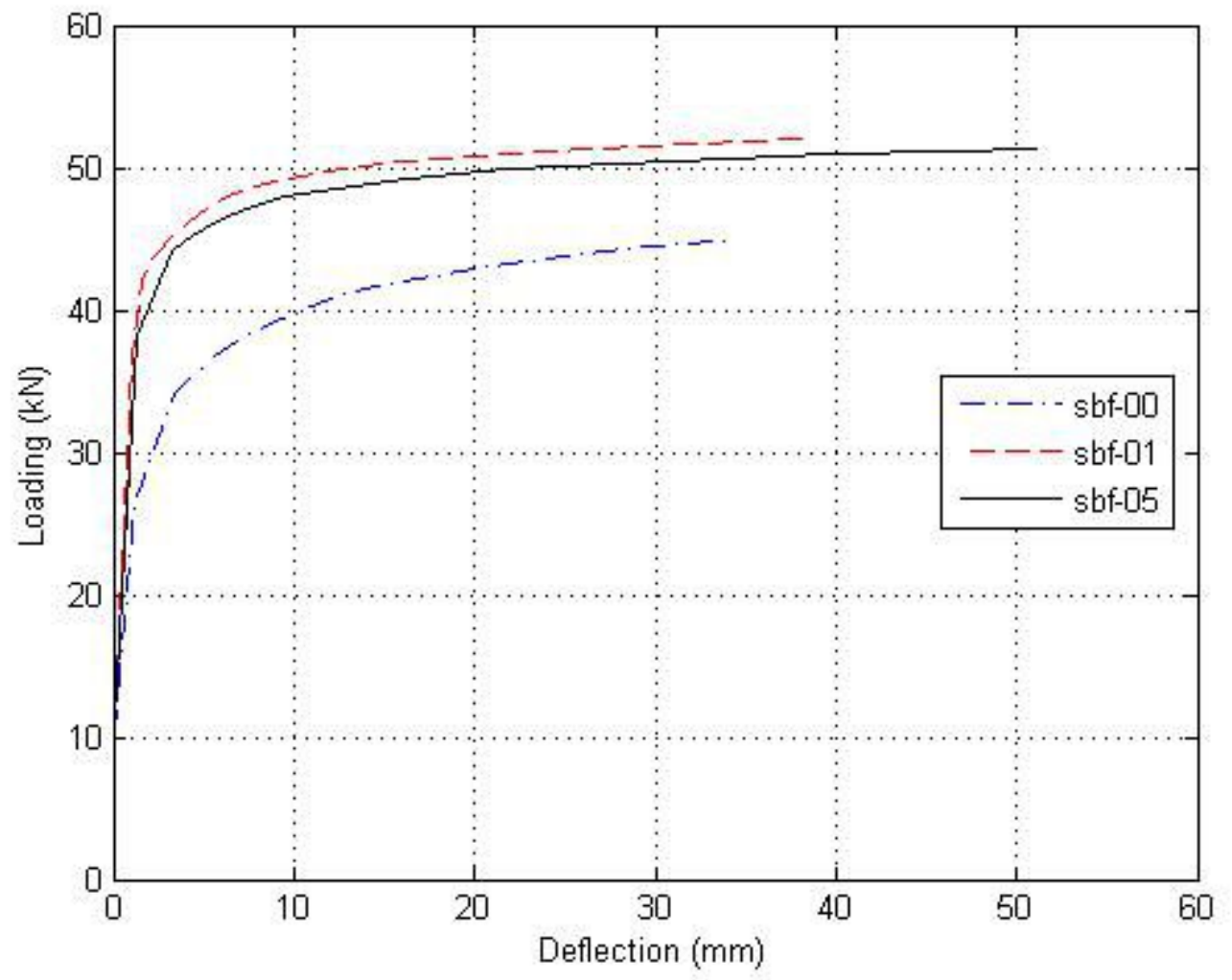

Figure 5-25 Comparison of finite element models

However, unlike the results observed in the experiments, wherein the specimen with the highest level of corrosion (sbf-05) had the highest flexural stiffness, the numerical results of specimen sbf-05 presented a softer response compared to sbf-01. It can be explained by the fact that according to the analytical bond evaluation for specimens tested in Cairns et al. (2008) (Figure $5-26)$, the bond deterioration starts at $0.1-\mathrm{mm}$ attack penetration, leading to a lower bond capacity in sbf-05. 


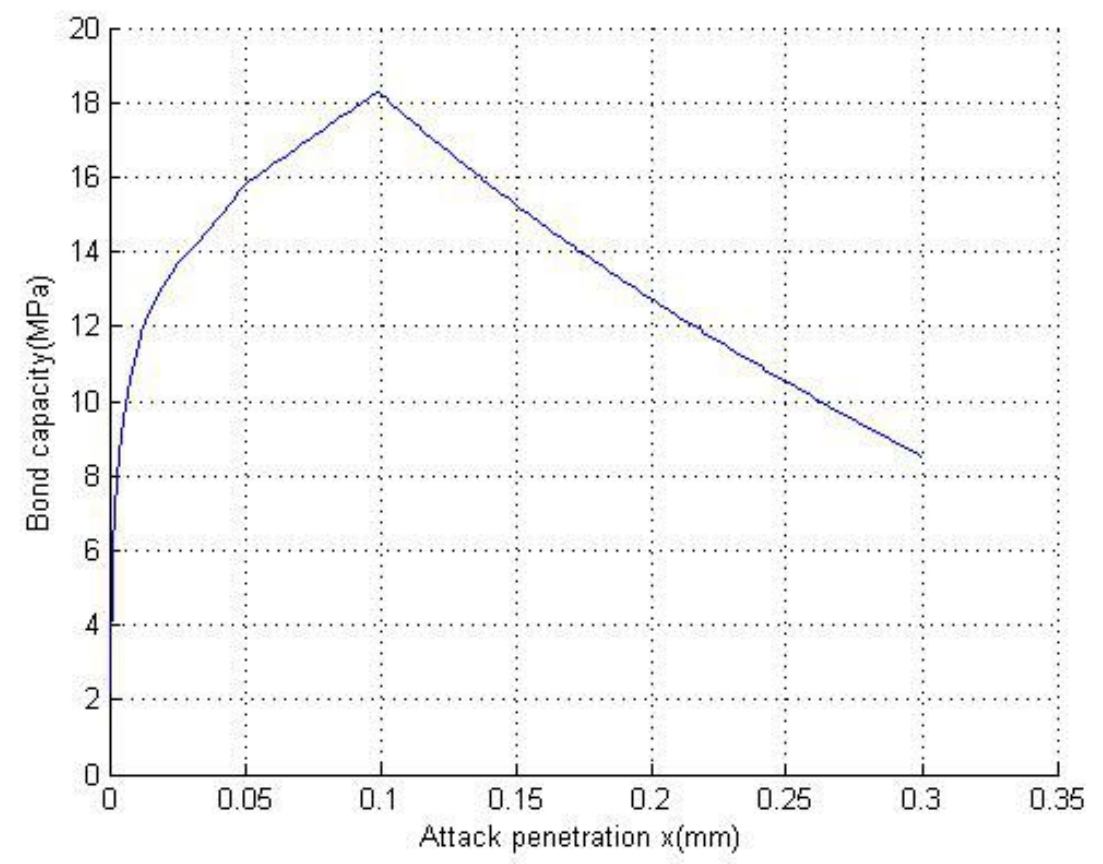

Figure 5-26 Analytical evaluation of bond strength for specimens in group sbf

This scenario may result from the selection of the volume ratio between oxides and virgin steel $n$, since it can impact the rate of bond deterioration. For instance, a higher value of $n$ can contribute to an earlier bond deterioration and a shorter period of initial increase in bond strength. In this validation, the ratio $n$ is chosen as 2 according to the literature review. However, based on the results from the numerical model, a smaller $n$ should have been selected for this experiment, which would have set the attack penetration for bond deterioration to a higher value than $0.1 \mathrm{~mm}$.

Thus, to study the influence of the selection of this parameter, a parametric investigation using the FE model with varying ratios of $n$ is performed in Chapter 6 . 


\subsubsection{Comparison with Du et al. (2007)}

The assumption of uniformly distributed corrosion along the reinforcing bars may not be applicable for all corrosion cases. For instance, corrosion-induced damage is commonly found in structures in coastal or cold regions, where concrete cover contamination by chlorides is the major cause of reinforcement corrosion. It is commonly observed in RC structures affected by chloride-induced corrosion that damage is caused by localized corrosion created by formation of pits on the steel bar surface. In order to evaluate the structural performance of concrete structures suffering from chloride-induced corrosion, the influence of localized corrosion should be considered.

To validate the applicability of the finite element model to beams with localized corrosion, the bending tests of corroded beams performed by Du et al. (2007) were analyzed. Only the mid-span regions of these beams were corroded artificially before being loaded. The beam specimens had dimensions of $150 \times 200 \times 2,100 \mathrm{~mm}$, and the length of the corroded tension bar was $600 \mathrm{~mm}$ (Figure 5-27).

There were 19 sets of specimens tested in this experimental study; they were identified by percentage of tension reinforcement and the location where corrosion was induced (compression bars, tension bars and/or stirrups) and. The specimens whose tension bars were corroded, i.e., control beam (T680) and 8.8\% corroded beam (T682) (measured by mass loss) were selected in this study to further validate the FEM. As the concrete cube strength is given as $36 \mathrm{MPa}$, the remaining material parameters can be evaluated from CEB-FIP (2010) and are summarized in Table 5-7 
Table 5-7 Material properties of specimens tested by Du et al. (2007)

\begin{tabular}{|c|c|}
\hline \multicolumn{2}{|l|}{ Concrete } \\
\hline Compressive strength $f_{c}^{\prime}$ & $36 \mathrm{MPa}$ \\
\hline Young's modulus $E_{c}$ & $33.6 \mathrm{GPa}$ \\
\hline Tensile strength $f_{t}^{\prime}$ & $3.02 \mathrm{MPa}$ \\
\hline \multicolumn{2}{|l|}{ Steel } \\
\hline \multicolumn{2}{|l|}{ Tension bar } \\
\hline Diameter $d_{b}$ & $16 \mathrm{~mm}$ \\
\hline Yielding strength $f_{y}$ & $529 \mathrm{MPa}$ \\
\hline Young's modulus $E_{s}$ & $201 G P a$ \\
\hline \multicolumn{2}{|l|}{ Stirrup and compression bar } \\
\hline Diameter $d_{s}$ & $8 \mathrm{~mm}$ \\
\hline Yielding strength $f_{y}$ & $526 \mathrm{MPa}$ \\
\hline Young's modulus $E_{s}$ & $203 G P a$ \\
\hline \multicolumn{2}{|l|}{ Interface } \\
\hline *Initial friction coefficient $\mu_{0}$ & 0.8 \\
\hline *Chemical adhesion stress $F a$ & $0.8 \mathrm{MPa}$ \\
\hline \multicolumn{2}{|l|}{ Rust product } \\
\hline $\begin{array}{l}* \text { Ratio between the volume of oxides products } \\
\text { and virgin steel } n\end{array}$ & 2 \\
\hline
\end{tabular}

Note: Properties marked by * are selected according to the literature review. 


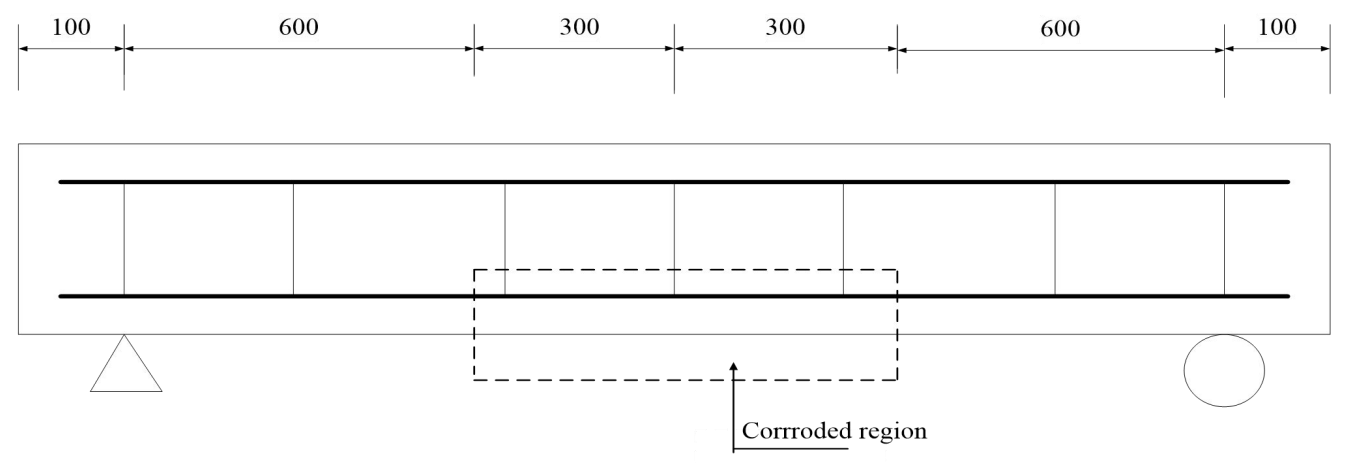

Figure 5-27 Bending test setup carried out by Du et al. (2007)

\subsubsection{Control specimen}

The control beam was modelled prior to the introduction of corrosion-induced damages. The FE meshing is $100 \times 20$ plane-stress elements and shown in Figure 5-28. As in the analysis of the beams tested by Mangat (1999), the difference between the FE model with perfect bond and with $0 \%$ corrosion level link elements is not significant. Hence, outside the corrosion region, perfect bond is assumed to reduce the required time for modelling. As a result, the link elements were not used in modelling and analyzing the control specimen.

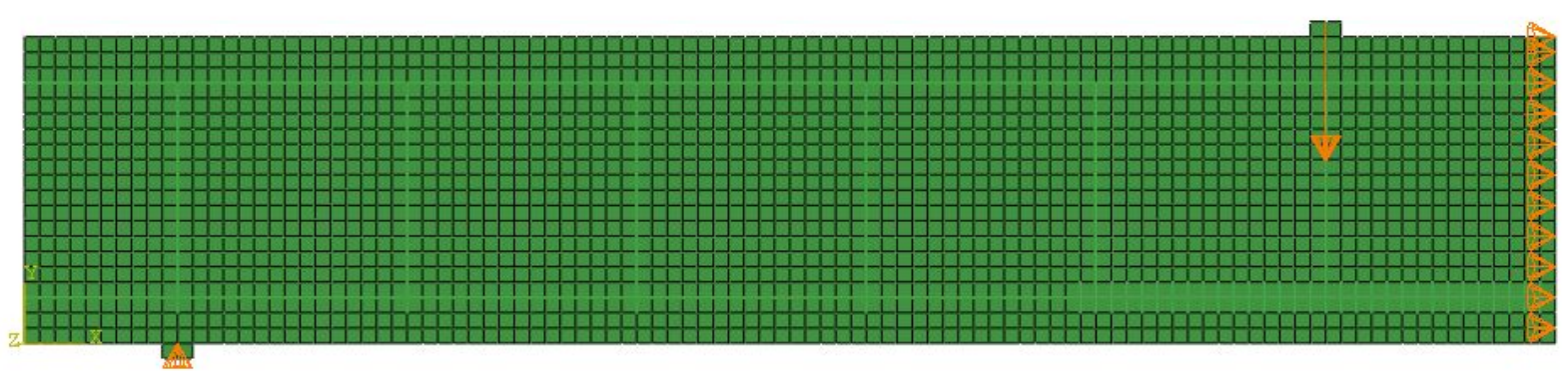

Figure 5-28 FE mesh of control beam as displayed in ABAQUS

The flexural response of the control beam is illustrated in Figure 5-29. The finite element model is able to simulate the experimental result reasonably well, although it is observed from the figure 
that the numerical results had an initial stiffer response and a slightly higher flexural strength.

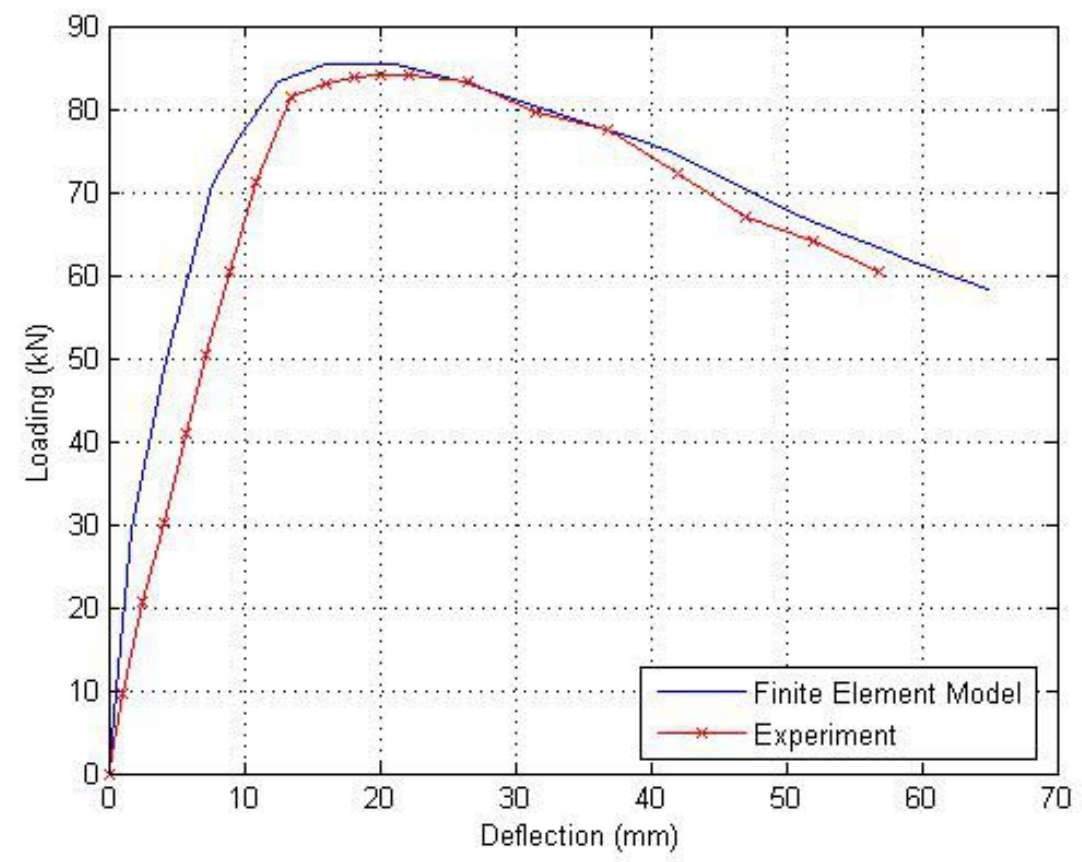

Figure 5-29 Load-defection response for control specimen in Du et al. (2007)

\subsubsection{Corroded specimen}

The corrosion level in the experiment was measured by mass loss, which can be evaluated by:

$$
M_{\text {loss }}=1-\frac{\left(r_{b}-x\right)^{2}}{r_{b}^{2}}
$$

where $M_{\text {loss }}$ is the percentage of mass loss, $r_{b}$ is the original radius of rebar and $x$ is the attack penetration.

Hence, a corrosion attack penetration is calculated as $0.36 \mathrm{~mm}$ from an $8.8 \%$ mass loss. In the experiment, although the reinforcing steel bars were corroded separately, the 
non-current-impressed bars were also corroded within the intended corrosion region, which means the transverse reinforcement in the selected specimen T682 was also damaged. However, the study of structural deterioration due to corrosion of stirrups is not the focus of this work. Therefore, the influence of corrosion-induced damage on the stirrups was not taken into consideration in the finite element model. Since the structural damage resulting from corrosion was only introduced within the corroded region of the tension bar, the link elements and the equivalent expansion strain were applied at the highlighted (corroded) region in Figure 5-30.

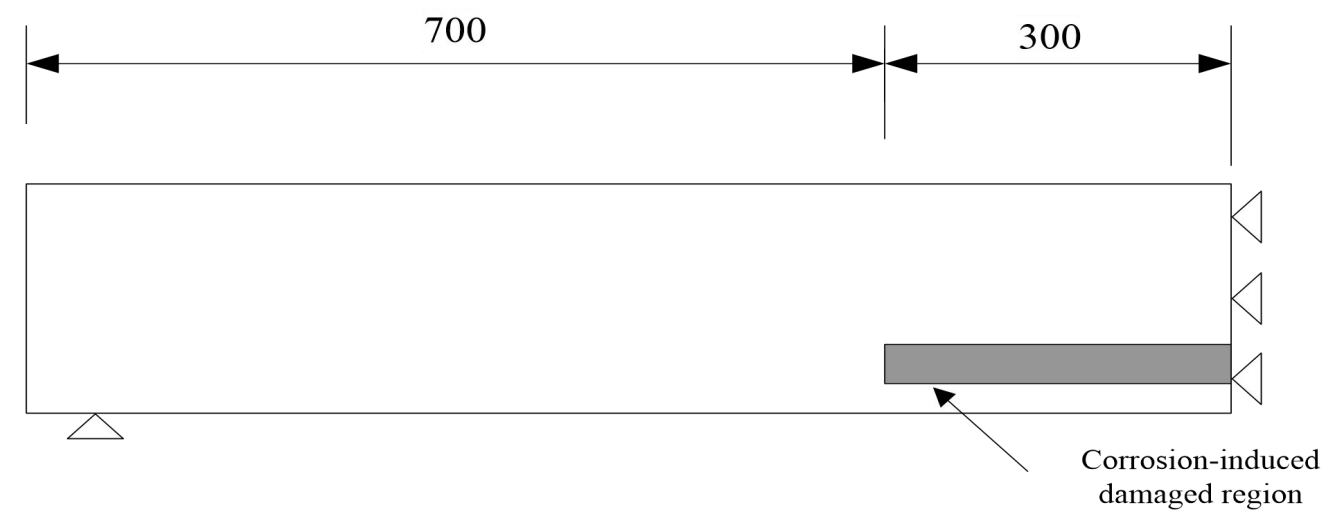

Figure 5-30 Corrosion-induced damaged region in FEM

Figure 5-31 presents the load-deflection curve for the FE analysis of the beam with localized corrosion along its mid-span. As shown in the figure, the numerical results compare well with published data in Du et al. (2007), as the damaged FE model can simulate the same degree of flexural deterioration. The finite element model with corrosion-induced damage slightly overestimates the initial stiffness and flexural capacity. This might be explained on the basis of the overlooked shear reinforcement corrosion, which can lead to further deteriorated flexural response. 


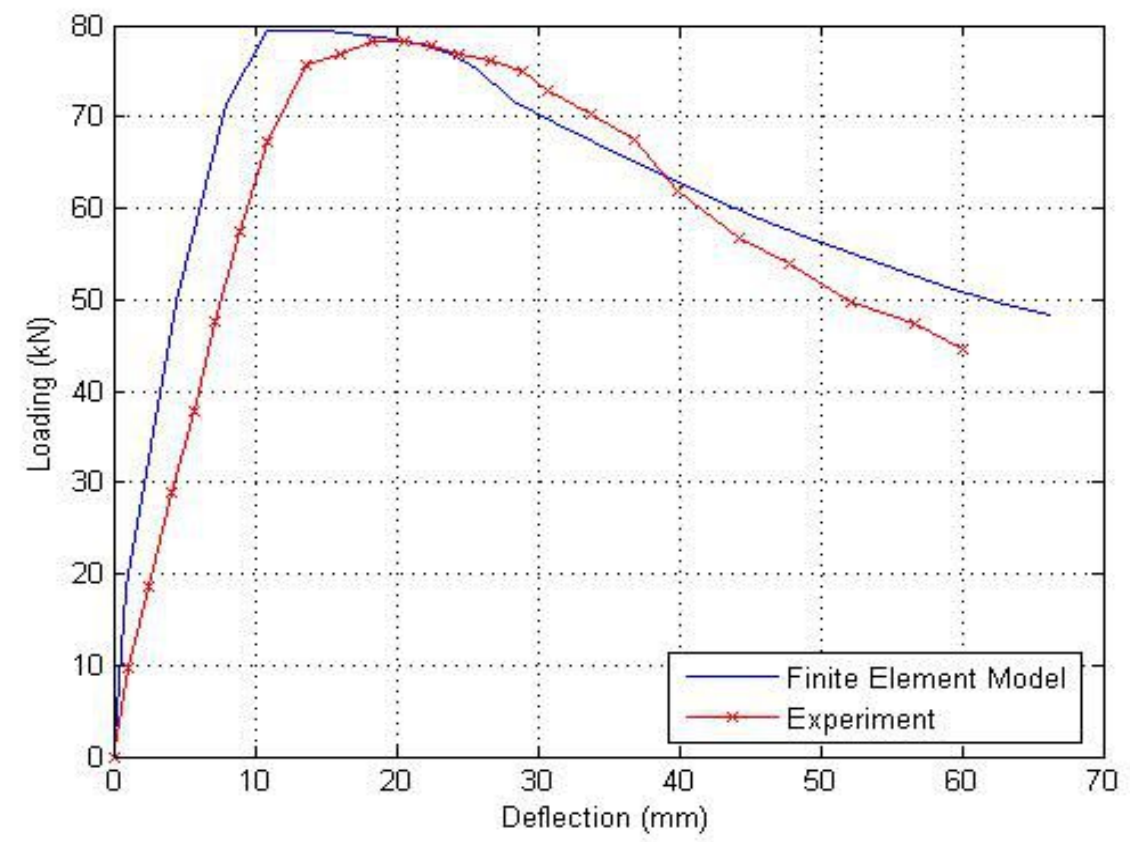

Figure 5-31 Load-defection response for corroded specimen with 8.8\% mass loss along mid-span

The comparison of the load-deformation responses of the FE analysis without and with corrosion is presented in Figure 5-32. Although both models estimate the same flexural stiffness before yielding, there is flexural stiffness and strength deterioration in the corroded specimen, becoming increasingly noticeable at large mid-span deflections.

In Du et al. (2007), corrosion-induced damage was only introduced along the mid-span region. However, the effect of different locations for corroded reinforcement has not been investigated. Therefore, it is worthwhile to extent this study by analyzing the FE beams with corrosion occurring along different regions of the reinforcement. Results of this analysis are presented in Chapter 6. 


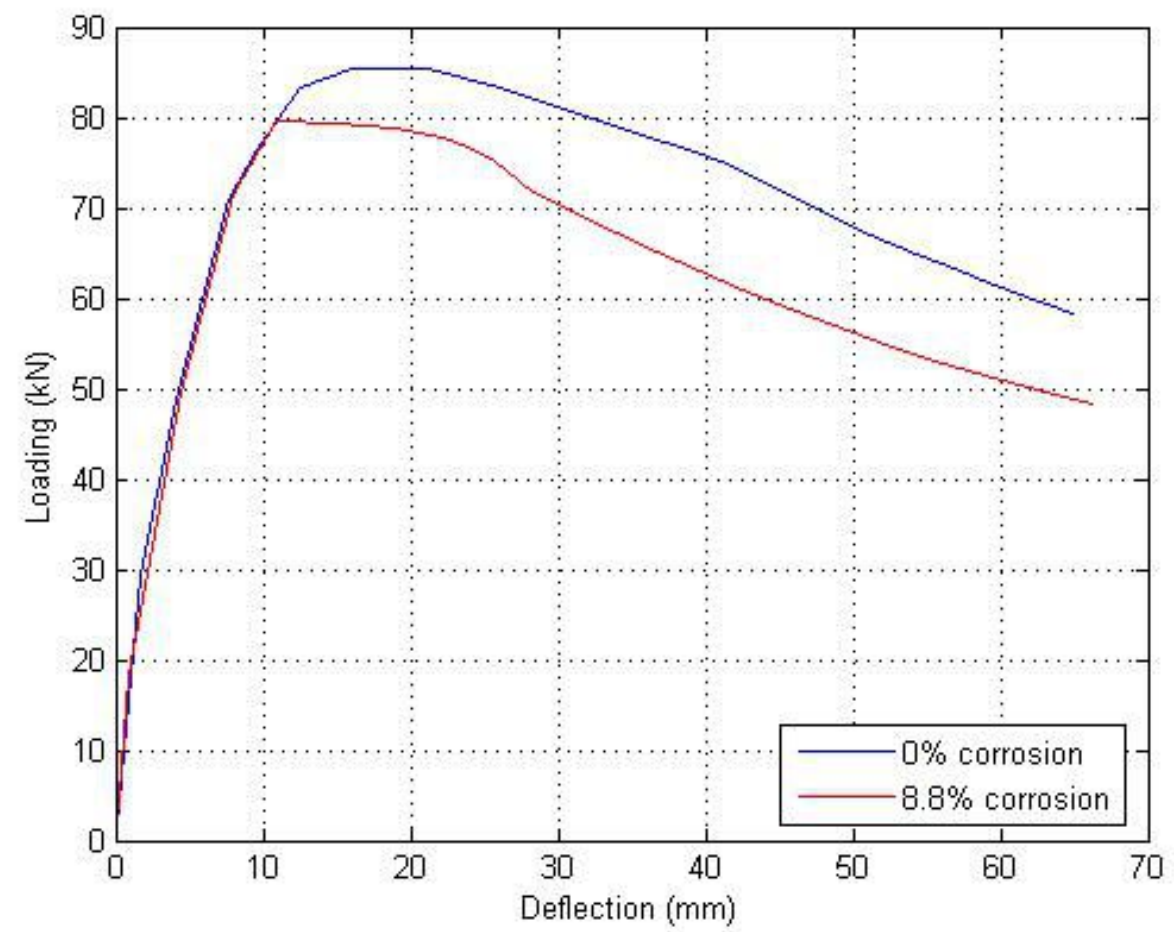

Figure 5-32 Comparison of load-defection responses for FE control and corroded specimens in Du et al. (2007)

\subsection{Summary}

The analytical and finite element models are verified against experimental observations and previous numerical studies. The following conclusions can be drawn:

1) The analytical model for bond is able to capture degradation experienced with increasing corrosion levels.

2) The application of link elements that mimic the bonding interaction between concrete and rebar successfully models the structural response of control flexural members.

3) Good agreement has been showcased between the finite element model with corrosion-induced damages accounted for and artificially corroded specimens tested by other researchers. 
After the validation of both models, they are utilized to conduct a parametric investigation to study how the important effects identified in the verification study impact the deterioration of an $\mathrm{RC}$ flexural member affected by reinforcement corrosion. The results are presented in the following Chapter 6. 


\section{Parametric Study}

\subsection{Introduction}

This chapter presents the results of a parametric study conducted using the analytical and finite element models developed and validated in previous chapters, in order to investigate the influence of various physical properties on the bond capacity and residual flexural response of beams when corrosion-induced damage is present. Based on the results from the validation analyses presented

in Chapter 5, a parametric study of the effect of (i) concrete strength, (ii) cover-to-bar diameter ratio, and (iii) volume ratio between oxides and virgin steel was carried out using the analytical model introduced in Chapter 3. The parametric study was performed on the numerical pullout test conducted by Lundgren (2007), used for validation in Chapter 5 .

The finite element model presented in Chapter 4 was then used to study (i) the influence of corrosion-induced damage (i.e., the damage on the reinforcing bar, concrete and bonding) and (ii) corrosion location on the residual behaviour of RC beams affected by flexural reinforcement corrosion. The parametric analysis using the FE model used as a reference the RC beams tested by Mangat (1999).

\subsection{Parametric study using the analytical model}

Since the analytical evaluation of the bond capacity of group\#1 specimens analyzed by Lundgren (2007), whose material parameters are summarized in Table 6-1, has been validated in Chapter 5, this group of specimens was chosen as the control specimen in the parametric study. An illustration of this control specimen is shown in Figure 5-4. 
Table 6-1 Material data used in Lundgren (2007)

\begin{tabular}{|l|l|}
\hline Concrete & $40 \mathrm{MPa}$ \\
\hline Compressive strength $f_{c}^{\prime}$ & $\begin{array}{l}1 \text { (the thickness of concrete cover } \mathrm{C}=20 \\
\mathrm{~mm})\end{array}$ \\
\hline Cover-to-bar diameter ratio $(\mathrm{C} / \mathrm{d})$ & 0.8 \\
\hline Interface & $2 \mathrm{MPa}$ \\
\hline Initial friction coefficient $\mu_{0}$ & \multicolumn{2}{|l|}{} \\
\hline Chemical adhesion stress $\mathrm{Fa}$ & 2 \\
\hline Rust product & $\begin{array}{l}\text { Ratio between the volume of oxides product } \\
\text { and virgin steel } n\end{array}$ \\
\hline
\end{tabular}

\subsubsection{The effect of concrete strength}

As mentioned in Chapter 5, if any of the material input parameters needed for the analysis is not provided by Lundgren (2007), it is estimated from the material models suggested by the CEB-FIP Model Code (2010), which provides important mechanical properties for concretes with different compressive strengths. However, the models found in CEB-FIP (2010) were still used to investigate the influence of concrete strength by estimating the corresponding tensile strength and elastic modulus (see Table 6-2). The bond capacity as calculated by the analytical model is illustrated in Figure 6-1 for specimens made of concrete with compressive strengths of $30 \mathrm{MPa}, 40$ $\mathrm{MPa}$ and $50 \mathrm{MPa}$. 
Table 6-2 Material data for concrete as provided by CEB-FIP(2010)

\begin{tabular}{|c|c|c|}
\hline Compressive strength $f_{c}^{\prime}$ & Tensile strength $f_{t}^{\prime}$ & Elastic modulus $E_{c}$ \\
\hline $30 \mathrm{MPa}$ & $2.9 \mathrm{MPa}$ & $33.6 \mathrm{GPa}$ \\
\hline $40 \mathrm{MPa}$ & $3.5 \mathrm{MPa}$ & $36.3 \mathrm{GPa}$ \\
\hline $50 \mathrm{MPa}$ & $4.1 \mathrm{MPa}$ & $38.6 \mathrm{GPa}$ \\
\hline
\end{tabular}

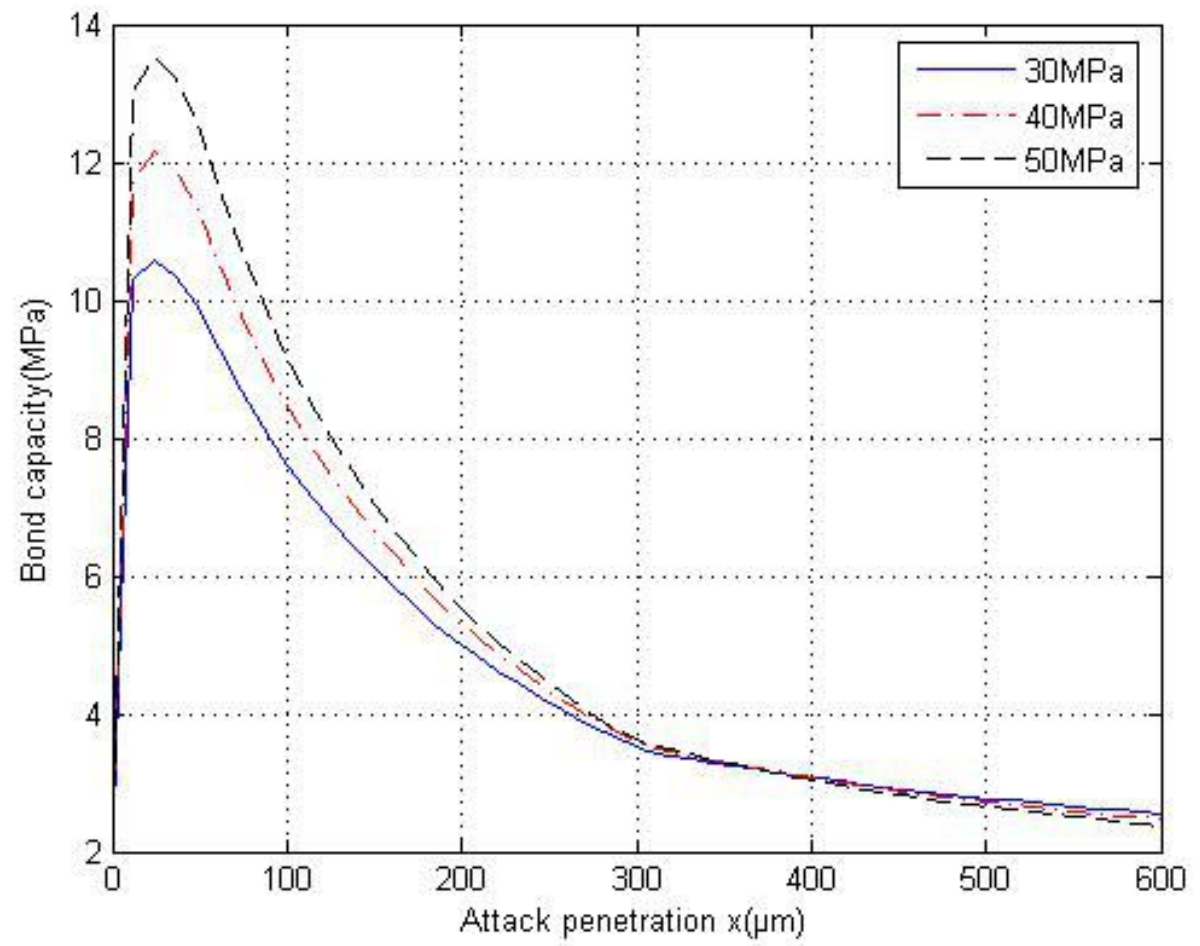

Figure 6-1 Comparison of bond capacity for specimens with different concrete compressive strength

It is observed from Figure 6-1 that the model with higher concrete strength and stiffness tends to have higher bond capacity at low levels of reinforcement corrosion in comparison to the model with lower concrete grade. This phenomenon is anticipated, since the ultimate confinement stress is evaluated by the thick-wall cylinder analogy in the analytical model, and the tensile capacity of the concrete cover is directly related to the tensile strength of the concrete. The higher this capacity is, the higher the confining stress and resistance to cracking provided by the concrete 
cover are, leading to a higher bonding capacity of the reinforcing bar.

However, a more rapid bonding deterioration is also noted in the specimen with higher concrete grade, and it results from the selection of post-cracking material models. In this work, the post-cracking model for concrete was introduced in Chapter 4, wherein the ultimate strain $\varepsilon_{u}$ is influenced by the fracture energy of concrete (Eq 3-31) and calculated using Eq 3-32, where the characteristic width $w_{c}$ is determined by the maximum aggregate size in concrete, which is assumed to be $10 \mathrm{~mm}$ for all specimens. For comparison, the fracture energies $G_{f}$ and ultimate strains $\varepsilon_{u}$ for different concretes are listed in Table 6-3, and the corresponding tensile stress-tensile strain curves are plotted in Figure 6-2.

Table 6-3 Fracture energy $G_{f}$ and ultimate strain $\varepsilon_{u}$ for different concretes

\begin{tabular}{|l|l|l|}
\hline $\begin{array}{l}\text { Compressive } \\
\text { strength }(\mathrm{MPa})\end{array}$ & Fracture energy $G_{f}=73\left(f_{c}^{\prime}\right)^{0.18}(\mathrm{~N} / \mathrm{m})$ & Ultimate strain $\varepsilon_{u}=\frac{2 G_{f}}{f_{t}^{\prime} w_{c}}$ \\
\hline 30 & 135 & 0.00287 \\
\hline 40 & 142 & 0.00269 \\
\hline 50 & 148 & 0.00242 \\
\hline
\end{tabular}

In Figure 6-2, although the higher grade concrete has higher tensile strength $f_{t}^{\prime}$ and fracture energy $G_{f}$, its ultimate strain $\varepsilon_{u}$ is smaller according to the softening model for tensile strength suggested by Bazant (1986). Therefore, the tensile stress of lower grade concrete declines to zero with increasing tensile strain at a slower rate. For instance, at a strain of $1.65 \times 10^{-3}$ in Figure 6-2, the tensile strength of concrete with $30 \mathrm{MPa}$ compressive strength exceeds the tensile strength in a concrete with $50 \mathrm{MPa}$ compressive strength, and it continues to provide higher tensile resistance at 
larger levels of tensile strain.

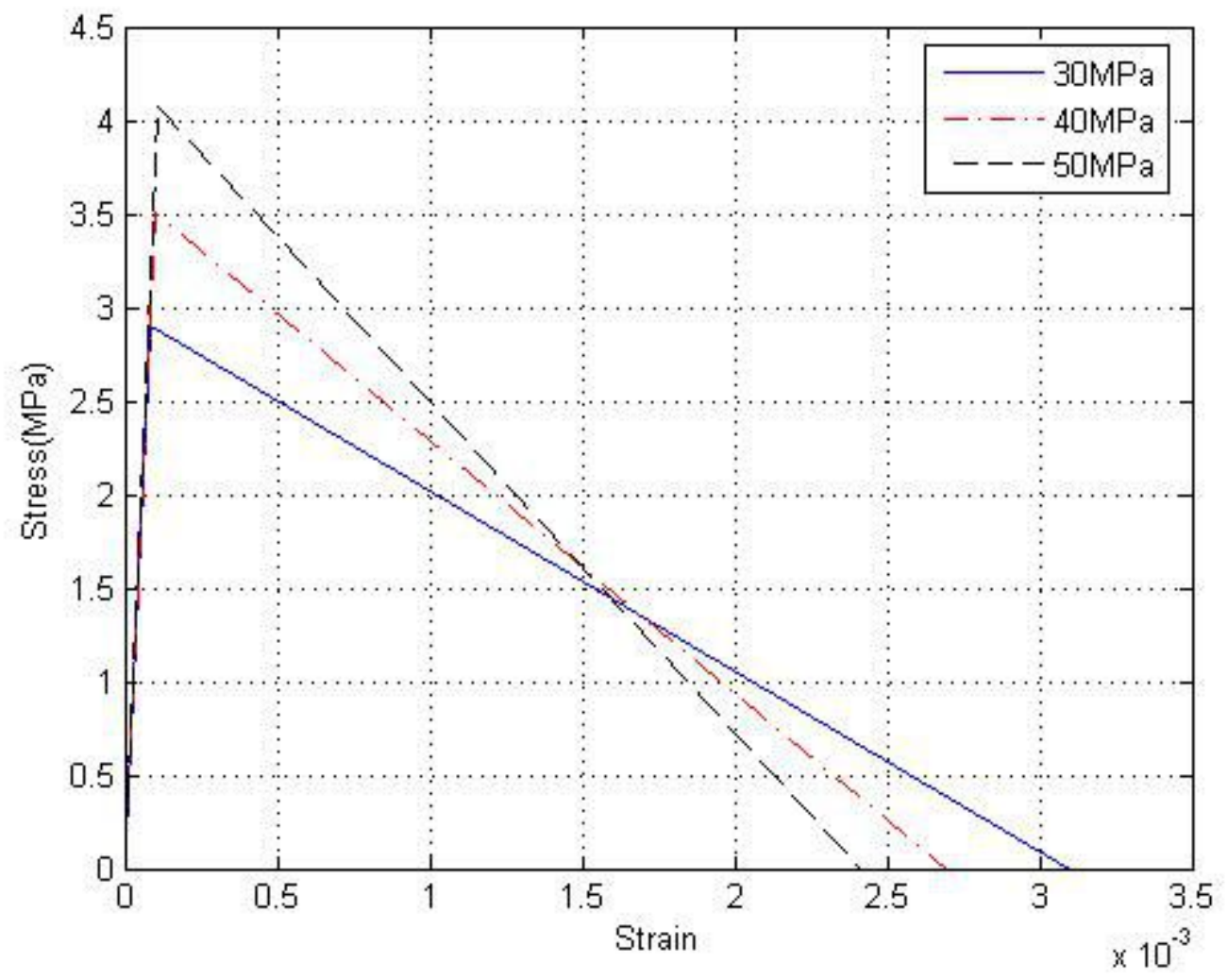

Figure 6-2 Tensile stress-strain relation for concretes with different compressive strengths

\subsubsection{The effect of the ratio $n$}

According to the analytical model presented in Chapter 3, the approximation of radial displacements along the concrete cover is important for evaluating the tensile strain in the thick-walled cylinder, and it is greatly impacted by the ratio between the volume of oxide products and virgin steel $n$. The ratio $n$ corresponding to different corrosion products is shown in Figure 3-2. To investigate the influence of this parameter, the analytical model was used to calculate the bond capacity of specimens with a ratio $n$ equal to 2, 2.5 and 3, which are marked as N2, N3.5 and N3, respectively. The analytical results are plotted in Figure 6-3. 


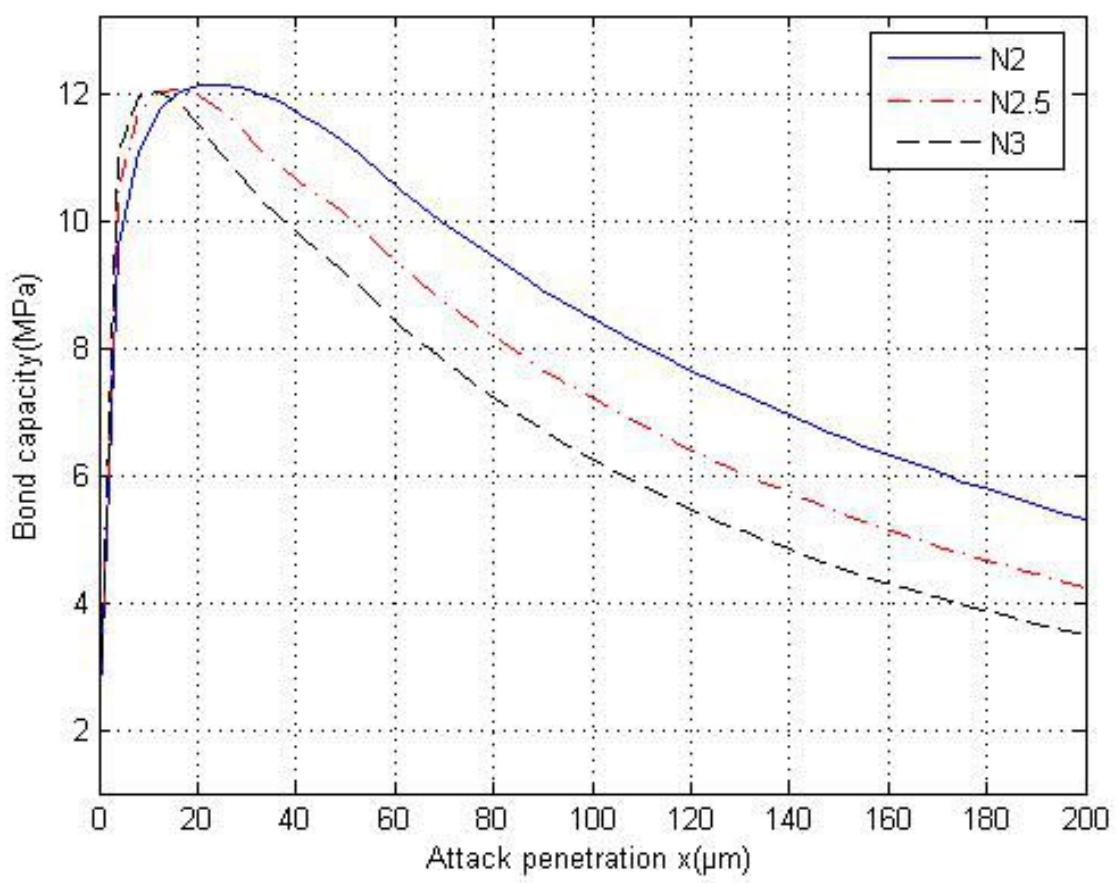

Figure 6-3 The comparison of bond capacity of specimens N2, N3.5 and N5

Figure 6-3 indicates that models with different values of $n$ have similar bond capacities but different rates of deterioration. The specimen with the highest value of $n$ (N3 specimen) reaches its maximum value at a smaller value of attack penetration $(10 \mu \mathrm{m})$ but degrades to zero at a more rapid rate, whereas the bond capacities of models with lower $n$ (2 and 2.5) peak at a larger attack penetration ( $22 \mu \mathrm{m}$ and $18 \mu \mathrm{m}$, respectively). In addition, the fact that similar bond capacities are observed in Figure 6-3 implies that the ratio between the volume of oxides and virgin steel only controls the rate of bond degradation. It can be explained by the fact that in the analytical model, the value of $n$ is used to evaluate the volume of oxide products, i.e., $\Delta V_{r}=n \Delta V_{s}$, where $V_{r}$ is the volume of oxides and $V_{s}$ is the virgin steel. A higher volume of rust products results in larger radial displacement at the concrete/steel interface, initiating cracking earlier on, but it does not affect the confining strength in the thick wall cylinder as no confinement condition is altered.

Lundgren (2002) suggested that the value of $n$ varies based on the different corrosion products 
formed around the reinforcing steel. It is realized that, although the analytical model is highly sensitive to this parameter, the assessment of the actual corrosion products formed might not be practical for an existing affected structure. Therefore, evaluations performed with the analytical model can be based on a range of reasonable assumptions for $n$ if this kind of assessment is not feasible.

\subsubsection{The effect of cover-to-rebar diameter ratio $(C / d)$}

The ratio of the minimum thickness of the concrete cover to the rebar diameter, $C / d$, is a parameter that provides an indication of the protection provided against corrosion, and its effect on bonding capacity has been investigated by many researchers (e.g., Al-Sulaimani 1990). Minimum concrete covers required by CAN/CSA-A23.1-04 are $40 \mathrm{~mm}$ for $\mathrm{RC}$ beams exposed to freezing and thawing in a saturated condition but not to chlorides, and $60 \mathrm{~mm}$ for $\mathrm{RC}$ beams exposed to more severe environments where chlorides are anticipated. The structural members with thicker cover not only have a higher physical protection against corrosion initiation, but also provide stronger mechanical resistance to bond degradation. Therefore, to study the bond deterioration of $\mathrm{RC}$ members with various protection covers, specimens with a concrete cover of $20 \mathrm{~mm}, 40 \mathrm{~mm}$ and $60 \mathrm{~mm}$ were modelled and analyzed with the analytical model, resulting in cover-to-rebar diameter (C/d) ratios of 2, 4, and 6, respectively, denoted as R2, R4 and R6.

Figure 6-4 illustrates that the bond capacity of specimens with a higher $C / d$ ratio have a longer initial build up to ultimate bond stress, which occurs at a higher level of corrosion attack. The improvement in bond capacity results from a higher resistance to cracking and larger confining stress when the concrete cover increases. 


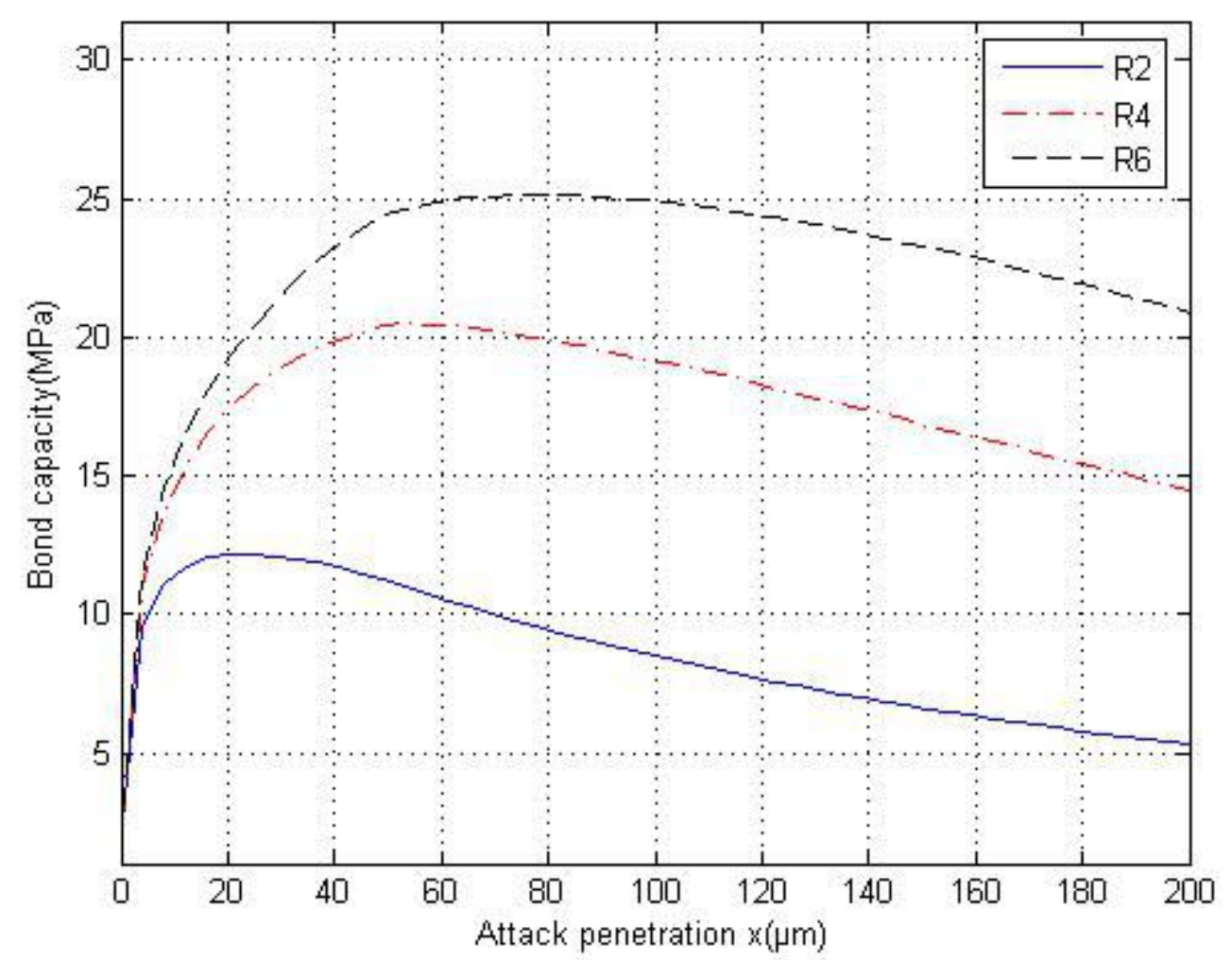

Figure 6-4 Comparison of bond capacity for specimens with $C / d=2(\mathrm{R} 2), C / d=4$ (R4) and $C / d=6$ (R6).

\subsection{Parametric study using the finite element model}

\subsubsection{The effect of different types of corrosion-induced damage}

As mentioned in Chapters 3 and 4, there are three kinds of corrosion-induced damage implemented in the finite element model: (1) the reduction of the cross-sectional area of the reinforcing steel bar, (2) concrete cracking due to corrosion products expansion, and (3) bond deterioration. In order to investigate how each of those 3 types of corrosion-induced damage impact the flexural behaviour of an affected RC beam, finite element analyses were conducted accounting for only one of the models above at a time. 
The RC beam with 5\% corrosion mass loss in the bending test performed by Mangat (1999), validated in Chapter 5, was selected for this study. The following finite element analyses were conducted: (1) FE model with only 5\% reduction of cross-sectional area of the reinforcing steel bar element (denoted as FE5\%S), (2) FE model with only concrete cracking due to 5\% corrosion expansion (denoted as FE5\%C), and (3) FE model with only the bond deterioration corresponding to a 5\% steel mass loss (denoted as FE5\%B). Figure 6-5 shows the experimental results obtained by Mangat (1999) with no steel corrosion (control specimen), finite element results FE5\%S, $\mathrm{FE} 5 \% \mathrm{C}$ and $\mathrm{FE} 5 \% \mathrm{~B}$, and the finite element results when all corrosion-induced damages are included in the analysis (FE5\%A).

From Figure 6-5, it is observed that the flexural behaviour is very similar up to steel yielding for the control beam and a beam with only 5\% reduction in the reinforcement cross section. As yielding of the reinforcement starts to take place, the inclusion of cross-sectional reduction results in a decrease in the flexural capacity. The results of the FE model with only corrosion-induced cracking accounted for $(\mathrm{FE} 5 \% \mathrm{C})$ show a noticeable reduction in stiffness at the initial loading stage, although its residual strength is not greatly impacted by the induced damage at large deformations. Compared to the numerical results of $\mathrm{FE} 5 \% \mathrm{~S}$ and $\mathrm{FE} 5 \% \mathrm{C}$, the $\mathrm{FE}$ analysis of FE5\%B displays the most significant deterioration in bending capacity, which implies that bond reduction is the main cause of corrosion-induced structural degradation of RC beams. Also shown in the figure are the results of the FE analysis when all corrosion-induced damage models are accounted for $(\mathrm{FE} 5 \% \mathrm{~A})$. It is noted that the results indicate deterioration in both residual capacity and stiffness. Therefore, in order to model realistically the degradation of flexural members due to reinforcement corrosion, the damage induced in the reinforcing steel, concrete and bonding should all be included in the finite element analysis. 


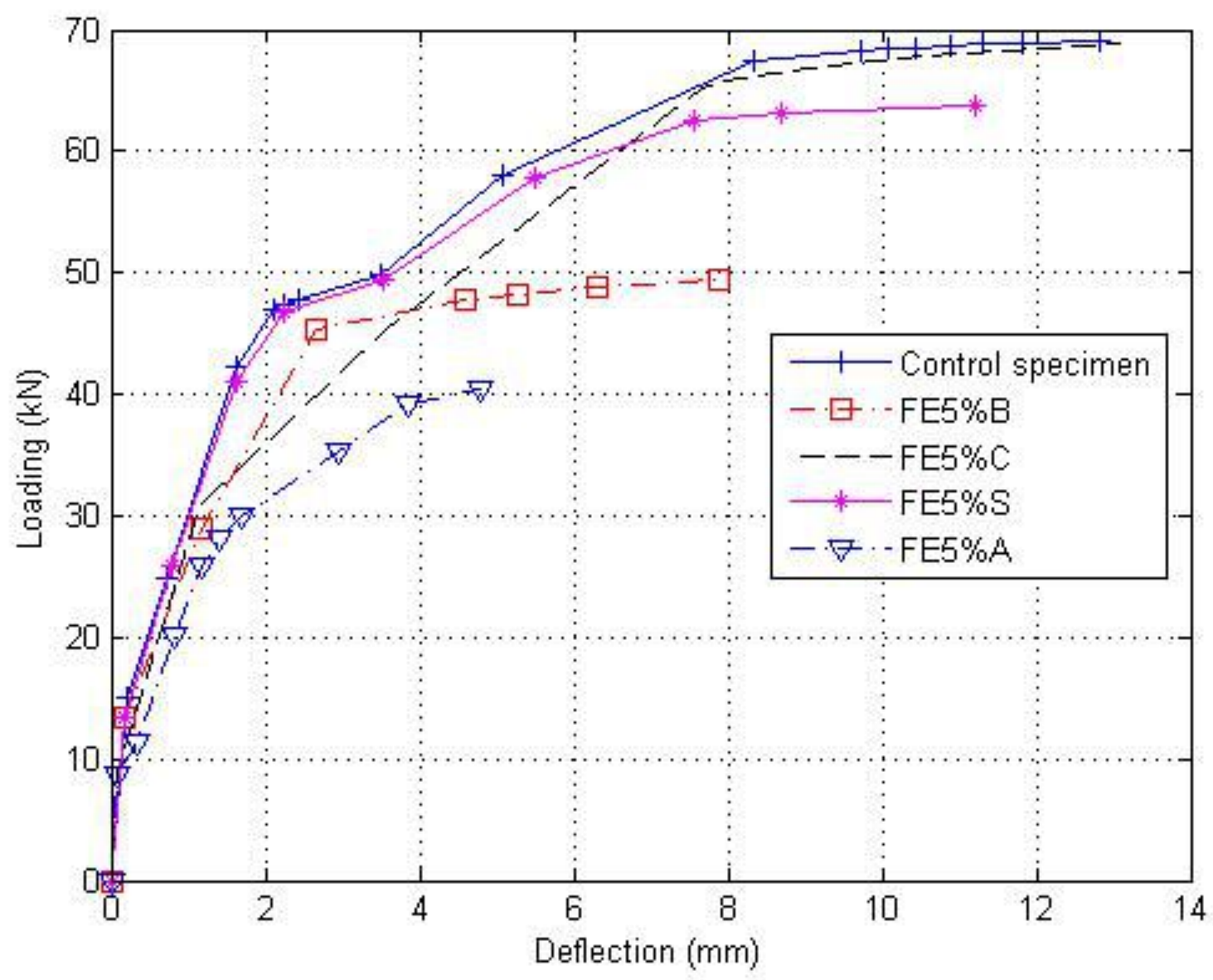

Figure 6-5 Load-deflection curves for beams with different types of corrosion-induced damage accounted for

\subsubsection{The effect of corrosion location along the reinforcement}

The assumption of uniform distribution of corrosion along the reinforcement is not always valid due to different types of corrosion (general or local) and expected corroded regions. Some structural components may only suffer severe corrosion at the mid-span region, whereas the effect of corrosion at the supports maybe more pronounced in other beams. The deterioration of flexural response may vary depending on the location and extent of corrosion-induced damage in an RC 
beam. In order to investigate the influence of corrosion location and extent along the reinforcement, the specimen tested by Mangat (1999) was chosen as a control specimen for the FE analyses.

There were three finite element models with different corroded regions analyzed (Table 6-4): (1) FELM, whose tension reinforcement was corroded $400 \mathrm{~mm}$ at mid-span, (2) FELS, which had a length of $200 \mathrm{~mm}$ of corroded tension reinforcement near each support, and (3) FELA, where the tension bar was corroded along the entire span. The corrosion level used in the analysis was that corresponding to $5 \%$ of steel mass loss. Note that no corrosion-induced damage model was applied to regions outside that where reinforcement was assumed to corrode.

The load-deflection curves for the three FE models presented in Table 6-4 are presented in Figure 6-6. Comparing the three responses, it is noted that the most severe flexural deterioration occurs in specimen FELA, which had the longest length of corroded tension reinforcement. The FE results for FELM and FELS, where only the mid-span or support regions were corroded, respectively, show that the latter specimen suffers more degradation of stiffness and capacity. In fact, by comparing the results of the FELS and FELA analyses, it is observed that most of the deterioration arises from the corroded reinforcement near the supports. This phenomenon shows that structural deterioration due to corrosion becomes more severe if reinforcement corrosion is initiated near the supports of the RC beam. 
Table 6-4 Finite element specimens with various corroded regions

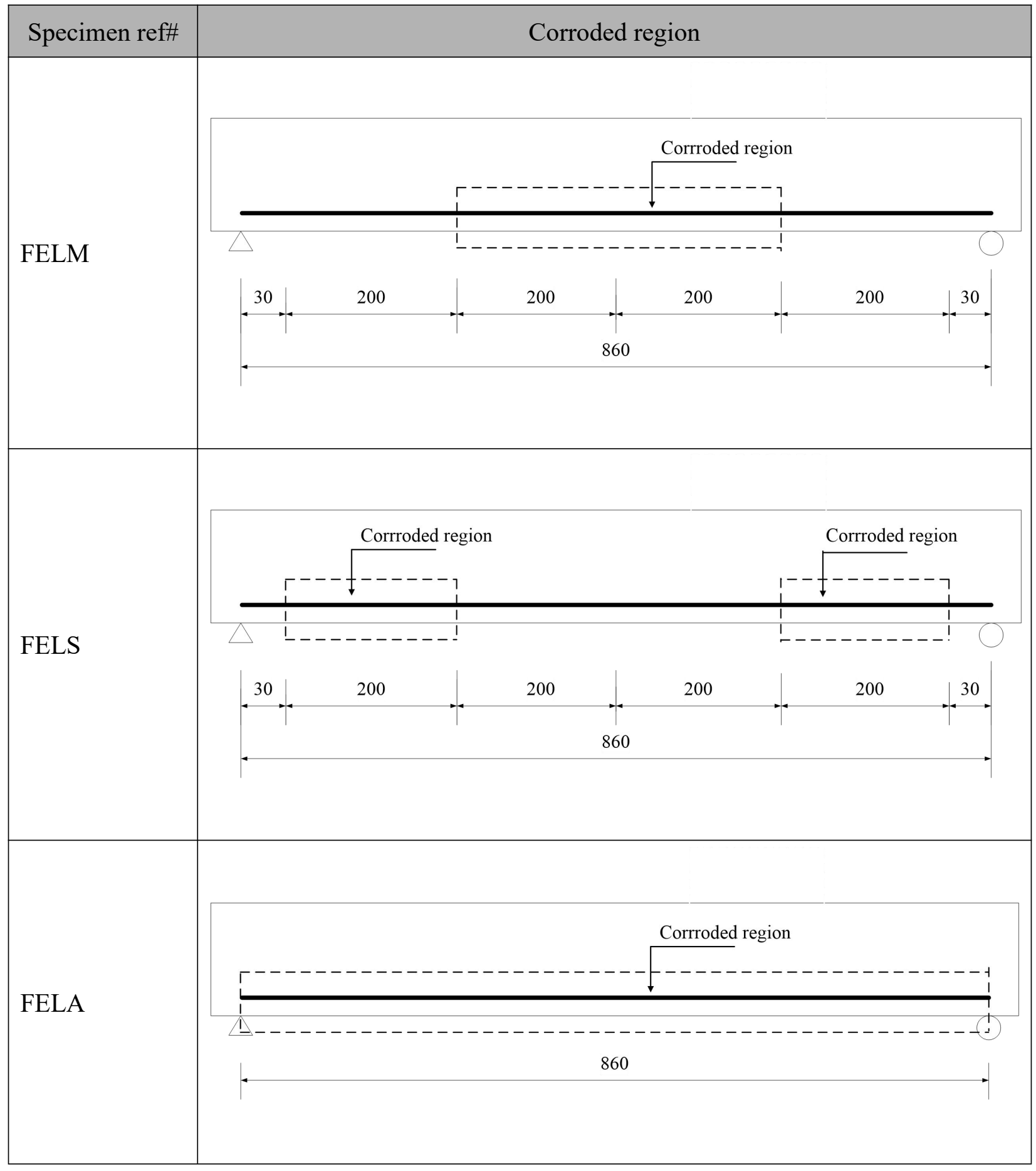




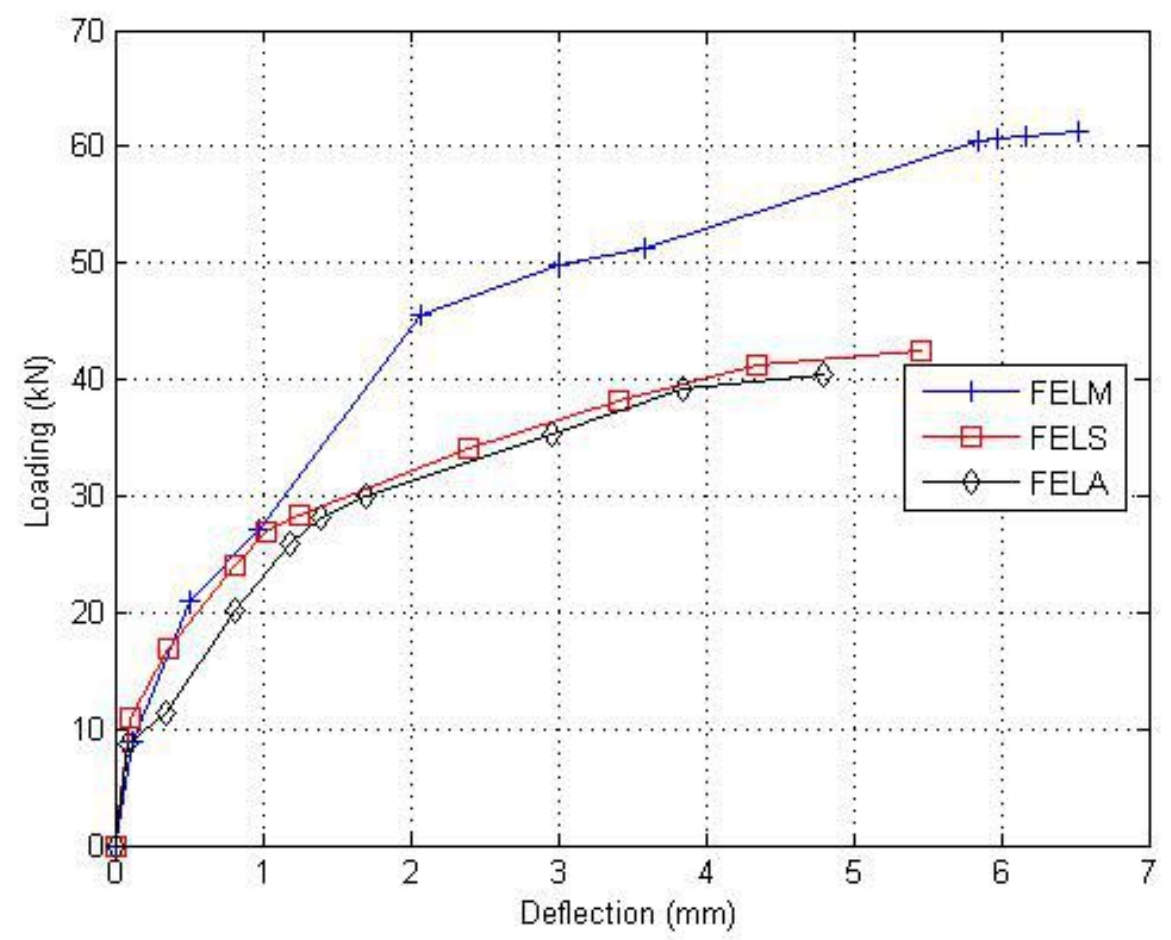

Figure 6-6 Load-deflection curves for beams with different corrosion regions

As discussed before, the volumetric expansion due to corrosion products build-up at the concrete/steel interface causes splitting of the concrete cover and bond deterioration. If the flexural components suffer very high levels of corrosion, the concrete cover might spall off, leading to no bond interaction remaining at the damaged region. To investigate the corrosion location effect in these extreme cases, finite element analysis were conducted in which the FE models of the beams had regions of concrete removed, simulating the severe damage state just discussed (see Table 6-5). Two scenarios were considered: (1) concrete was removed along the mid-span of the beam, and (2) concrete was removed near supports. The height of the removed concrete was equal to the diameter of the thick-wall cylinder model $(50 \mathrm{~mm})$, and the total length of exposed region was 400 $\mathrm{mm}$ for both models, with case (2) having $200 \mathrm{~mm}$ of concrete removed near each support (Table $6-5) . .10 \%$ of steel mass loss was used in the area where concrete was removed. Note that no corrosion-induced damage model was applied to regions where the specimen was not corroded. 
Table 6-5 Finite element specimens with various exposure regions

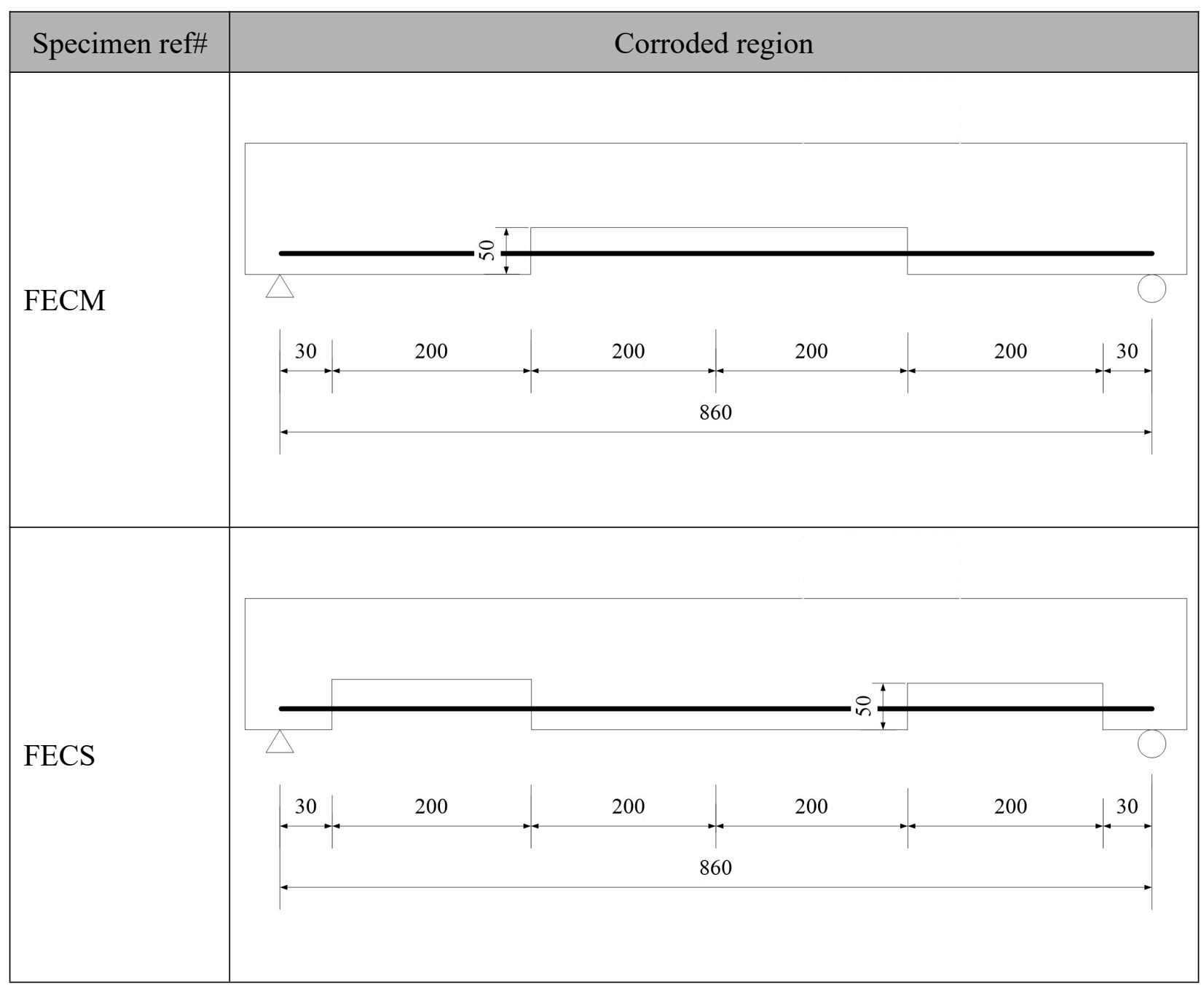

Figure 6-7 shows the resulting load-deformation curves for the FE analyses of specimens FECM and FECS. Like the results presented in the previous section (Figure 6-6), the analysis of the specimen with mid-span damage (FECM) presents stiffer response and higher residual strength compared to beam FECS. Also, in this extreme case where the concrete cover has spalled off near supports, the effect of corrosion location is amplified in comparison to Figure 6-6, where the concrete is not removed, implying that the influence of corrosion location is more pronounced as the corrosion level increases. 


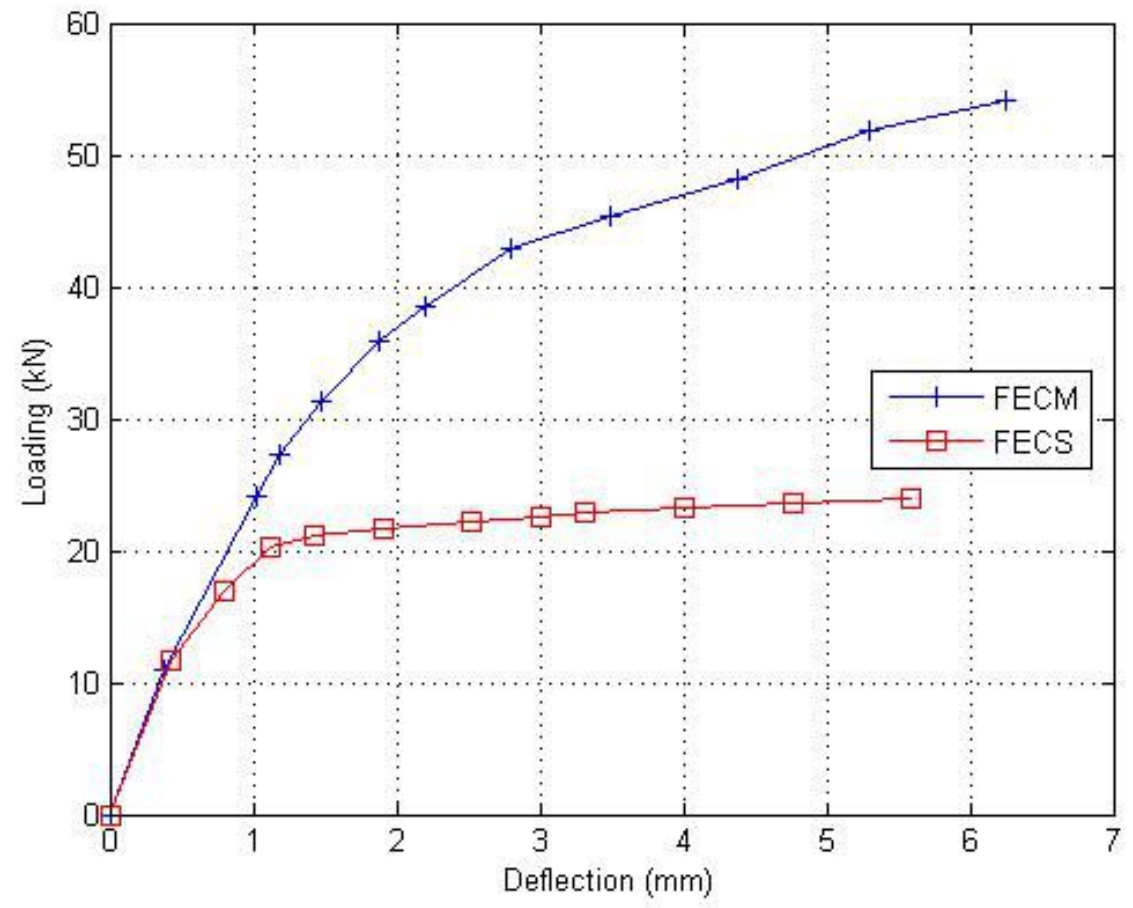

Figure 6-7 Load-deflection curves for beams with different exposed regions

It is noted that the damaged length in the analyzed beams (FELS, FELM, FECS and FECM) is around $50 \%$ of the full length of the tension reinforcement, and the damaged regions in FELS and FECS were quite close to the supports (only $30 \mathrm{~mm}$ spacing in an $860-\mathrm{mm}$ span), which shows similar observations from bending experiments performed by Masnavi (2013) and Cousin and Martín-Pérez (2010). 


\section{Closure}

\subsection{Conclusions}

The effect of the loss of bond due to reinforcement corrosion on the structural performance of flexural members has been investigated by analytical and numerical studies. The analytical model for bond degradation was studied first to evaluate the change in bond strength with increasing levels of reinforcement corrosion. Then, the analytical model was implemented in finite element modelling through the use of link elements that connect the nodes of concrete and steel elements, and simulate the bonding interaction by providing stiffness along the longitudinal direction of the reinforcing steel.

For the development of the analytical model of bond deterioration, investigations of each mechanism contributing to bond were conducted, where assumptions were made based on experimental observations and methodologies suggested by other researchers. For instance, to evaluate the confinement stress provided by the concrete cover due to corrosion expansion at the steel/concrete interface, the thick-wall cylinder model according to Wang et al. (2004) was adopted with a modified tensile strain distribution along the concrete cover.

The bond deterioration model was then implemented in the commercially available package, nonlinear finite element software ABAQUS. A two-dimensional finite element beam model was built, in which the concrete was modelled as 4-node plane-stress elements, while the 2-node truss elements were chosen for the reinforcing bars. To model the bonding interaction between concrete and steel, link elements programmed in ABAQUS through a user-subroutine were implemented and applied. The link elements can calculate the bond stress corresponding to a level of corrosion mass loss based on the analytical evaluation. Besides bond degradation, other corrosion-induced damages, i.e., the reduction in cross-sectional area of the reinforcement and the cracking in the 
concrete cover, were modelled by modifying the cross-section area of the steel truss elements and applying an equivalent expansion strain in the concrete plane-stress elements, respectively.

The analytical model was validated against published experimental and numerical observations. The FE model was subsequently validated by comparing numerical results to the published data of three sets of experimental bending tests. Numerical results with and without link elements (where perfect bond was assumed) were also compared. Since not all of the material properties needed for validation were provided by the authors, material input data that was not readily available was selected according to a review of the literature. From the results of the validations, the following conclusions can be drawn:

1. The analytical evaluation shows reasonably good agreement with published data as the corrosion level increases.

2. Both 2D FE models with and without link elements are able to simulate the residual behaviour of control specimens in the experiments. The difference between finite element results with and without link elements when corrosion is not present is small.

3. The models with corrosion-induced damage provide good agreement with experimental observations, as they are sensitive to the corrosion levels and able to capture the structural deterioration for specimens reinforced by ribbed bars, and to exhibit an enhanced structural performance for beams with plain reinforcement, in both cases when the attack penetration increased.

Since validation of both analytical and finite element models was established, to gain a better understanding of corrosion-induced damage in RC beams and extend the application of the analytical and numerical models, the following parametric studies were performed using both the 
analytical and finite element models:

Using the analytical model:

1. the effect of concrete strength on bond capacity,

2. the effect of cover-to-rebar diameter ratio on bond capacity, and

3. the effect of the volume ratio between oxides and virgin steel on bond capacity.

Using the finite element model:

1. the influence of the type of corrosion-induced damage (damage on reinforcing bar, concrete and/or bond) accounted for in the analysis on the flexural response of affected RC beams, and 2. the influence of corrosion location and extent along the tension reinforcement.

These important effects were tested on pullout and bending tests validated in Chapter 5, and it was observed that:

For the analytical model:

1. The FE models with higher tensile capacity in the concrete cover, i.e., higher concrete strength or higher cover-to-rebar diameter ratio, have a higher ultimate bonding stress.

2. The selection of a post-cracking model for concrete impacts the analytical bond evaluation at high levels of corrosion, as this highly depends on the residual tensile capacity of the concrete cover.

3. The ratio between the volume of oxide products and virgin steel only affects the rate of bond degradation, since it does not influence the confinement capacity of the thick-wall cylinder model.

For the finite element model:

1. Each mechanism of corrosion-induced damage can lead to different degrees of structural 
degradation. Thus, all of these mechanisms should be included for structural evaluation of corroded RC structures.

2. The loss of bond between steel and concrete due to steel corrosion is the main cause of flexural degradation, as the most significant deteriorated performance is noted in specimen with only bond deterioration taken into account.

3. RC beams whose tension reinforcement is corroding near the supports have a softer response and lower residual capacity compared to beams where the damage is located at mid-span.

Based on the observations of the models validation and findings from the parametric investigation, useful information has been provided for the application of the analytical and finite element models. The following suggestions are made to ensure the accuracy of the assessment:

1. The physical properties at the concrete/steel interface, such as the friction coefficient $\mu$ and the ratio between the volume of oxide products and virgin steel $n$, should be based on practical and reasonable assumptions, since they are not easy to determine on site and/or experimentally.

2. Since the post-cracking behaviour for concrete is crucial for the evaluation of confining stress provided by the concrete cover, the selection of important properties, e.g., the fracture energy and the tensile softening curve, should be investigated for the concrete in the tested specimen.

3. It is recognized that a realistic and practical assessment of an RC beam affected by reinforcement corrosion would also have to account for corrosion-induced damage, if any, on the compressive reinforcement and stirrups, which was not included in this research. 


\subsection{Recommendations for future work}

Although the analytical and numerical models have been built and validated in this research, some improvements should be made to obtain more accurate results in the future. In the analytical model for bond deterioration, the methodology proposed by Wang et al. (2004) is used for the evaluation of the confinement stress provided by the concrete cover, in which some of assumptions may not be realistic:

1. A uni-axial stress-strain response is adopted to model concrete. But in fact, the thick-wall cylinder model experiences tensile and compressive stress at the same time due to the volumetric expansion at the concrete/steel interface, and the state of bi-axial stresses can affect the capacity of the model.

2. The rust by-products are assumed to be free to expand, in other words, the stiffness of the iron oxides is significantly large and the volume does not reduce during the corrosion process. However, as suggested by Lundgren (2002), the corrosion products can behave like granular material, which means that this layer in between the reinforcing steel and concrete is compressible, with its stiffness increasing as the volume reduces.

In the finite element analysis, an equivalent expansion strain is applied at the steel/concrete interface to simulate the corrosion-induced expansion damage in a two-dimensional concrete model. But a more realistic result should be acquired through 3D modelling, since the out-of-plane damage may not be reflected in plane-stress elements. Therefore, a three-dimensional model with corrosion-induced damage should be further investigated and optimized, since a significant amount of calculation time is required. 


\section{References}

ABAQUS (2014). ABAQUS 6.14 Documentation, Dassault Systèmes Simulia Corp., Providence, RI, USA.

ACI Committee 408 (2003). Bond and Development of Straight. Reinforcing Bars in Tension. American Concrete Institute

Almusallam, A. A., Al-Gahtani, A. S., \& Aziz, A. R. (1996). Effect of reinforcement corrosion on bond strength. Construction and building materials, 10(2), 123-129.

Almusallam, A. A., Al-Gahtani, A. S., Aziz, A. R., Dakhil, F. H., \& Rasheeduzzafar. (1996). Effect of reinforcement corrosion on flexural behaviour of concrete slabs. Journal of materials in civil engineering, 8(3), 123-127.

Al-Sulaimani, G. J., Kaleemullah, M., \& Basunbul, I. A. (1990). Influence of corrosion and cracking on bond behaviour and strength of reinforced concrete members. ACI Structural Journal, 87(2).

Amleh, L., \& Ghosh, A. (2006). modelling the effect of corrosion on bond strength at the steel-concrete interface with finite-element analysis. Canadian Journal of Civil Engineering, 33(6), 673-682.

Auyeung, Y., Balaguru, P., \& Chung, L. (2000). Bond behaviour of corroded reinforcement bars. ACI Materials Journal, 97(2).

Baltay, P., \& Gjelsvik, A. (1990). Coefficient of friction for steel on concrete at high normal 
stress. Journal of Materials in Civil Engineering, 2(1), 46-49.

Bazant, Z. P. (1986). Mechanics of distributed cracking. Applied Mechanics Reviews, 39(5), 675-705.

Bazant, Z. P., and Oh, B. H. (1983). Crack Band Theory for Fracture of Concrete, Materials and Structures, Vol. 16, No. 93, pp. 155-177.

Berra, M., Castellani, A., Coronelli, D., Zanni, S., \& Zhang, G. (2003). Steel-concrete bond deterioration due to corrosion: finite-element analysis for different confinement levels. Magazine of Concrete Research, 55(3), 237-247.

Brameshuber, W. (2006). Report 36: Textile Reinforced Concrete-State-of-the-Art Report of RILEM TC 201-TRC (Vol. 36). RILEM publications.

Cabrera, J. G., \& Ghoddoussi, P. (1992, October). The effect of reinforcement corrosion on the strength of the steel/concrete bond. In Int. Conf., Bond in Concrete-from Res. to Pract (Vol. 3, pp. 10-11).

Cairns, J., Du, Y., \& Law, D. (2007). Influence of corrosion on the friction characteristics of the steel/concrete interface. Construction and Building Materials, 21(1), 190-197.

Chaker, V. (1992). Corrosion forms and control for infrastructure. ASTM STP 1137, ASTM, West Conshohocken, PA.

Chen, W. F., \& Han, D. J. (2012). Plasticity for structural engineers. Springer Science \& Business Media. 
Chung, L., Kim, J. H. J., \& Yi, S. T. (2008). Bond strength prediction for reinforced concrete members with highly corroded reinforcing bars. Cement and concrete composites, 30(7), 603-611.

Chung, L., Cho, S. H., Kim, J. H. J., \& Yi, S. T. (2004). Correction factor suggestion for ACI development length provisions based on flexural testing of RC slabs with various levels of corroded reinforcing bars. Engineering structures, 26(8), 1013-1026.

Coronelli, D. (2002). "Corrosion cracking and bond strength modelling for corroded bars in reinforced concrete." ACI Structural Journal 99(3): 267-276.

Cousin, B., \& Martin-Perez, B. (2010). Chloride Ingress in Pre-Tensioned Prestressed Concrete Beams and the Effect of Corrosion on Their Structural Behaviour. In Sixth International Conference on Concrete under Severe Conditions: Environment and Loading.

Fang, C., K. Lundgren, L. Chen and C. Zhu (2004). Corrosion influence on bond in reinforced concrete. Cement and Concrete Research 34(11): 2159-2167.

Fédération Internationale du Béton (fib): Model Code 2010 - final draft, vol. 1, Bulletin 65, and vol. 2, Bulletin 66, Lausanne, Switzerland, 2012

Gambarova P. G. and Rosati G. P. (1997). Bond and splitting in bar pull-out: behavioural laws and concrete cover role. Magazine of Concrete Research, 49, No. 179, 99 - 110.

Gambarova P. G. and Rosati G. P. and Schumm C. E. (1998). Bond and splitting: a vexing question. In Bond and Development of Reinforcement, A Tribute to Dr. Peter Gergely 
(Leon R. (ed.)) SP-180, ACI International, Farmington Hills, MI, USA, pp. 23 - 43.

Glass, G. K. and N. R. Buenfeld (2000). Chloride-induced corrosion of steel in concrete. Progress in Structural Engineering and Materials 2001(2): 448-458.

H.-S. Lee, T. Noguchi, F. Tomosawa (2002). Evaluation of the bond properties between concrete and reinforcement as a function of the degree of reinforcement corrosion. Cem. Concr. Res, 32, pp. $1313-1318$

Huang, C.-H. Effects of rust and scale of reinforcing bars on the bond performance of reinforcement concrete. Journal of Materials in Civil Engineering 26(4): 576-581.

Jin, W. and Y. Zhao (2001). Effect of corrosion on bond behaviour and bending strength of reinforced concrete beams. Journal of Zhejiang University 2(3): 298-308.

Kupfer, H., Hilsdorf, H. K., \& Rusch, H. (1969, August). Behaviour of concrete under biaxial stresses. In ACI Journal proceedings (Vol. 66, No. 8). ACI.

Lee, H.-S., T. Noguchi and F. Tomosawa (2002). Evaluation of the bond properties between concrete and reinforcement as a function of the degree of reinforcement corrosion. Cement and Concrete Research 32(8): 1313-1318.

Lee, J., Fenves, G. (1998). Plastic-damage model for cyclic loading of concrete structures. Journal of Engineering Mechanics, Vol. 124, No.8, 892-900

Li, C., S. Yang and M. Saafi (2014). Numerical Simulation of Behaviour of Reinforced Concrete Structures considering Corrosion Effects on Bonding. Journal of Structural Engineering 
0(0): 04014092.

Lundgren, K (1999). Three-Dimensional Modelling of Bond in Reinforced Concrete. PHD Thesis, Chalmers University of Technology.

Lundgren, K., \& Gylltoft, K. (2000). A model for the bond between concrete and reinforcement. Magazine of Concrete Research, 52(1), 53-63.

Lundgren, K. (2002). Modelling the effect of corrosion on bond in reinforced concrete. Magazine of Concrete Research 54(3): 165-173.

Lundgren, K. (2007). Effect of corrosion on the bond between steel and concrete: an overview. Magazine of Concrete Research, 59(6), 447-461.

Lutz, L. A., \& Gergely, P. (1967, November). Mechanics of bond and slip of deformed bars in concrete. In ACI Journal Proceedings (Vol. 64, No. 11). ACI

Malm, R., James, G., \& Sundquist, H. (2006). Monitoring and evaluation of shear crack initiation and propagation in webs of concrete box-girder sections. In International Conference on Bridge Engineering-Challenges in the 21st Century, November 1-3, 2006, Hong Kong. Civil Division, The Hong Kong Institution of Engineers.

Mangat P. S., and Elgarf, M. S. (1999) Flexural Strength of Concrete Beams with Corroding Reinforcement, ACI Structural Journal, V. 96, No. 1, pp. 149-158.

Mangat, P. S. and M. S. Elgarf (1999). Bond characteristics of corroding reinforcement in concrete beams. Materials and Structures 32: 89-97. 
Masnavi, A. (2013). Bond and Development Length in Concrete Beams with Exposed Reinforcement.

Ngo, D. and Scordelis, A. C. (1967). Finite element analysis of reinforced concrete beams. J. Am. Concrete Inst., 64, 152-163

Noghabai, K. (1996). Environmental effects on bond in reinforced concrete structures. Durability of Building Materials and Components, 7(1), 2-6.

Pantazopoulou, S.J., and Papoulia, K. D. (2001). Modelling cover-cracking due to reinforcement corrosion in RC structures. Journal of Engineering Mechanics, 127(4), 342-351.

Press, William H.; Vetterling, William T. (1992). Numerical Recipes in Fortran 77: The Art of Scientific Computing. Cambridge University Press. p. 179. ISBN 0-521-43064-X., Extract of page 179

Ren, W., Sneed, L. H., Yang, Y., \& He, R. (2014). Numerical Simulation of Prestressed Precast Concrete Bridge Deck Panels Using Damage Plasticity Model. International Journal of Concrete Structures and Materials, 1-10.

Rosenberg, A., Hansson, C. M., \& Andrade, C. (1989). Mechanisms of corrosion of steel in concrete. Materials Science of Concrete, 1, 285-314.

Sanchez, I., Albertos, T. S., Ortega, J. M., and Climent, M. A. (2010). Influence of environmental conditions on durability, properties of fly ash mortars. Proc., 2nd Int. Conf. on Sustainable Construction Materials and Technologies, Ancona, Italy. 
Tastani, S.P., and Pantazopoulou, S.J. (2013). Reinforcement and Concrete Bond: State Determination along the Development Length. Journal of Structural Engineering, 139(9), $1567-1587$.

Tepfers, R. (1979). Cracking of concrete cover along anchored deformed reinforced bars. Magazine of Concrete Res., 31(106), 3-12.

Tepfers, R., (1979). Cracking of concrete cover along anchored deformed reinforcing bars. Magazine of Concrete Research, 31, No. 106, 3 - 12.

Wang, X. and X. Liu (2004). Modelling bond strength of corroded reinforcement without stirrups. Cement and Concrete Research 34(8): 1331-1339.

X. Wang, and X. Liu (2006). Bond strength modelling for corroded reinforcements, Construction and Building Materials, 20, pp. $177-186$

Xu, S. L. and X. H. Cai (2010). Bond behaviour of corroded reinforcing bar and ultra high toughness cementitious composites (UHTCC). Fracture Mechanics of Concrete and Concrete Structures -Assessment, Durability, Monitoring and Retrofitting of Concrete Structures. B. H. Oh, O. C. Choi and L. Chung. Seoul, Korea Concrete Institute: 794-800.

Youlin, X. (1992, October). Experimental study of bond-anchorage properties for deformed bars in concrete” . In International Conference of Bond in Concrete: from research to practice. Proceeding topic1: Bond of ordinary reinforcement (Vol. 1, pp. 9-17).

Ziari, A and Kianoush, M.R (2013). Finite-Element Parametric Study of Bond and Splitting 
Stresses in Reinforced Concrete Tie Members. Journal of Structural Engineering. 10.1061/(ASCE)ST.1943-541X.0000903. 